\title{
EXTRACTION OF PODOPHYLLOTOXIN FROM PODOPHYLLUM PELTATUM USING PULSED ELECTRIC FIELD TREATMENT
}

\author{
A Thesis \\ Presented to \\ The Faculty of Graduate Studies \\ of \\ - The University of Guelph \\ by \\ SUHA H. ABDULLAH \\ In partial fulfilment of requirements \\ for the degree of \\ Master of Science
}

June, 2010

(C) Suha H. Abdullah, 2010 
Library and Archives

Canada

Published Heritage

Branch

395 Wellington Street

Ottawa ON K1A ON4

Canada
Bibliothèque et

Archives Canada

Direction du

Patrimoine de l'édition

395 , rue Wellington

Ottawa ON K1A ON4

Canada
Your file Votre référence

ISBN: 978-0-494-81531-1

Our file Notre référence

ISBN: 978-0-494-81531-1
NOTICE:

The author has granted a nonexclusive license allowing Library and Archives Canada to reproduce, publish, archive, preserve, conserve, communicate to the public by telecommunication or on the internet, loan, distribute and sell theses worldwide, for commercial or noncommercial purposes, in microform, paper, electronic and/or any other formats.

The author retains copyright ownership and moral rights in this thesis. Neither the thesis nor substantial extracts from it may be printed or otherwise reproduced without the author's permission.
AVIS:

L'auteur a accordé une licence non exclusive permettant à la Bibliothèque et Archives Canada de reproduire, publier, archiver, sauvegarder, conserver, transmettre au public par télécommunication ou par l'Internet, prêter, distribuer et vendre des thèses partout dans le monde, à des fins commerciales ou autres, sur support microforme, papier, électronique et/ou autres formats.

L'auteur conserve la propriété du droit d'auteur et des droits moraux qui protège cette thèse. $\mathrm{Ni}$ la thèse ni des extraits substantiels de celle-ci ne doivent être imprimés ou autrement reproduits sans son autorisation.
In compliance with the Canadian Privacy Act some supporting forms may have been removed from this thesis.

While these forms may be included in the document page count, their removal does not represent any loss of content from the thesis.
Conformément à la loi canadienne sur la protection de la vie privée, quelques formulaires secondaires ont été enlevés de cette thèse.

Bien que ces formulaires aient inclus dans la pagination, il n'y aura aucun contenu manquant. 


\section{ABSTRACT \\ EXTRACTION OF PODOPHYLLOTOXIN FROM PODOPHYLLUM PELTATUM USING PULSED ELECTRIC FIELD TREATMENT}

\author{
Suha H. Abdullah \\ University of Guelph, 2010
}

\author{
Co-Advisors: \\ Professor G. S. Mittal \\ Professor O. D. Baik
}

Pulsed electric field technology (PEF) was applied to Podophyllum peltatum as a novel approach to enhance the extraction of podophyllotoxin. Podophyllotoxin is a well-known chemical in the pharmaceutical industry and is valuable for its medicinal activities, particularly for the treatment of cancer and venereal warts (Moraes et al. 2004). However, the demand for podophyllotoxin exceeds the supply and conventional extraction methods are inefficient (Haijun et al. 2004, Farkya et al. 2004). PEF treatment was carried out in four phases, with PEF generators employing instant charge reversal (Phases I and II) and rectangular pulses (Phases III and IV). All of the experiments were performed at room temperature, except for Phase II which was conducted at a temperature of $45^{\circ} \mathrm{C}$.

Instant charge reversal pulses were inefficient for the electropermeabilization of $P$. peltatum at room temperature. This was attributed to the brief duration of peak voltage and its inadequacy to damage the tough cell of $P$. peltatum. However, when the temperature was raised to $45^{\circ} \mathrm{C}$, considerable evidence suggested that the electropermeabilization of $P$. peltatum occurred, raising the mean concentration of podophyllotoxin from $7.63 \pm 0.16 \mathrm{mg} / \mathrm{g}$ to $8.18 \pm 0.21 \mathrm{mg} / \mathrm{g}(\mathrm{p}<0.0001)$. PEF treatment 
with 252,000 and 302,400 rectangular pulses were successful in raising the concentration of podophyllotoxin by up to $47 \%$. However, concentration decreased dramatically at 403,200 pulses. It was hypothesized that podophyllotoxin was degraded due to PEF treatment. Although the exact mechanism of electropermeabilization of biological cells is unknown, the synergistic effect between temperature and PEF treatment enhanced the extraction of podophyllotoxin from $P$. peltatum. 


\section{ACKNOWLEDGEMENTS}

This thesis is dedicated to my father Hussein, mother Awsaf, sister Ruba, and brother Eamon. I am blessed to have you have all in my life. You have provided me with unconditional love, support and guidance and I am forever indebted to you.

I owe my deepest gratitude to Dr. Gauri Mittal, who has been my professor, advisor and friend for many years.

Thank you to Dr. Oon-Doo Baik and Shuna Zhao for their valuable assistance all the way from the University of Saskatchewan.

I would like to especially thank Dr. Jixian Zhang for all his help and pleasant talks we shared many times in the laboratory.

Without God, my family and friends, I would have not reached where I am today. 


\section{TABLE OF CONTENTS}

1 INTRODUCTION

1.1 PREFACE 1

1.2 THESIS ORGANIZATION

$\underline{2}$ BACKGROUND 3

2.1 PODOPHYLLOTOXIN

2.1.1 The Chemical 3

2.1.2 Resources 6

2.2 PULSED ELECTRIC FIELD 11

2.3 BIOLOGICAL APPLICATION OF PULSED ELECTRIC FIELD TECHNOLOGY 15

$\begin{array}{lll}2.3 .1 & \text { Background } & 15\end{array}$

2.3.2 Electropermeabilization 16

2.3.3 Electroporation of Plants Versus Microorganisms 18

2.3.4 Conventional Plant Treatment Methods 20

2.3.4.1 Osmotic Dehydration 21

2.3.4.2 Thermal Processing $\quad 23$

2.3.4.3 Mechanical Pressing 24

2.3.4.4 Solid-Liquid Extraction or Solvent Extraction $\quad 27$

2.3.4.5 Conclusion for Conventional Methods 31

$\underline{3}$ PROGRESS ON PULSED ELECTRIC FIELD TREATMENT OF PLANTS

3.1 EFFECT OF ELECTRICAL FIELD STRENGTH

3.1.1 Dehydration Rate 39

$\begin{array}{ll}3.1 .2 & \text { Extraction of Solutes }\end{array}$

$\begin{array}{lll}3.1 .3 & \text { Solid-Liquid Extraction } & 44\end{array}$

3.1.4 Mechanical Pressing 46

3.2 EFFECT OF PULSE NUMBER

3.3 EFFECT OF PARTICLE SIZE

3.4 EFFECT OF TEMPERATURE

3.5 EFFECT OF PULSE DURATION AND SHAPE

4 RESEARCH OBIECTIVE

5 MATERIALS AND METHODS

$\begin{array}{lll}5.1 & \text { OVERVIEW } & 60\end{array}$

5.2 PREPARATION OF PODOPHYLLUM PELTATUM SAMPLES

5.3 PULSED POWER GENERATOR

5.3.1 Instant Charge Reversal Pulse Generator $\quad 62$

5.3.2 Rectangular Pulse Generator $\quad 65$

5.4 TREATMENT CHAMBER

5.5 DESIGN OF EXPERIMENTS

$\begin{array}{lll}5.5 .1 & \text { Phase I } & 70\end{array}$

$\begin{array}{lll}5.5 .2 & \text { Phase II } & 71\end{array}$

$\begin{array}{lll}5.5 .3 & \text { Phase III } & 72\end{array}$

$\begin{array}{lll}\text { 5.5.4 Phase IV } & 73\end{array}$ 
5.6 PULSED ELECTRIC FIELD TREATMENT OF PODOPHYLLUM PELTATUM 74

$\begin{array}{lll}\text { 5.6.1 Phase I } & 74 \\ 5.6 .2 & \text { Phase II } & 74\end{array}$

$\begin{array}{lll}\text { 5.6.2 Phase II } & 77\end{array}$

$\begin{array}{lll}\text { 5.6.3 Phase III } & 78\end{array}$

5.6.4 Phase IV 81

5.7 POST-PEF TREATMENT AND ANALYSIS $\quad 82$

5.7.1 Vacuum Drying $\quad 82$

5.7.2 Scanning Electron Microscopy $\quad 82$

5.7.2.1 Sample Fracturing $\quad 82$

5.7.2.2 Sputter Coating 83

5.7.2.3 Podophyllum peltatum Micrograph Acquisition 84

5.7.3 Solvent Extraction of Podophyllotoxin from Podophyllum peltatum 86

5.7.4 High Performance Liquid Chromatography Analysis 87

5.7.5 Statistical Analysis of Results $\quad 88$

6 RESULTS AND DISCUSSION $\quad 89$

6.1 PODOPHYLLUM PELTATUM PRIOR TO PULSED ELECTRIC FIELD TREATMENT 89

6.2 PULSED ELECTRIC FIELD TREATMENT

6.2.1 Phase I 99

$\begin{array}{lll}6.2 .2 & \text { Phase II } & 105\end{array}$

$\begin{array}{lll}6.2 .3 & \text { Phase III } & 107\end{array}$

6.2.4 Phase IV 116

6.2.5 Possible Mechanism of Enhanced Podophyllum peltatum Permeability With Pulsed

Electric Field Treatment $\quad 123$

7 CONCLUSION AND RECOMMENDATIONS

7.1 CONCLUSIONS $\quad 128$

$\begin{array}{llr}7.2 & \text { FUTURE WORK } & 129\end{array}$

REFERENCES

APPENDIX A - EXPERIMENTAL DATA

APPENDIX B - STATISTICAL ANALYSIS

SAS STATISTICAL ANALYSIS OF PHASE I RESULTS

SAS STATISTICAL ANALYSIS OF PHASE II RESULTS 


\section{LIST OF FIGURES}

Figure 2.1: Structural formula of podophyllotoxin (Himachal Pharmaceuticals 2009) ..... 4

Figure 2.2: Skeletal base formula of podophyllotoxin without binded units (Himachal Pharmaceuticals 2009)

Figure 2.3: Illustration of $P$. peltatum plant, (a) rhizome, (b) roots, (c) aerial shoot, (d) flower, and (e) leaves of a sexual shoot (Schoepke 2003).

Figure 2.5: Podophyllotoxin after purification, in the form of prismatic crystals (x 35) (Viehoever \& Mack 1937)...

Figure 2.4: Simplified illustration of plant cell barriers

Figure 2.6: Pulse waveforms for (a) exponential decay, (b) rectangular monopolar, (c) oscillatory, (d) instant charge reversal, and (e) exponential bipolar (Mittal 2009) ......... 12

Figure 2.7: Treatment chambers used to treat biological materials with PEF where (a) parallel-plate and (b) co-axial .

Figure 2.8: From left to right: alfalfa mash before pressing, untreated alfalfa mash after pressing, and PEF treated mash after pressing (Gachovska et al. 2006)

Figure 3.1: Disintegration index vs time for PEF treatment of apple tissues at different values of electric field strength (Bazhal et al. 2003)

Figure 5.1: Flow diagram of experimental procedure

Figure 5.2: Flow diagram of instant charge reversal pulse generation in PEF system used in Phases I and II (Ho et al. 1997) 63

Figure 5.3: PEF system set-up for instant charge reversal pulses for Phases I and II ...... 64

Figure 5.4: PEF system set-up for rectangular pulses for Phasès III and IV 65

Figure 5.5: Parallel electrode treatment chamber used in Phase I, set in vertical position on a hinge-jointed frame

Figure 5.6: Components of the unassembled parallel-plate treatment chamber used in Phase I

Figure 5.7: Parallel electrode treatment chamber with a surrounding heat jacket used in Phase II ....

Figure 5.8: Parallel electrode treatment chamber used in Phase II with a surrounding heating jacket, set up in vertical position while connected to PEF system and heating bath

Figure 5.9: Parallel electrode treatment chamber used in Phases III and IV with current meter surrounding the electrode wire.

Figure 5.10: Instant charge reversal pulse captured by oscilloscope during Phase II PEF treatment of $<48 P$. peltatum with $50 \mathrm{kV} / \mathrm{cm}$ 
Figure 5.11: LED lights on monitor that indicate that the system is charged and ready for PEF treatment

Figure 5.12: Near-rectangular monopolar pulse acquired from oscilloscope displaying (1) voltage waveform and (2) current waveform

Figure 6.1: Cross-section of $P$. peltatum rhizome: A. Vascular bundle, B. Cortex, C.

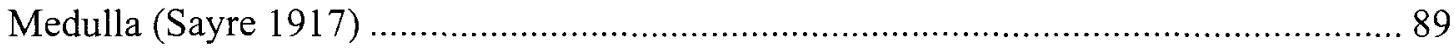

Figure 6.2: Fragment of $P$. peltatum rhizome cross-section $(40 \mathrm{x})$

Figure 6.3: Composition of powdered $P$. peltatum: (Cryst) crystals of calcium oxalate, $(\mathrm{RV})$ reticulated vessels, (PV) pitted vessels, (Tr) tracheids, (Par) parenchyma in longitudinal view, and (P) parenchyma in cross-section (Sayre 1917) ..........................92

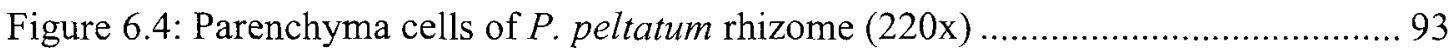

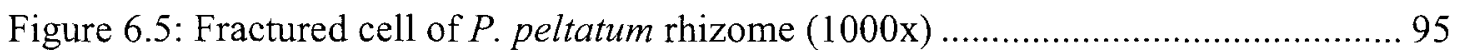

Figure 6.6: Powdered P. peltatum roots and rhizomes $(50 \mathrm{x}),<60$ mesh (left) and $<48$

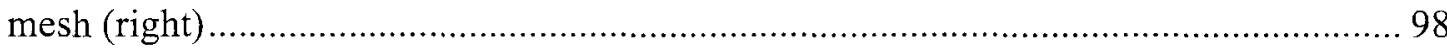

Figure 6.7: Effect of varying particle size on the extraction of podophyllotoxin $(\mathrm{mg} / \mathrm{g})$ from $\mathrm{PEF}$ treated $P$. peltatum using instant charge reversal pulses....... 100

Figure 6.8: Effect of temperature on the extraction of podophyllotoxin from PEF treated $<48$ mesh $P$. peltatum using instant charge reversal pulses

Figure 6.9: Examination of exterior cell of a $P$. peltatum control sample to determine condition of cell wall prior to PEF treatment $(7500 \mathrm{x})$. Secondary treatment was $1 \mathrm{~h}$ soaking followed by vacuum drying.

Figure 6.10: Deep red colour change observed in Phase III experiment with $>48$ mesh $P$. peltatum

Figure 6.11: Examination of exterior cells of $>48$ mesh $P$. peltatum to determine condition of cells after colour change. Sample was soaked in water for $1 \mathrm{~h}$, PEF treated with 201,600 rectangular pulses and $18.57 \mathrm{kV} / \mathrm{cm}$ at room temperature $(60 \mathrm{x})$.

Figure 6.12: Examination of exterior cells of $>48$ mesh $P$. peltatum to determine condition of cells after colour change. Sample was soaked in water for $1 \mathrm{~h}, \mathrm{PEF}$ treated with 201,600 rectangular pulses and $18.57 \mathrm{kV} / \mathrm{cm}$ at room temperature $(500 \mathrm{x})$.

Figure 6.13: Cross-sectional examination of $>48$ mesh $P$. peltatum to determine condition of interior cells after colour change. Sample was soaked in water for $1 \mathrm{~h}, \mathrm{PEF}$ treated with 201,600 rectangular pulses and $18.57 \mathrm{kV} / \mathrm{cm}$ at room temperature $(500 \mathrm{x})$. Crosssection was obtained by cutting with blade.

Figure 6.14: Cross-sectional examination of $>48$ mesh $P$. peltatum to determine condition of interior cells after colour change. Sample was soaked in water for $1 \mathrm{~h}, \mathrm{PEF}$ treated with 201,600 rectangular pulses and $18.57 \mathrm{kV} / \mathrm{cm}$ at room temperature $(1000 \mathrm{x})$. Crosssection was obtained by cutting with blade.

Figure 6.15: Examination of exterior cells of $>48$ mesh $P$. peltatum to determine condition of cells after colour change due to PEF treatment with temperature control. 
Sample was soaked in water for $1 \mathrm{~h}$, PEF treated with 252,000 rectangular pulses and $17.7 \mathrm{kV} / \mathrm{cm}$, at room temperature $(700 \mathrm{x})$

Figure 6.16: Examination of exterior cells of $>48$ mesh $P$. peltatum to determine condition of cells after colour change due to PEF treatment with temperature control. Sample was soaked in water for $1 \mathrm{~h}, \mathrm{PEF}$ treated with 252,000 rectangular pulses and $17.7 \mathrm{kV} / \mathrm{cm}$, at room temperature $(700 \mathrm{x})$. 


\section{LIST OF TABLES}

Table 2.1: Units that are bound to podophyllotoxin base formula to form its derivatives

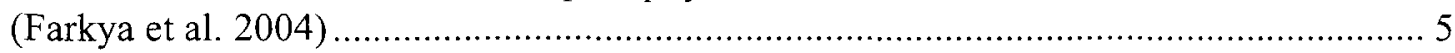

Table 2.2: Maximum concentration of podophyllotoxin extracted from $P$. peltatum ........ 9

Table 2.3: PEF process parameters defined ........................................................ 13

Table 2.4: Ranges of approximate PEF process variables to achieve reversible or irreversible damage in soft-cellular plant tissues..................................................... 18

Table 3.1: Summary of PEF treatment for soft-cellular plants ................................... 34

Table 3.2: Summary of results from PEF treatment of soft-cellular plants .................... 37

Table 5.1: Size of $P$. peltatum particles after grinding and sieving ............................. 62

Table 5.2: Phase I experiment variables using instant charge reversal pulses ............... 71

Table 5.3: Phase I controlled variables using instant charge reversal pulses ................. 71

Table 5.4: Phase II experiment variables using instant charge reversal pulses ............... 71

Table 5.5: Phase II controlled variables using instant charge reversal pulses ................. 71

Table 5.6: Phase III experiment variables using rectangular monopolar pulses ............. 72

Table 5.7: Phase III controlled variables using rectangular monopolar pulses .............. 72

Table 5.8: Phase IV experiment variables using rectangular monopolar pulses ............. 73

Table 5.9: Phase IV controlled variables using rectangular monopolar pulses ............... 73

Table 6.1: Statistical analysis for the effect of varying particle size and PEF process variables on the extraction of podophyllotoxin $(\mathrm{mg} / \mathrm{g})$ from $P$. peltatum using instant charge reversal pulses.

Table 6.2: Mean concentration of podophyllotoxin from $P$. peltatum of varying particle size without any PEF treatment, soaking, or vacuum drying.

Table 6.3: Mean concentration of podophyllotoxin from control and PEF treated $P$. peltatum samples of varying particle sizes compared with $P$. peltatum samples without any secondary treatment.

Table 6.4: Effect of high temperature and PEF process variables on the extraction of podophyllotoxin $(\mathrm{mg} / \mathrm{g})$ from $<48$ mesh $P$. peltatum using instant charge reversal pulses.

Table 6.5: Change in concentration between PEF treated and control $>48$ mesh $P$. peltatum samples, exposed to $1 \mathrm{~h}$ pre-soaking, 252,000 rectangular pulses, and 17.70 $\mathrm{kV} / \mathrm{cm}$. Temperature of PEF treated samples was maintained below $54^{\circ} \mathrm{C}$.

Podophyllotoxin was extracted with various solvent extraction parameters with $30 \%$ aqueous ethanol solution.

Table 6.6: Change in concentration between PEF treated and control $>48$ mesh $P$. peltatum samples, exposed to $1 \mathrm{~h}$ pre-soaking, 302,400 and 403,200 rectangular pulses, 
and $19.4 \mathrm{kV} / \mathrm{cm}$. Temperature of PEF treated samples was maintained below $54^{\circ} \mathrm{C}$. Podophyllotoxin was extracted with various solvent extraction parameters with $30 \%$ aqueous ethanol solution

Table A I: Phase I results for PEF treatment of $24 \mathrm{~h}$ pre-soaked $P$. peltatum performed at room temperature $\left(24^{\circ} \mathrm{C}\right)$ with instant charge reversal pulses of $2 \mu$ s duration and $0.5 \mathrm{~Hz}$ frequency. Extraction of podophyllotoxin was performed with $30 \%$ aqueous ethanol at $50^{\circ} \mathrm{C}$ for $2 \mathrm{~min}$.

Table A2: Phase II results for PEF treatment of 24 h pre-soaked, $<48$ mesh $P$. peltatum performed at high temperature $\left(45^{\circ} \mathrm{C}\right)$ with instant charge reversal pulses of $2 \mu$ s duration and $0.5 \mathrm{~Hz}$ frequency. Extraction of podophyllotoxin was performed with $30 \%$ aqueous ethanol at $50^{\circ} \mathrm{C}$ for $2 \mathrm{~min}$.

Table A3: Phase III results for PEF treatment of $1 \mathrm{~h}$ pre-soaked, $>48$ mesh $P$. peltatum performed at room temperature $\left(24^{\circ} \mathrm{C}\right)$ with rectangular pulses. Extraction of podophyllotoxin was performed with $30 \%$ aqueous ethanol at $50^{\circ} \mathrm{C}$ for $2 \mathrm{~min}$.

Table A4: Phase IV results for PEF treatment of 1 h pre-soaked, $>48$ mesh $P$. peltatum performed at room temperature $\left(24^{\circ} \mathrm{C}\right)$ with rectangular pulse frequency of $840 \mathrm{~Hz} \ldots 144$ 


\section{INTRODUCTION}

\subsection{PREFACE}

Podophyllotoxin is a well-known chemical in the pharmaceutical industry for its valuable anticancer activities and prominent use in chemotherapy. The main plant source of the chemical, Podophyllum emodii, has been listed as an endangered species due to overexploitation (Liu et al. 2007). Furthermore, the second most commonly used source, Podophyllum peltatum, contains only one third of the concentration of podophyllotoxin available in Podophyllum emodii (Farkya et al. 2004). Conventional extraction of this chemical involves the mechanical fragmentation of dehydrated $P$. peltatum followed by solvent extraction at warm temperatures (Izadifar \& Baik 2008). However, intact cell membranes within the interior of each ground particle of $P$. peltatum inhibit the diffusion of podophyllotoxin out of the cell. Damage to these barriers would potentially increase the concentration of podophyllotoxin extracted compared to the status quo. By introducing pulsed electrical field treatment, the barriers of $P$. peltatum could be damaged by an increase in the transmembrane potential of the cell barriers (Ho \& Mittal 2000).

Thus far, the application of pulsed electric field technology has been successful in causing transient pores in living animal cells for the insertion of molecules (Fincan \& Dejmek 2002). Pulsed electric field treatment has also been successful in sterilization and pasteurization by inactivating the microbial organisms in liquid foods (Barbosa-Canovas

et al. 2000). Recently, researchers have focused on treating soft-cellular vegetables and fruits and results have proven to compliment conventional food treatment methods well. Successfully accomplishing the objective of this research would maximize the amount of 
podophyllotoxin extracted from $P$. peltatum. Furthermore, enhanced yield of podophyllotoxin could battle the issue of dwindling supplies of $P$. peltatum, source the increasing demand of podophyllotoxin and possibly deter $P$. peltatum from experiencing the same fate of $P$. emodii.

\subsection{THESIS ORGANIZATION}

Chapter 2 provides a background of the chemical podophyllotoxin and its medicinal value. The discovery and pharmaceutical advancements of podophyllotoxin and its derivatives are discussed. Several issues with regards to podophyllotoxin and its plant sources are presented. Chapter 2 also introduces pulsed electric field technology and the general theory behind the operation of the system. The type of pulses, process parameters, and treatment chambers involved in pulsed electric field technology are discussed. This is followed by a brief introduction to the current use of pulsed electric field technology for enhancing biological applications. Chapter 3 outlines the progress achieved thus far for the use of pulsed electric field technology for the treatment of plant materials. A discussion of the parameters investigated and their effect on the soft-cellular plants is presented. Chapter 4 highlights the limitations of current extraction techniques of podophyllotoxin and demonstrates the objectives of the research. Chapter 5 presents the materials used and the methodology conducted to treat $P$. peltatum with pulsed electric field technology. Chapter 6 presents the results and discussion of the investigation of $P$. peltatum by scanning electron microscopy, experimental results, and statistical analysis. Finally, Chapter 7 summarizes the results of the research and provides recommendations for future research work. 


\section{BACKGROUND}

\section{$2.1 \quad$ PODOPHYLLOTOXIN}

\subsubsection{The Chemical}

Podophyllotoxin is a highly potent chemical that is found naturally in a few plant species and is well-known in the pharmaceutical industry for its valuable anticancer activities and prominent use in chemotherapy. The toxic chemical is mainly found in the leaves, rhizomes, and roots of Podophyllum species from the Berberidaceae family. However, the chemical is also present in negligible amounts in other plant families such as Cupressaceae and Linaceae (Haijun et al. 2004). Historically, Podophyllum plants have been used in folk and ancient Chinese medicine for centuries, initially as a poison, and then smaller doses were prescribed for the treatment of gout, tuberculosis, gonorrhea, syphilis, menstrual disorders, pathogenic infections and as a topical medication for venereal warts (Liu et al. 2007, Haijun et al. 2004, Farkya et al. 2004, Meijer 1974). Over the years, interest in this chemical increased due to its promising "medical powers", which prompted intensive research to determine its chemical, clinical, and pharmacological capacity (Moraes et al. 2000). It is believed that the chemical has the ability to bind to and deactivate DNA topoisomerase II complexes, which are enzymes responsible for facilitating DNA replication of cancer cells. The uncontrolled growth and replication of cancer cells is then halted and the spread of the disease is impeded (Farkya et al. 2004).

The clinical applicability of podophyllotoxin was initially disregarded due to its harmful side effects on the human body, in particular the gastrointestinal system causing 
vomiting, convulsions, violent cramps, and death in highly toxic doses (Farkya et al. 2004, Canel et al. 2000, Viehoever \& Mack 1937). This prompted pharmaceutical companies to manipulate the podophyllotoxin chemical since it was too toxic to the human body for the direct treatment of diseases. In an attempt to benefit from the intriguing medical effects of podophyllotoxin and simultaneously reduce the toxicity of the chemical to allow for safe medical treatment, a total of 600 derivatives of podophyllotoxin were created in a duration of 20 years (Haijun et al. 2004). This wave of semi-synthetic preparations gave rise to several important and widely used anticancer medications: etoposide, teniposide, and etopophose (Bedir et al. 2006, Farkya et al. 2004, Moraes et al. 2000). Podophyllotoxin derivatives are used to treat acute leukemia, lung, testicular, stomach and pancreatic cancers, to name a few (Bedir et al. 2006, Haijun et al. 2004). In addition to cancer treatment, the preparations are also used to treat rheumatoid arthritis and topically treat dermatological diseases such as genital warts (Bedir et al. 2006). The successful creation of such valuable and safe medical compounds continues to fuel pharmacists to produce new derivatives of podophyllotoxin with enhanced pharmacological properties and extensive curing effects, keeping the chemical in high demand (Farkya et al. 2004). The structural formula of podophyllotoxin is shown in Figure 2.1.<smiles>COc1cc([C@H]2c3cc4c(cc3[C@@H](O)[C@@H]3COC(=O)[C@H]23)OCO4)cc(OC)c1OC</smiles>

Figure 2.1: Structural formula of podophyllotoxin (Himachal Pharmaceuticals 2009) 
A skeletal structure of podophyllotoxin is demonstrated in Figure 2.2, where the units attached to the $R_{1}, R_{2}, R_{3}$, and $R_{4}$ positions are illustrated in Table 2.1 , and are manipulated to obtain the many derivatives of podophyllotoxin.

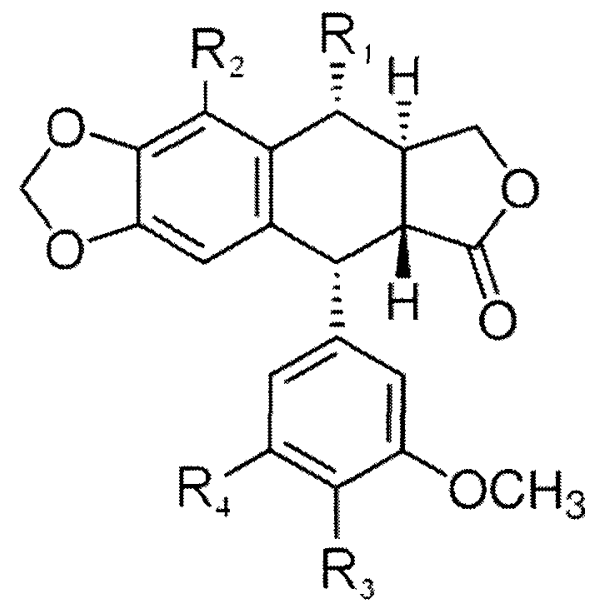

Figure 2.2: Skeletal base formula of podophyllotoxin without binded units (Himachal Pharmaceuticals 2009)

Table 2.1: Units that are bound to podophyllotoxin base formula to form its derivatives (Farkya et al.

\begin{tabular}{|c|c|c|c|c|}
\hline Name & $\mathrm{R}_{1}$ & $\mathrm{R}_{2}$ & $\mathrm{R}_{3}$ & $\mathrm{R}_{4}$ \\
\hline Podophyllotoxin & $\mathrm{OH}$ & $\mathrm{H}$ & $\mathrm{OCH}_{3}$ & $\mathrm{OCH}_{3}$ \\
\hline Etoposide & & $\mathrm{H}$ & $\mathrm{OH}$ & $\mathrm{OCH}_{3}$ \\
\hline Etopophose & & & & \\
\hline Teniposide & & $\mathrm{OPO}(\mathrm{OH})_{2}$ & $\mathrm{OCH}_{3}$ \\
\hline
\end{tabular}




\subsubsection{Resources}

The main source of podophyllotoxin is the rhizomes of the Podophyllum emodii plant, also known as Podophyllum hexandrum, native to the Himalayas (Canel et al. 2001, Farkya et al. 2004). The rhizomes in the $P$. emodii plant contain the highest concentration of podophylltoxin with respect to other organs of the plant, which requires the plant to be fully uprooted during harvest to extract the chemical (Farkya et al. 2004). Within the rhizomes exists the podophyllum resin which is made up of several natural chemical compounds, of which podophyllotoxin is found in highest abundance (Farkya et al. 2004). However, P. emodii is now considered to be endangered due to its overexploitation for medicinal purposes (Cushman et al. 2005, Canel et al. 2001). As a result of dwindling supplies and increasing demand of podophyllotoxin, scientists have explored other sources, one of which has led them to the alternative species, Podophyllum peltatum.

Podophyllum peltatum is the second most commonly used source in the industry for the production of podophyllotoxin. It was not until 1974 where scientists' attention shifted from $P$. emodii towards the $P$. peltatum plant and its bioactive constituents (Moraes et al. 2000). P. peltatum is a flowering, herbaceous plant commonly found in the understory of forest regions throughout North America. The plant is also referred to as mayapple or American mandrake (Liu et al. 2007). From the cold winters of Quebec in Canada to the hot climates of Texas in the United States, the $P$. peltatum plant is flexible to withstand a wide spectrum of environmental conditions (Farkya et al. 2004). As a perennial plant, the leaves and shoots die in the autumn through winter while the rhizomes remain alive in 
the soil. It is one of the first plants to reemerge in the spring and grows in colonies of up to 1000 shoots (Sohn \& Policansky 1997). Figure 2.3 is an illustration of the P. peltatum plant (Schoepke 2003). Each individual $P$. peltatum plant has 1 or more aerial shoots, which are attached to the horizontal rhizome found underneath the ground. Typically, a rhizome has around 6 nodes, in which the aerial shoots and roots are attached. Due to branching of the rhizome, the number of aerial shoots and roots can be extended with Increasing number of nodes (Sohn \& Policansky 1997). Each stem contains two leaves of similar size on a sexual shoot or one leaf on a vegetative shoot (Jones \& Watson 2001).

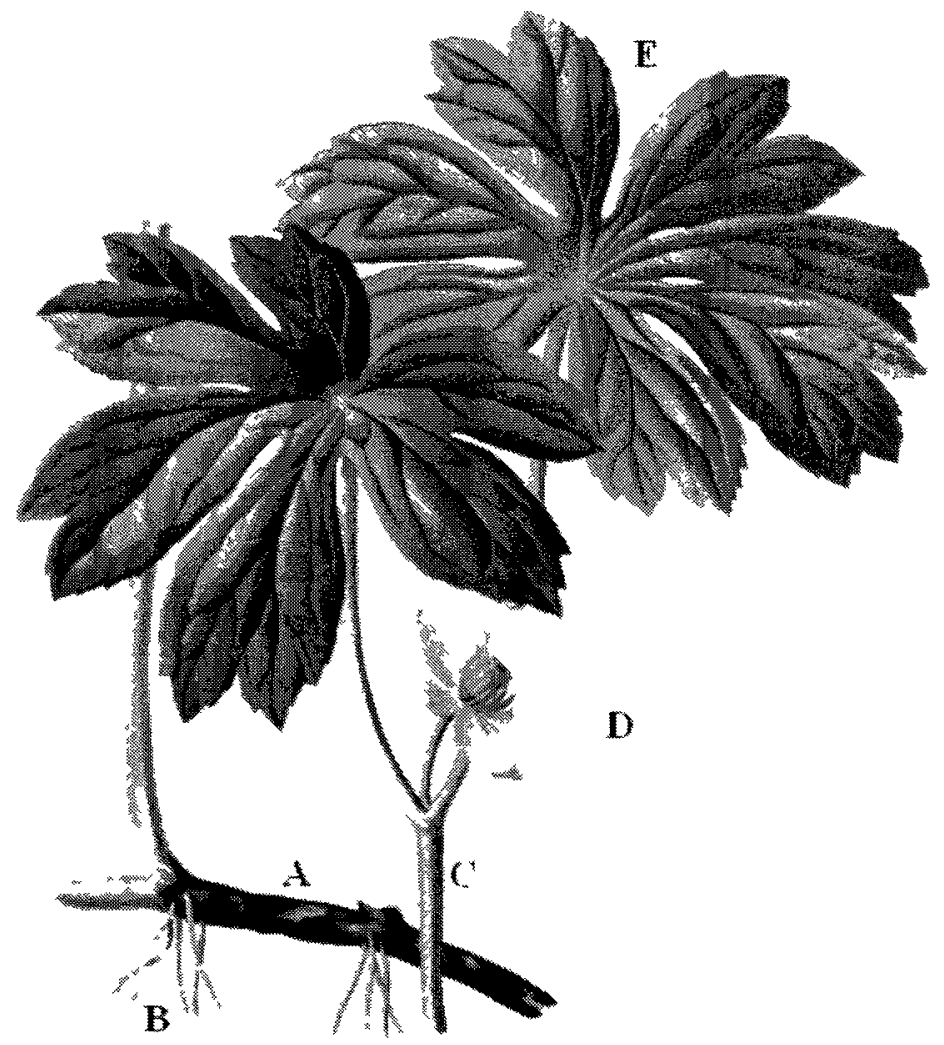

Figure 2.3: Illustration of $P$. peltatum plant, (a) rhizome, (b) roots, (c) aerial shoot, (d) flower, and (e) leaves of a sexual shoot (Schoepke 2003) 
However, it is reported that $P$. emodii contains podophyllotoxin up to three times more than P. peltatum (Farkya et al. 2004). Several values of podophyllotoxin concentration in the Podophyllum species have been identified from different literature sources and are illustrated in Table 2.2. Podophyllotoxin makes up approximately $5 \%$ of the total dry matter of $P$. peltatum (Eyberger et al. 2006). Podophyllotoxin is a highly expensive chemical due to the low yield that is obtained upon extraction from the plant material (Farkya et al. 2004). Unfortunately, a limitation exists when using Podophyllum plants as a resource as they have a lengthy juvenile phase that requires a growth period of 5 to 7 years in order to be harvested. In addition, the reproductive abilities of Podophyllum plants are poor (Haijun et al. 2004, Farkya et al. 2004).

Furthermore, the demand for podophyllotoxin has also increased dramatically ever since the company patent for the production of etoposide expired, which created a surge of pharmaceutical companies competing to develop the drug and further enhanced derivatives (Moraes et al. 2000). In an attempt to address the issues of supply and demand, biotechnologists achieved complete chemical synthesis of podophyllotoxin, however it has been deemed complicated with a large number of steps, low yield, uneconomical and hence commercially unacceptable (Bedir et al. 2006, Farkya et al. 2004). Further attempts have focused on the technology of in vitro plant cell, tissue, and organ culture of $P$. emodii and $P$. peltatum as an alternative source for podophyllotoxin production. Cell culture of the Podophyllum spp. presents the most viable option compared to tissue and organ culture (Canel et al. 2001). Potentially, this option could offer a continuous supply of podophyllotoxin of consistent quality since the prospective 
production of podophyllotoxin in bioreactors means the cells are cultured in a controlled environment (Farkya et al. 2004). However, the yield of the chemical was low and the productivity of the cultured cells decreased dramatically as they were scaled-up for commercial purposes (Haijun et al. 2004, Farkya et al. 2004). Additionally, the process of growing plant cell cultures in bioreactors is an expensive method relative to the conventional agricultural production (Haijun et al. 2004). The optimization of the overall culture and bioreactor process is essential in order to increase yield and productivity, and deem the proposed solution to be feasible and profitable. Recent studies have also examined the use of the leaves of $P$. peltatum as opposed to the roots and rhizomes, and results have reported higher concentrations in favour of the leaves (Canel et al. 2001, Moraes et al. 2000). However, this is a majorly inconsistent yield. Overall, the amount of podophyllotoxin does not only vary significantly within the different plant species, but also within different parts of an individual plant. Moraes et al. (2000) claimed that the podophyllotoxin content in the roots and rhizomes of $P$. peltatum varied less than in the leaf blades (Moraes et al. 2000). Table 2.2 is a compilation of various sources, summarizing the maximum podophyllotoxin concentration yield obtained in experimentation from $P$. peltatum rhizomes and leaves.

Table 2.2: Maximum concentration of podophyllotoxin extracted from $P$. peltatum

\begin{tabular}{|c|c|c|c|}
\hline \multirow{2}{*}{ Reference } & \multirow{2}{*}{$\begin{array}{c}\text { Extraction } \\
\end{array}$} & Method & \multicolumn{2}{|c|}{ Plant, Part } \\
\cline { 3 - 4 } & aqueous & 14.7 & Rhizomes (mg/g) \\
\hline Moraes et al. (2000) & ethanolic & 3.65 & 29.9 \\
\hline Canel et al. (2001) & aqueous & 14.72 & 8.53 \\
\cline { 2 - 4 } & unknown & 30.58 & 42.17 \\
\hline Cushman et al. (2005) & ethyl acetate & - & - \\
\hline Bedir et al. (2006) & ethyl acetate & - & 45.1 \\
\hline $\begin{array}{c}\text { Zheljazkov et al. } \\
(2009)\end{array}$ & & & \\
\hline
\end{tabular}


Podophyllotoxin functions as a defense mechanism for $P$. peltatum, protecting the plant from herbivorous predators, insects, fungi and viruses (Moraes et al. 2004).

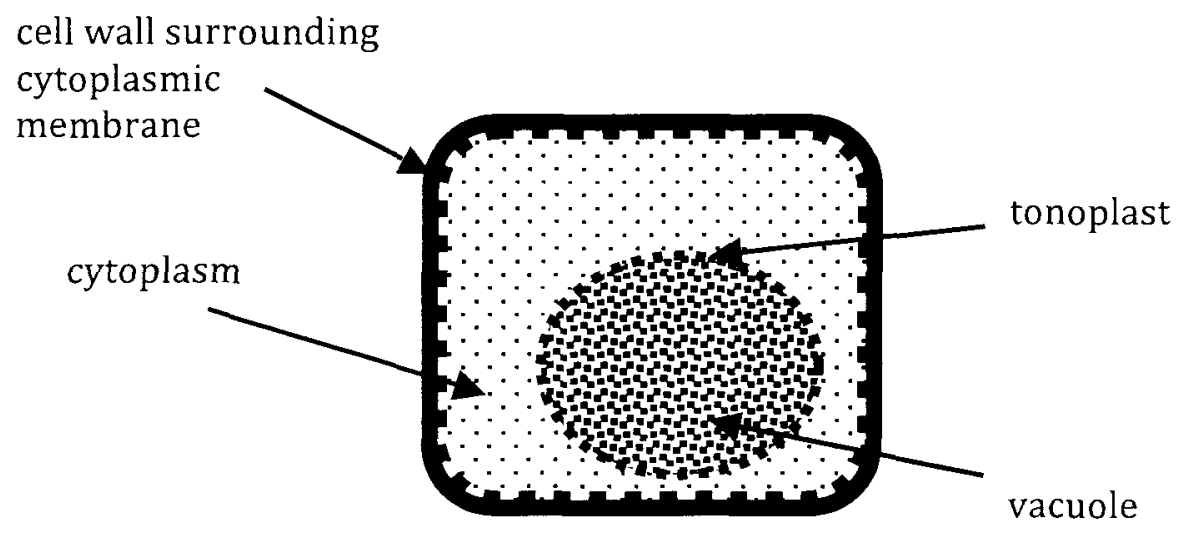

Figure 2.4: Simplified illustration of plant cell barriers

The toxic chemical is stored in the plants vacuole and is released upon disruption of the cell barriers (Figure 2.4). The barriers that must be overcome for the release of podophyllotoxin from the plant cell are the tonoplast, cytoplasmic membrane and cell wall.

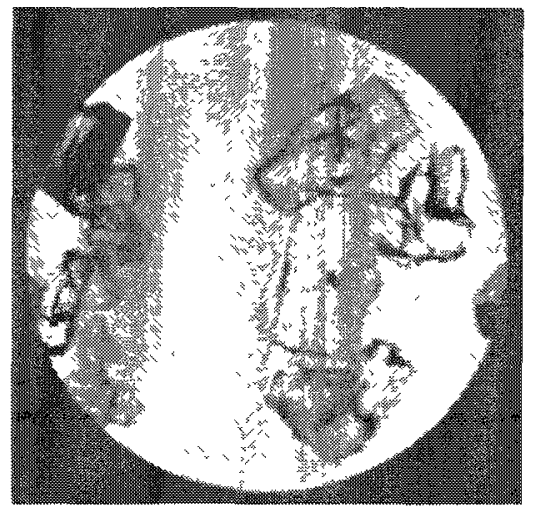

Figure 2.5: Podophyllotoxin after purification, in the form of prismatic crystals (x 35) (Viehoever \& Mack 1937)

Figure 2.5 shows podophyllotoxin in its crystalline form after vigorous extraction and purification techniques. In large quantities, podophyllotoxin resembles a crystal white powder, with a molecular formula of $\mathrm{C}_{22} \mathrm{O}_{22} \mathrm{H}_{8}$ (Viehoever \& Mack 1937). 


\subsection{PULSED ELECTRIC FIELD}

Pulsed electric field (PEF) technology comprises of an electrical system which discharges stored energy in the form of a single, short pulse of electrical energy at a defined repetition rate. Typically, the electrical load applied by a PEF system involves high voltage pulses, which exert high energy and power on a sample placed between two electrodes. The large electric field intensities are attained by a series of high-voltage energy storage capacitors termed the capacitor bank. The capacitors are charged steadily with a relatively low electrical power supply and are capable of storing a great extent of electrical energy in an electric field. Upon the activation of a switch, bursts of this stored energy are rapidly discharged into the treatment chamber in the form of pulses (BarbosaCanovas et al. 2000).

In this manner, a large power multiplication occurs (Bluhm 2006). The pulses impose a surge of intense electrical field for a brief period ranging from a few nanoseconds to a few microseconds (Guderjan et al. 2005, Bluhm 2006). The brief pulse of high electrical energy is characterized by its shape, which can be described as rectangular, exponential, oscillatory or instant-charge-reversal (Figure 2.6). The most commonly used pulse shapes for PEF applications are exponential and rectangular and the waveforms are demonstrated on a voltage-time graph (Mittal 2009). 


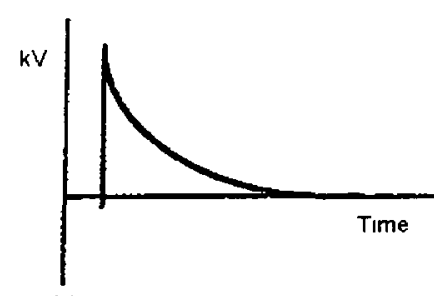

(a)

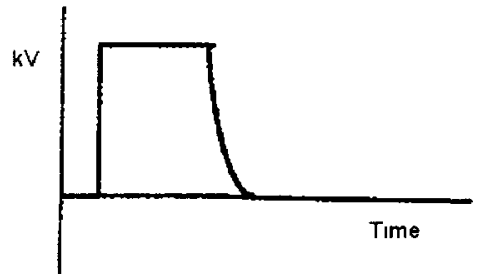

(b)

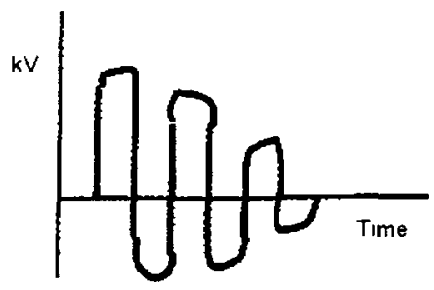

(c)

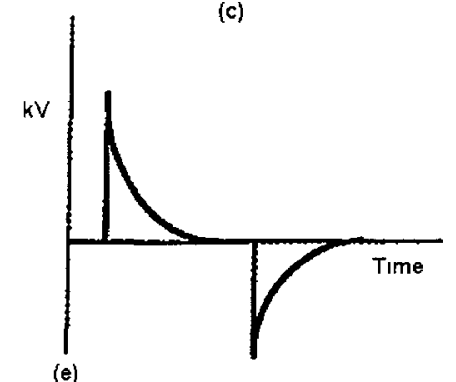

(d)

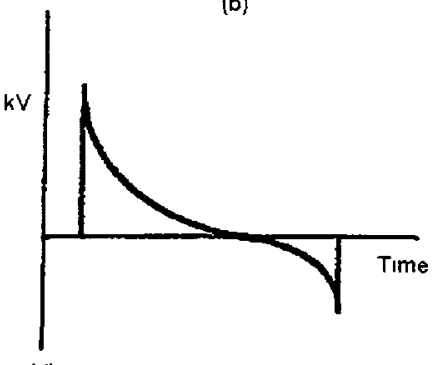

Figure 2.6: Pulse waveforms for (a) exponential decay, (b) rectangular monopolar, (c) oscillatory, (d) instant charge reversal, and (e) exponential bipolar (Mittal 2009)

In rectangular pulses, the voltage increases rapidly, maintains a peak voltage for a brief period and then drops back down to zero voltage. Relative to instant-charge-reversal and exponential pulses, higher amounts of energy are required to be stored in rectangular pulse generators to support the formation of rectangular pulses. This is due to the fact that rectangular pulses maintain a higher peak voltage for a longer period of time. However, rectangular pulses are reported to be more effective than exponential or instant-chargereversal pulses as they have wider pulse width at high voltages meanwhile the other pulses have a long tail of low voltage electrical energy which imposes minimal effects on a sample (Bazhal et al. 2002). In exponential decay, the pulsed electric field voltage increases instantaneously to a peak voltage and then slowly decays to zero voltage.

All pulse shapes can be further classified as monopolar or bipolar (Mittal 2009). However, it is stated that bipolar pulses are more efficient than monopolar pulses (Bazhal 
et al. 2002). In bipolar pulses, alternating positive and negative pulses are separated by a relaxation period. If there was no relaxation time, then the pulse shape would be defined as instant-charge-reversal. However, even with a high pulse frequency where it seems that pulses are constantly ongoing without intermission, there must be a gap between each pulse for any given bipolar pulse shape. Barbosa-Canovas et al. (2000) states that even for a frequency of $1000 \mathrm{~Hz}$, the relaxation time between each $4 \mu$ s-wide pulse is $0.996 \mu$ s. Figure 2.6 illustrates the difference between a monopolar and bipolar exponential decay pulse.

The choice of pulse shape and parameters ultimately depends on the desired application, technological capabilities and economical requirements. PEF process parameters in Table 2.3 are varied to obtain the desired effect depending on an application.

Table 2.3: PEF process parameters defined

\begin{tabular}{|l|c|c|l|}
\hline $\begin{array}{l}\text { PEF Process } \\
\text { Parameter }\end{array}$ & Symbol & $\begin{array}{l}\text { Commonly } \\
\text { Used Unit }\end{array}$ & Definition \\
\hline Number of pulses & $\mathrm{n}$ & - & $\begin{array}{l}\text { Number of pulses released from pulse } \\
\text { generator during total treatment time }\end{array}$ \\
\hline Pulse shape & - & - & $\begin{array}{l}\text { Type of electric pulse released from } \\
\text { pulse generator }\end{array}$ \\
\hline Electric field strength & $\mathrm{E}$ & $\mathrm{V} / \mathrm{cm}$ & $\begin{array}{l}\text { Average voltage applied for each cm } \\
\text { of sample. Average voltage is divided } \\
\text { by distance between the two electrodes }\end{array}$ \\
\hline Frequency & $\mathrm{f}$ & $\mathrm{Hz}$ & Number of pulses applied per second \\
\hline Total treatment time & $\mathrm{t}_{\mathrm{PEF}}$ & $\mathrm{s}$ & $\begin{array}{l}\text { Total time sample is exposed to pulsed } \\
\text { electric field. Product of number of } \\
\text { pulses and pulse duration }\end{array}$ \\
\hline Pulse duration & $\mathrm{t}_{\mathrm{i}}$ & $\mu \mathrm{s}$ & $\begin{array}{l}\text { Width of pulse, length of time each } \\
\text { pulse is applied }\end{array}$ \\
\hline Pulse repetition time & $\Delta \mathrm{t}$ & $\mathrm{ms}$ & Time gap between each pulse applied \\
\hline
\end{tabular}


There are typically two types of treatment chambers used for PEF treatment: parallel plate and co-axial (Figure 2.7). Parallel plate treatment chambers are used for batch operations and are composed of two circular disc electrodes in parallel. The sample undergoing PEF treatment is placed between the two electrodes. The length between the two electrodes is defined as the electrode gap distance. This is used to determine the electric field strength $(\mathrm{V} / \mathrm{cm})$ by dividing the applied voltage by electrode gap distance. Thus, parallel plate treatment chambers provide a uniform treatment.

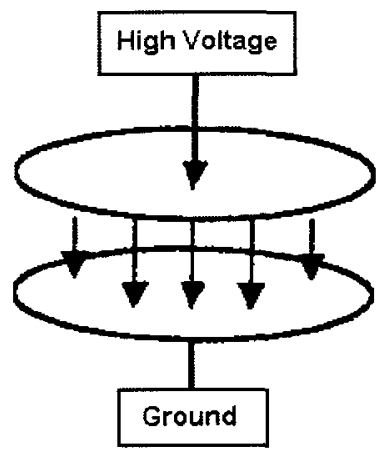

(a)

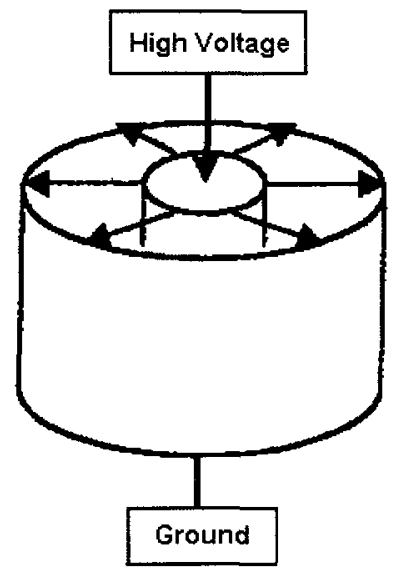

(b)

Figure 2.7: Treatment chambers used to treat biological materials with PEF where (a) parallel-plate and (b) co-axial

Co-axial treatment chambers are used for continuous operations where fluids are pumped between the two electrodes. These chambers consist of an inner cylinder electrode surrounded by an annular cylinder electrode. The fluid enters one side of the electrode and exits the other end. However, co-axial treatment chambers do not provide a uniform treatment as the electric field strength decreases towards the outer electrode. 


\subsection{BIOLOGICAL APPLICATION OF PULSED ELECTRIC FIELD TECHNOLOGY}

\subsubsection{Background}

Pulsed electric field technology was first developed during World War II since the initial development of PEF technology was intended for creating weaponry (Bluhm 2006). The application of PEF has since evolved for entirely different purposes. Advancements in the research and development of PEF systems have resulted in its successful use in medicine and biotechnology for the delivery of genetic materials and drugs into biological cells (Bazhal et al. 2002, Fincan \& Dejmek 2002). More recently, the scientific community has focused its research efforts on implementing the technology in food processing, pasteurization and sterilization of food products (Fincan \& Dejmek 2002). This multidisciplinary approach combining electricity and biology stems from the favourable effects that electricity can induce when exposed to animal, plant, and microbial cells (Lebovka et al. 2001). When cells are subjected to an external electrical field in pulsed power treatment, the cell's natural transmembrane potential is increased to a critical level (Amami et al. 2005). The transformation can be partial and reversible, however, if the voltage exceeds threshold levels, it can result in complete and irreversible changes to the cells structure. This ultimately depends on the intensity of PEF treatment by fine-tuning the PEF process variables involved such as number of pulses, duration of pulse applied and the strength of the electric field (Amami et al. 2005). As a result of increased electric potential, the electrical pulses applied on the biological material create transient or permanent pores on the membranes of a cell (Galindo et al. 2008, Fincan \& Dejmek 2002). Consequently, the permeability and conductivity of the cell is increased 
and the stability of the cell's natural structure and function are compromised (Eshtiaghi \& Knorr 2002). This phenomenon is termed electropermeabilization.

\subsubsection{Electropermeabilization}

In the area of biotechnology, electropermeabilization has been exploited to increase the permeability of the cell membranes and creation of pores for the insertion of large molecules such as DNA into the living cell (Fincan \& Dejmek 2002). Under normal conditions, this would not have been possible due to the cells selective permeability. In the food industry, PEF processing has been mainly developed as a sterilization and preservation method for the inactivation of microorganisms (Barbosa-Canovas et al. 2000). These studies have involved the use of non-thermal PEF treatment in liquid food products as a means to preserve the quality of food and enhance the shelf-life (Jemai \& Vorobiev 2002). In this case, the cell membranes of microorganisms are electropermeabilized causing cytoplasmic content leakage, leading to the death of the microbial cell. This method has been found to be useful for the inactivation of common spoilage and pathogenic microorganisms found in liquid foods such as Escherichia, Salmonella, and Listeria species (Zhao et al. 2009). The feature that most attracted researchers for the treatment of liquid foods was the successful reduction of microbial cells without the alteration of flavour, colour, texture and nutritional content of the food product (De Vito et al. 2008).

Recently, the application of PEF treatment of soft-cellular plants has been investigated (De Vito et al. 2008). Nonetheless, there is a shortage of studies in this area (Jemai \& 
Vorobiev 2002). Regardless, PEF application of soft-cellular plants provides great potential as a novel processing technique. Unlike PEF, regular electrical methods are restricted due to uncontrolled increase in sample temperature and therefore deterioration of the biological material. PEF processing eliminates the effects of ohmic heating by adjusting PEF process parameters to appropriate settings. Hence, allowing electropermeabilization of cell membranes without significant temperature elevation (Bazhal et al. 2001, De Vito et al. 2008).

The mechanisms of PEF induced electropermeabilization have not been determined. However, the most accepted theory describing the process is the electromechanical model established by Zimmermann et al. (1974). In this process, the tissue undergoing PEF treatment is placed in a chamber in between two oppositely charged electrodes. Ions within the cells are attracted to the opposing electrode causing structural disruptions to the membranes. This initiates the formation of pores and is referred to as electroporation, which leads to improved permeability (Fincan \& Dejmek 2002). After the formation of pores, the chemical barriers become electropermeabilized and permit molecules to enter and exit the cell. This causes an imbalance of the natural osmotic equilibrium between the cell's intracellular and extracellular environment.

The electropermeabilization process is characterized by key phases: formation of pores in cellular membrane or wall, increased conductivity, enhanced mass transfer, and the resealing and repair of the cellular barrier (Sensoy \& Sastry 2004). It is unclear when irreversible or reversible damage occurs, however, several publications list approximate 
ranges to demonstrate the breakpoint that separates between reversible and irreversible cellular damage.

Table 2.4: Ranges of approximate PEF process variables to achieve reversible or irreversible damage in soft-cellular plant tissues

\begin{tabular}{|c|c|c|c|c|}
\hline Source & \multicolumn{2}{|c|}{$\begin{array}{c}\text { Electric Field Strength } \\
(\mathrm{kV} / \mathrm{cm})\end{array}$} & \multicolumn{2}{c|}{ PEF Treatment Time } \\
\hline & Reversible & Irreversible & Reversible & Irreversible \\
\hline & & & & \\
\hline Guderjan et al. (2005) & $1-10$ & $1-10$ & $20 \mathrm{~ns}-10 \mathrm{~ms}$ & $10 \mathrm{~ms}-15 \mathrm{~ms}$ \\
\hline Lebovka et al. (2001) & $<0.2$ & $10-50$ & - & - \\
\hline $\begin{array}{c}\text { Soliva-Fortuny et al. } \\
\text { (2009) }\end{array}$ & $<1$ & $1-2$ & - & - \\
\hline De Vito et al. (2008) & $<0.5$ & $0.5-1$ & $<0.1 \mathrm{~ms}$ & $0.1 \mathrm{~ms}-1 \mathrm{~s}$ \\
\hline $\begin{array}{c}\text { Bazhal \& Vorobiev } \\
(2000)\end{array}$ & $0.1-0.2$ & $>1.5$ & - & - \\
\hline Jalté et al. (2009) & $<0.5$ & $0.5-1$ & $<0.1 \mathrm{~ms}$ & $0.1-10 \mathrm{~ms}$ \\
\hline
\end{tabular}

As demonstrated in Table 2.4, there is variation with regards to the threshold values of electropermeabilization. Due to the many variables involved, consistency is difficult to achieve as each plant material varies. In addition, research has not been standardized to provide comparative results. It is essential to establish optimal PEF process variables for each proposed application individually.

\subsubsection{Electroporation of Plants Versus Microorganisms}

Biological applications of PEF have mainly been focused on the inactivation of microorganisms, and only recently, attention has been shifted toward the application of PEF treatment of soft-cellular plant materials (Taiwo et al. 2003). However, there are drastic differences between a plant cell and microbial cell. The average size of microbial cells range between $1 \mu \mathrm{m}$ to $10 \mu \mathrm{m}$ in diameter, whereas the average plant cell is larger 
with a size range of $40 \mu \mathrm{m}$ to $200 \mu \mathrm{m}$ (Soliva-Fortuny et al. 2009). Accordingly, researchers have found that the larger the size of the cell being exposed to PEF treatment, the lower the electric field strength required to cause a large enough transmembrane potential to induce cell electropermeabilization. Therefore, smaller sized microbial cells require higher electric field strengths to achieve inactivation (Jemai \& Vorobiev 2002). This is demonstrated in the process parameters that are used for inactivation of microorganisms in PEF pasteurization, where electric field strengths typically range in between $20-50 \mathrm{kV} / \mathrm{cm}$. Meanwhile, the electorpermeabilization of plant cells are conducted at electric field strengths of $0.1-3 \mathrm{kV} / \mathrm{cm}$ (Bazhal et al. 2002). However, it is important to note that this range has been defined for plant cells that are characterized as having "soft-cellular tissues", as experimentation on tougher plant cells have not been conducted by investigators. Hence, variation of prescribed treatment not only differs between types of organisms, but also between varying plant or microbial cells depending on their rigidity and structure.

In the case of microorganisms, the issue of thicker barriers poses increased resistance to PEF treatment. PEF treatment of $S$. aureus and E. coli inoculated green tea provided different results even though the same PEF process variables of electric field strength and treatment time were used. The bacteria $E$. coli was effectively inactivated by PEF compared to the more resistant $S$. aureus (Zhao et al. 2008). This was due to the fact that S. aureus is Gram-positive, which are a category of bacteria that typically have a thicker and more rigid peptidoglycan cell wall than Gram-negative bacteria. As a result, E. coli was inactivated by a $\log$ reduction of 5.4 meanwhile $S$. aureus experienced a lower $\log$ 
reduction of 4.9. This indicates that the mode of action of PEF on microorganisms vary in effect depending on the thickness of the cell walls.

This leads to the discussion of barrier thickness and rigidity, and its effect on electrical resistance in plant cells. A major difference that exists between the plant and microbial cell is the existence of a cell wall surrounding the plant cell. The microorganism cell typically only possesses a cytoplasmic membrane to protect its constituents; meanwhile the plant cell has both the membrane and thick cellulose cell wall. Since variation in treatment was required to adjust for the increased resistance in the Gram-positive microorganism, the same can be expected for plant cells. Therefore, in comparison to soft-cellular plants, it is expected that harsher PEF treatment will be required to damage the cells of tougher plants.

\subsubsection{Conventional Plant Treatment Methods}

Current literature involves the use of PEF technology to enhance conventional plant processing methods such as osmotic dehydration, thermal processing and drying, solidliquid extraction, and mechanical pressing. These are all extensively used heat and mass transfer based processing techniques that rely on the permeability of the cells and the diffusion of substances through the cell walls (Knorr \& Angersbach 1998). Although conventional treatments are extensively used within the industry, the ability to reach maximum potential of a given process falls short and PEF has proven great potential in compensating for their shortcomings. Prior to examining the literature one must understand the nature of each of the current plant processing techniques. In each case, 
specific examples will be introduced to reveal the diversity of applications that PEF can enhance.

\subsubsection{Osmotic Dehydration}

Osmotic dehydration is a natural process that occurs once plants such as fruits and vegetables are suspended in a hypertonic solution with high solute concentration, high osmotic pressure and low water activity. In a simultaneous and countercurrent manner, water flows out of the plant cells to minimize the high concentration existing between the solution and the plant (water loss from the plant) and solutes flow from the solution into the less concentrated vicinity within the plant (solid gain within the plant material). In food processing, osmotic dehydration is a valuable technique used to reduce the quantity of water within a plant material as an alternative to high temperature drying, or as a precursor step to future freezing or air-drying processes. As a result, the amount of energy required to dehydrate the product is reduced without affecting the plants structural integrity from thermal denaturation or crystal formation that degrade the plants integrity and quality (Amami et al. 2005). However, the major drawback of osmotic dehydration is that it is a slow and lengthy process due to the plants thick cellular wall and membranes, which create resistance to the transfer of water and solutes (López et al. 2009). In fact, the movement of substances through the cell wall and its permeability governs the rate of osmotic dehydration (Amami et al. 2007). The parameters that can alter the rate of osmotic dehydration are solution concentration, temperature, speed of stirring and the nature of the plant material (Amami et al. 2005). However, these parameters can only be optimized to a certain extent, improving the osmotic dehydration rate by restricted amounts. For instance, increasing the concentration of a sugar or salt osmotic solution 
results in an increase in the osmotic pressure gradients and therefore a faster dehydration rate, however, this increased solute concentration creates a negative impact on the nutritional quality of the product (Taiwo et al. 2003).

In accordance to results from previous studies, the rate of osmotic dehydration can experience dramatic increase by introducing PEF treatment to the plant material prior to the osmotic dehydration process. PEF pretreatment will lead to the electropermeabilization of the cell wall which will augment the transfer of water and solutes between the plant material and solution and accelerate the overall process (Amami et al. 2005). An additional observation was made by Taiwo et al. (2003) for the dehydration of apple, where PEF treatment prior to osmotic dehydration resulted in enhanced water loss due to the enhanced permeability of the cell walls. Therefore, since water loss was enhanced by PEF, the need for osmotic dehydration to expel the remaining water was reduced, which resulted in lower sugar uptake during the osmotic dehydration process. This is beneficial since sugar reduces the nutritional quality of a food product.

An interesting study combined PEF technology and vacuum impregnation, while depending on the natural phenomenon of osmotic dehydration to enhance the freezing tolerance of spinach leaves and improve the overall quality of the leaves after thawing (Phoon et al 2008). During vacuum impregnation, spinach leaves were placed in a concentrated solution named trehalose to promote the solutions entry into the plants cells by osmosis. The purpose of vacuum impregnation was to cause outgassing by the 
removal of gas from the plants air gaps in intercellular spaces and then allowing the cryoprotectant solution to fill these empty gaps. However, this was found to be insufficient to preserve the fresh-like qualities of the spinach as the solution was only entering the intercellular region and not the intracellular space inside the plant cells and hence, the introduction of PEF treatment was investigated. By ensuring strict control of the PEF process parameters, the cell wall was exposed to a transmembrane potential enough to cause local transient pores while avoiding complete and permanent electropermeabilization that compromises the viability of the cells. This enhanced permeability due to PEF and allowed for the entrance of the trehalose solution into the cells through the permeable membrane by means of osmotic solute uptake; provided that the samples were placed in vacuum impregnation immediately after PEF treatment. Samples were then frozen and inspected after thawing, where results demonstrated that the use of PEF in combination with vacuum impregnation and the osmotic solution substantially improved the freezing tolerance of spinach leaves (Phoon et al 2008).

\subsubsection{Thermal Processing}

Thermal processing involves the use of heat to increase a product temperature to achieve an objective such as drying, pasteurization, or sterilization. For example, thermal treatment is used for the removal of moisture from food products to reduce microbial activity and limit unwanted chemical reactions (Zhao et al. 2008). However, thermal treatment requires high amounts of energy, and in addition, can pose the risk of degrading the nutritional quality, colour, flavour and taste of the food product (Arevalo et al. 2004). With respect to plants that contain valuable compounds such as nutraceuticals, the bioactive components are at risk of thermal degradation. The key characteristic of PEF 
processing is that it is a nonthermal technique that can compliment or eliminate the need of thermal treatment. The use of PEF allows for "gentle processing" which will not deter the quality of foods but instead allow for manufacturers to process plant-based foods that are attractive to the consumers (Guderjan et al. 2005). For instance, Zhao et al. (2008) found that the application of thermal treatment to reduce microbial content in green tea compromised the quality of the product since the polyphenols in the tea were vulnerable to decomposition. However, the replacement of thermal treatment with PEF processing maintained product quality by preserving the nutritional content and the colour of the green tea while reducing the microbial population to appropriate levels. Success was also reported when PEF pretreatment was used for the drying of potato slabs using a fluidized bed dryer with reduced levels of hot air flow. With PEF pretreatment, there was a $1 / 3$ reduction in drying time of the potato slabs, resulting in substantial energy savings (Knorr \& Angersbach 1998). In a similar experiment, PEF enhanced the drying rate of potato by increasing the moisture diffusion coefficient by up to $40 \%$ (Arevalo et al. 2004). With the treatment of apples, Taiwo et al. (2003) stated that drying with thermal techniques alters the physical and biochemical structure of the apples causing shrinkage and change in colour, texture, and taste. However, when the apples were treated with PEF as opposed to high temperature thermal processing, the product did not experience tissue softening and enzymatic browning. Moreover, the apple experienced increased moisture loss and a reduction in drying time (Taiwo et al. 2003).

\subsubsection{Mechanical Pressing}

Mechanical pressing is a food processing technique that involves the separation of liquid from a porous solid by mechanical compression (Chalermchat \& Dejmek 2005). 
Mechanical pressing is applied for discharging water and juices from partially or fully hydrated food products. However, to achieve the aforementioned, mechanical pressing alone is not sufficient as it does not release the full quantity of liquid within the plant (Gachovska et al. 2006). A considerable amount of cells remain unaffected after pressing since the complete disintegration of all the cells present within a biological material cannot be achieved simply by mechanical pressing. This results in a limitation in the maximum amount of constituents to be released by the cells, and the plant material as a whole (Guderjan et al 2007). To maximize the amount of cells disrupted by mechanical pressing, fragmentation such as cutting or grinding of the material must be performed. However, fragmentation can result in the release of a low quality liquid since ruptured tissue and unwanted particulates from the disrupted cells may be removed with the juice. This results in a turbid product, high in suspended solids, which is not desirable for the producer or attractive to the consumer (Bazhal et al. 2002). For production, following filtration, clarification and purification steps are therefore required. Using coarser food particles and introducing the use of PEF to increase the permeabilization of the cell wall and enhances mass transfer results in juice yields that are of higher quality, which in turn reduce or eliminate the clarification and purification processes and save time and energy (El-Belghiti et al. 2008).

Researchers implemented PEF treatment to enhance juice yield from alfalfa mash prior to pressing. As a result, PEF treated alfalfa mash caused a $38 \%$ increase in extracted alfalfa juice compared to untreated alfalfa mash (Gachovska et al. 2006). Furthermore, alfalfa's constituents are deemed highly nutritional, especially the white and green proteins found 
in the juice. Conventional separation of green protein from white protein is achieved by heating, centrifugation, and filtration, however, an addition benefit of PEF was discovered when the natural separation of these two materials occurred by sedimentation for PEF treated alfalfa (Gachovska et al. 2006). Gachovska et al. (2006) presented a visual illustration of the effects of PEF pretreatment for extraction of juice from mechanically pressed alfalfa. Figure 2.8 shows the results of pressing on alfalfa (a) without PEF treatment and pressing, (b) with pressing but without PEF treatment, and (c) with pressing and PEF pretreatment.
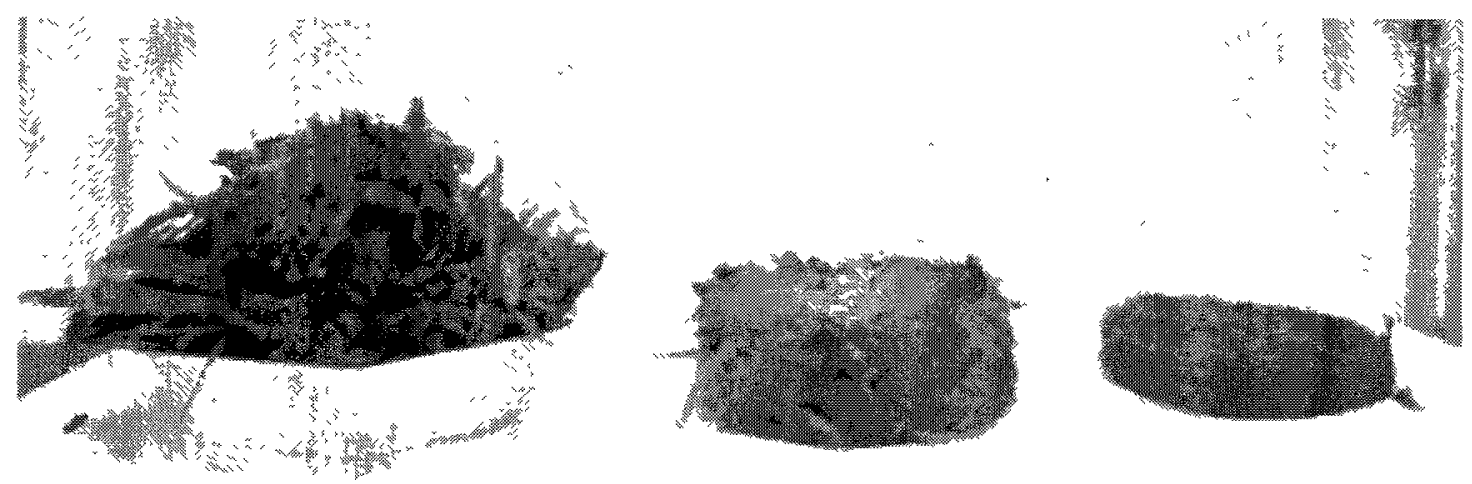

Figure 2.8: From left to right: alfalfa mash before pressing, untreated alfalfa mash after pressing, and PEF treated mash after pressing (Gachovska et al. 2006)

It is observed that the PEF pretreated alfalfa is much more compressed than the alfalfa without PEF treatment. This serves to demonstrate the effects of PEF treatment on biological materials, such as damage to the cell wall, increase in permeability, loss of turgor pressure, and collapse in overall cellular structure (Figure 2.8). In addition, it was observed that the PEF pretreated alfalfa mash freely continued to leak water quickly after pressing, however, the untreated material did not experience any dripping until after $24 \mathrm{~h}$ (Gachovska et al. 2006). This reveals that since the cellular structure of the untreated 
material is still intact and undamaged, the cell wall is able to maintain the constituents within the cell.

Chalermchat \& Dejmek (2005) investigated the combination method of mechanical pressing and PEF technology to enhance the liquid expression of potatoes. The potato products were treated with PEF first and then introduced to mechanical pressing. The PEF pretreated potato expressed twice as much more liquid than the control (Chalermchat \& Dejmek 2005). In a different experiment, Bazhal et al. (2001) performed pressing followed by PEF treatment in the final stage of compression for maximizing juice expression in order to affect cells that remained intact even after mechanical pressing. Significant changes were observed in the rate of juice yield compared to control. Just as juice yield began to level off during mechanical compression, PEF was introduced with continued pressing and the juice yield began to increase again as post-pressing intact cells were now electropermeabilized by PEF treatment. Bazhal et al. (2001) noted that the simultaneous PEF treatment with pressing can collaboratively cause cell wall breakdown, eliminate cell resealing, and continuous pressure imposed on the material would encourage the flow of the fluid from the damaged cells to the fluid channels surrounding the cells and particles. There are various methods in which PEF can be implemented with mechanical pressing, however, it is agreed amongst most of the scientific community that PEF processing in the initial stages of pressing yield maximal results (Grimi et al. 2009).

\subsubsection{Solid-Liquid Extraction or Solvent Extraction}

Solid-liquid extraction is extensively used as a food processing technique to remove valuable soluble constituents from a solid by means of a liquid solvent. This extraction 
method has been used to remove sucrose in sugar beets, lipids from oilseeds, phytochemicals from plants, and extracts from tea leaves, to name a few (Sensoy \& Sastry 2004). Commonly used organic solvents are water, ethanol, hexane, and carbon dioxide. Natural chemicals are preferred with respect to toxicity and the use of water as a solvent is a safer alternative for use in the food industry (El-Belghiti et al. 2008). However, not all solutes are soluble in water and therefore the use of other solvents is necessary. It is favourable to limit the use of chemical solvents as the existence of these chemicals in food products can potentially harm consumers.

The extraction process is a transient mass transfer operation, however, it is a rather slow process due to a series of steps that must occur. Foremost, the solid is soaked within the solvent and the fluid eventually becomes embedded within the plant material. Depending on the solubility of the target extract, the solute becomes dissolved within the solvent. The mass transfer of the solute due to the existing concentration gradient is first defined by the prolonged solute diffusion through the cells followed by the faster mass transfer through the solvent by convection (Amami et al. 2005). The greatest setback of this process is that the diffusion rate of the solute within the cell is restrained by the rate of solute diffusion through the cell's thick wall matrix (Aguilera 2003). The approximate diffusivity of a small solute to pass through the cell's wall is almost $10^{6}$ times lower than the solutes ability to diffuse through the cell's adjacent fluid (Sensoy \& Sastry 2004). Once this hurdle is overcome and the solute transfer to the external surface of the cell, it is then transferred to the bulk solution where it is discharged from the solid. The solute 
that is being recovered in this case is termed the extract, which can then be isolated from the solvent through further processing, such as the evaporation of solvent.

Often, heating of the solid is performed prior to extraction to destruct the cell walls and facilitate the diffusion of solutes through the material López et al. (2009). Mechanical fragmentation of the solid is also performed prior to solvent extraction to enhance the mass diffusion of solutes by damaging the cell walls and in addition, increase the surface area of solid exposed to the solvent and decrease the distance that solutes must migrate to reach the bulk fluid. Current processes involving solid-liquid extraction are energy intensive and time consuming (El-Belghiti et al. 2008). Furthermore, the additional steps such as heating and mechanical fragmentation incur further time, cost and energy as the complete degradation of cell walls from thermal denaturation and material cutting and grinding allow the unsolicited transfer of substances into the fluid, calling for further purification processes (López et al. 2009). All of the aforementioned concerns can be addressed by the implementation of PEF treatment. With the use of PEF, the cell's outer membrane can encounter the creation of pores and resulting in enhanced permeability. Numerous studies have been performed to examine the potential of PEF treatment in combination with solid-liquid extraction for numerous applications.

El-Belghiti et al. (2008) successfully used PEF pretreatment to enhance the extraction of natural antioxidants from the fennel plant through solid-liquid extraction. The amount of antioxidant extraction achieved reached $98 \%$, which was the same amount obtained when fennel was processed thermally at $60-80^{\circ} \mathrm{C}$ and grated into thin particulates (E1-Belghiti 
et al. 2008). The natural oxidants were extracted for their use in food preservation to replace synthetic antioxidants, which are of concern as their carcinogenicity pose risk to the consumer (El-Belghiti et al. 2008).

Solid-liquid extraction was also employed for the extraction of high quality oil from the rapeseed. Rapeseed oil is not only used for cooking purposes, but is also high in demand due to its use in biodiesel production (Guderjan et al. 2007). Production requires seed fragmentation and crushing followed by oil separation using solid-liquid extraction. To achieve high quality oil, hulling is performed to remove the seed coat, which can introduce impurities into the oil such as hull pigments and chlorophylls, however, it is a costly process (Guderjan et al. 2007). Using PEF treatment not only increased the oil yield from rapeseed, but also increased the quality of oil extracted from both the hulled and non-hulled rapeseed due to increased antioxidant content.

Corrales et al. (2008) implemented PEF pretreatment in an attempt to recycle grape byproducts for the solid-liquid extraction of polyphenols from the skin, stems and seeds of grapes. When compared to control samples, PEF treated grape samples experienced an increase in total phenolic content by approximately two folds (Corrales et al. 2008). Electropermeabilization of the cell walls created permanent pores increasing the extraction of solutes into the solvent. From an industrial perspective, the authors found that in addition to increased polypohenol extraction, the shortened extraction time and reduced use of solvents was also beneficial. 
The use of solid-liquid extraction is not limited to the food industry. Pharmaceutical products are often obtained by soaking the plant roots, leaves, or stems in a solvent and then extracting the bioactive compounds (Sensoy \& Sastry 2004). The widespread use of solid-liquid extraction can be made more efficient by implementing PEF technology (Bazhal et al. 2002).

\subsubsection{Conclusion for Conventional Methods}

PEF technology offers the potential to enhance, compliment or simply replace conventional food processing methods, as all of the shortcomings experienced in current technology demonstrate the need for improvement. Current techniques are energy intensive and slow as they depend on natural processes, whereas PEF treatment is more aggressive and direct. PEF treatment of soft-cellular plant tissues can enhance numerous

processes, and details of several investigations are outlined in Table 3.1. Regardless, of all the studies completed, adequate understanding and fine-tuning of PEF process parameters are required for effective application of PEF treatment. Nonetheless, results of all the studies have proven favourable towards the use of PEF treatment for plant materials, as results have been consistently positive. 


\section{PROGRESS ON PULSED ELECTRIC FIELD TREATMENT OF PLANTS}

Table 3.1 summarizes numerous studies that have been performed to determine the optimal PEF treatment variables for enhancing conventional soft-cellular tissue processing such as extraction, juice yield, and osmotic dehydration. Since the exact effect of PEF treatment on plant materials is still undefined, the results and behaviour of PEF treatment varies largely for different types of plants. However, one can extrapolate trends based on the effect that PEF process variables have had on plant materials in past research. The objective of Table 3.1 is to gain a sense of how electrical field strength, pulse number, pulse duration and other PEF process parameters play a role in altering the biological functions of plant cells in a manner that is beneficial.

It is important to recognize that plant tissues are considered to be heterogeneous materials that pose resistance to PEF treatment (Bazhal et al. 2002). Hence, for successful electropermeabilization, modifications to the plant product itself or the PEF process variables are required (Fincan \& Dejmek 2002). Table 3.1 outlines any modifications made to the plant material, such as grinding or mashing, to assist in the PEF process and achieving a positive outcome.

The effects of varying each of the PEF process parameters on plants can be monitored by observing changes in physical characteristics. The influence of electropermeabilization on several factors such as plants' electrical, thermal, diffusion, and physical characteristics are also reviewed to quantify the degree of disintegration of the cells 
structure. Although this is an indirect observation of the PEF induced damage on plant cells, it gives research an insight that demonstrates the effectiveness of the treatment. Observational indicators can include change in liquid yield, structural integrity, solute content, and osmotic dehydration rate. Some researchers chose to estimate the cells' condition upon application of PEF by using the calculated cell disintegration index. The disintegration index is defined as ranging from $\mathrm{Zp}=0$ for intact cells to $\mathrm{Zp}=1$ for total cell disintegration and is calculated by taking into consideration the measured electrical conductivity of intact and damaged cells (Taiwo et al. 2003). In most cases, researchers maintain all process parameters constant except the parameter of interest to examine its effect on the plant material. The research studies that demonstrate the general trend incurred by the majority of researchers have been reviewed in Table 3.1. The results of each study are summarized in Table 3.2 . 
Table 3.1: Summary of PEF treatment for soft-cellular plants

\begin{tabular}{|c|c|c|c|c|c|c|c|c|c|c|c|c|c|}
\hline \multirow[b]{2}{*}{ Reference } & \multirow[b]{2}{*}{ Plant } & \multirow[b]{2}{*}{$\begin{array}{l}\text { Particle } \\
\text { Size' } \\
(\mathrm{mm})\end{array}$} & \multicolumn{11}{|c|}{ PEF Process Conditions } \\
\hline & & & $\begin{array}{l}\text { Treatment } \\
\text { Chamber }^{2}\end{array}$ & $\begin{array}{l}\text { Pulse Shape }{ }^{3} \& \\
\text { Pulse Generator }\end{array}$ & $\begin{array}{l}\text { E Tested } \\
(\mathrm{kV} / \mathrm{cm})\end{array}$ & $\begin{array}{c}\mathrm{E} \\
\text { Optimal } \\
(\mathrm{kV} / \mathrm{cm})\end{array}$ & $t_{1}(\mu s)$ & $t_{P E F}(s)$ & $\begin{array}{c}\Delta \mathrm{t} \\
(\mathrm{ms})\end{array}$ & $\begin{array}{c}\mathrm{f} \\
(\mathrm{Hz})\end{array}$ & $\begin{array}{c}\mathrm{N} \\
\text { Tested }\end{array}$ & $\begin{array}{c}\mathrm{N} \\
\text { Optimal }\end{array}$ & $\begin{array}{l}\mathrm{T} \\
{\left[\mathrm{T}_{\text {opumbal }}\right]} \\
\left({ }^{\circ} \mathrm{C}\right)\end{array}$ \\
\hline $\begin{array}{c}\text { Amami et al. } \\
(2007)\end{array}$ & Carrot & $28 \times 10$ & $\mathrm{PP}, 1, \mathrm{SS}$ & $\begin{array}{l}\text { RM, } 1500 \text { V-20 } \\
\text { A, UTC, France }\end{array}$ & 0.60 & - & 100 & 0.05 & - & - & 500 & - & RT \\
\hline $\begin{array}{c}\text { Amami \& } \\
\text { Vorobiev } \\
(2005)\end{array}$ & Apple & $28 \times 8.5$ & $\mathrm{PP}, 0.85, \mathrm{SS}$ & $\begin{array}{l}\text { RM, } 1500 \text { V-20 } \\
\text { A, UTC, France }\end{array}$ & $0.1-1.1$ & 0.9 & 100 & 0.1 & - & - & $\begin{array}{l}100- \\
1000\end{array}$ & 750 & RT \\
\hline $\begin{array}{c}\text { Arevalo et al. } \\
(2004)\end{array}$ & $\begin{array}{l}\text { Apple } \\
\text { Potato }\end{array}$ & $35 \times 7$ & $\mathrm{PP}, 0.1, \mathrm{SS}$ & $\begin{array}{c}\text { RM, } 2100 \text { V- } \\
22000 \text { W, Model } \\
350-12, \text { Velonex, } \\
\text { USA } \\
\end{array}$ & $\begin{array}{c}0.75 \& \\
1.5\end{array}$ & No effect & $\begin{array}{l}100- \\
300 \\
100\end{array}$ & - & - & 1 & $\begin{array}{c}5-60 \\
5-120\end{array}$ & $\begin{array}{c}60 \\
\text { no } \\
\text { effect }\end{array}$ & RT \\
\hline $\begin{array}{c}\text { Bazhal et al. } \\
(2001)\end{array}$ & Apple & $\begin{array}{l}3-5(w) x \\
10-40(1)\end{array}$ & $\mathrm{PP}, 2, \mathrm{SS}$ & $\begin{array}{l}\text { RM, } 1500 \text { V-15 } \\
\text { A, UTC, France }\end{array}$ & $0.1-0.52$ & $\begin{array}{c}0.52 \text { for } \\
t_{\mathrm{PHF}}>300 \\
\mathrm{~s}\end{array}$ & 100 & 0.005 & 10 & 0.01 & 50 & - & RT \\
\hline $\begin{array}{c}\text { Bazhal et al. } \\
(2003)\end{array}$ & $\begin{array}{c}\text { Carrot } \\
\text { Potato } \\
\text { Cucumber } \\
\text { Apple } \\
\text { Aubergine } \\
\text { Pear } \\
\text { Banana }\end{array}$ & $10 \times 10 \times 10$ & $\mathrm{PP}, 0.1, \mathrm{SS}$ & $\begin{array}{l}\text { RM, } 1500 \mathrm{~V}-15 \\
\text { A, UTC, France }\end{array}$ & $0-1.5$ & $\begin{array}{l}0.248 \\
0.360 \\
0.352 \\
0.435 \\
0.673 \\
0.853 \\
0.976\end{array}$ & $\begin{array}{c}10- \\
1000\end{array}$ & $\begin{array}{c}0.00001- \\
1\end{array}$ & 30 & - & $1-1000$ & - & RT \\
\hline $\begin{array}{l}\text { Brodelius et } \\
\text { al. (1988) }\end{array}$ & $\begin{array}{c}\text { Cultured } \\
\text { plant cells }\end{array}$ & $\begin{array}{l}\text { Individual } \\
\text { cell }\end{array}$ & $\mathrm{PP},-, \mathrm{SS}$ & $\begin{array}{l}\text { ED, Dialog, } \\
\text { Germany }\end{array}$ & $0.3-15$ & $\begin{array}{c}5(T \\
\text { mugosum }) \\
10(C \\
\text { rubrum })\end{array}$ & - & - & 100 & - & 3,10 & $\begin{array}{c}\text { no } \\
\text { effect }\end{array}$ & RT \\
\hline $\begin{array}{l}\text { Corrales et al. } \\
(2008)\end{array}$ & $\begin{array}{l}\text { Grape by- } \\
\text { products }\end{array}$ & $\begin{array}{l}\text { skin, stem } \\
\& \text { seed }\end{array}$ & $\mathrm{PP}, 3, \mathrm{SS}$ & $\begin{array}{c}\text { ED, } 10000 \mathrm{~V}- \\
8000 \mathrm{~W} \\
\text { PurePulse, USA }\end{array}$ & 3 & - & - & 15 & - & 2 & 30 & 30 & RT \\
\hline
\end{tabular}

${ }^{T}$ Unless specified, cuboidal dimensions axbxc represent wxlxh and cylindrical dimensions dxe represent dxh.

${ }^{2}$ Treatment chamber type, electrode gap $(\mathrm{cm})$, electrode type; where $\mathrm{PP}=$ parallel plate, $\mathrm{CF}=\mathrm{co}$-field, $\mathrm{SS}=$ stainless steel, and $\mathrm{PL}=\mathrm{platinum}$.

${ }^{3} \mathrm{RM}=$ rectangular monopolar, $\mathrm{RB}=$ rectangular bipolar, and $\mathrm{ED}=$ exponential decay. 
Table 3.1 Continued: Summary of PEF treatment for soft-cellular plants

\begin{tabular}{|c|c|c|c|c|c|c|c|c|c|c|c|c|c|}
\hline \multirow[b]{2}{*}{ Reference } & \multirow[b]{2}{*}{ Plant } & \multirow[b]{2}{*}{$\begin{array}{c}\text { Particle } \\
\operatorname{Size}^{1}(\mathrm{~mm})\end{array}$} & \multicolumn{11}{|c|}{ PEF Process Conditions } \\
\hline & & & $\begin{array}{l}\text { Treatment } \\
\text { Chamber }^{2}\end{array}$ & $\begin{array}{l}\text { Pulse Shape }{ }^{3} \& \\
\text { Pulse Generator }\end{array}$ & $\begin{array}{l}\text { E Tested } \\
(\mathrm{kV} / \mathrm{cm})\end{array}$ & $\begin{array}{c}\mathrm{E} \\
\text { Optimal } \\
(\mathrm{kV} / \mathrm{cm})\end{array}$ & $t_{1}(\mu s)$ & $t_{P E F}(s)$ & $\begin{array}{l}\Delta \mathrm{t} \\
(\mathrm{ms})\end{array}$ & $\begin{array}{c}\mathrm{f} \\
(\mathrm{Hz})\end{array}$ & $\begin{array}{c}\mathrm{N} \\
\text { Tested }\end{array}$ & $\begin{array}{c}\mathrm{N} \\
\text { Optimal }\end{array}$ & $\begin{array}{l}\mathrm{T},[\mathrm{T} \\
\text { Optimal }] \\
\left({ }^{\circ} \mathrm{C}\right)\end{array}$ \\
\hline $\begin{array}{l}\text { De Vito et } \\
\text { al. (2007) }\end{array}$ & Apple & $26 \times 10$ & $\mathrm{PP}, 0.1, \mathrm{SS}$ & $\begin{array}{c}\text { RB, } 400 \mathrm{~V}-38 \mathrm{~A} \\
\text { UTC, France }\end{array}$ & $0.1-0.4$ & 0.4 & $\begin{array}{c}10 \\
100 \\
1000\end{array}$ & $\begin{array}{c}0.004 \\
0.04\end{array}$ & 0.1 & - & 2,20 & - & $\begin{array}{l}\text { RT-50, } \\
{[50]}\end{array}$ \\
\hline $\begin{array}{l}\text { El-Belghiti } \\
\text { et al. (2008) }\end{array}$ & Fennel & $\begin{array}{c}\text { varying: } \\
0.1 \times 0.4 \times 6 \text { to } \\
1.8 \times 6 \times 30- \\
60\end{array}$ & $\mathrm{PP},-, \mathrm{SS}$ & $\begin{array}{l}\text { RM, } 1500 \text { V-15 } \\
\text { A, UTC, France }\end{array}$ & $0-0.6$ & $\begin{array}{l}0.3-0.6 \\
(G R 3-7)\end{array}$ & 100 & 0.085 & 10 & - & $0-850$ & $\begin{array}{c}200- \\
900 \\
\text { (GR3-7) }\end{array}$ & $\begin{array}{l}\mathrm{RT}, 60- \\
90,[\mathrm{RT}]\end{array}$ \\
\hline $\begin{array}{c}\text { Eshtiaghi \& } \\
\text { Knorr } \\
(2002) \\
\end{array}$ & Sugar beet & $35 \times 60 \times 150$ & $\mathrm{PP}, 3.8, \mathrm{SS}$ & $\begin{array}{c}\text { ED, } 10000 \mathrm{~V}- \\
8000 \mathrm{~W} \\
\text { Germany }\end{array}$ & $1.2-3.6$ & 2.4 & - & - & - & 1 & $1-200$ & 20 & RT \\
\hline $\begin{array}{l}\text { Fincan \& } \\
\text { Dejmek } \\
(2002)\end{array}$ & $\begin{array}{l}\text { Onion } \\
\text { epidermis }\end{array}$ & $5 \times 5 \times 1$ & $\begin{array}{l}\text { PP, } 0.012 \\
\quad \text { SS }\end{array}$ & $\begin{array}{c}\text { RM, } 320 \text { V-30 } \\
\text { A, Cellect, } \\
\text { Sweden }\end{array}$ & $0.17-0.52$ & 0.52 & 100 & 0.0001 & - & - & 1 & - & RT \\
\hline $\begin{array}{l}\text { Gachovska } \\
\text { et al. (2006) }\end{array}$ & Alfalfa & Mashed & $\begin{array}{l}\mathrm{PP}, 0.4-0.1 \\
\text { SS }\end{array}$ & $\begin{array}{c}\text { RB, self- } \\
\text { constructed }\end{array}$ & $1.5 \& 6$ & $1.5 \& 6$ & - & - & - & 1 & 400 & 400 & $\mathrm{RT}$ \\
\hline $\begin{array}{l}\text { Grimi et al. } \\
(2009)\end{array}$ & Grape & - & $\mathrm{PP},-, \mathrm{SS}$ & $\begin{array}{l}\text { RB, } 400 \text { V }-38 \mathrm{~A}, \\
\text { UTC, France }\end{array}$ & 0.4 & - & 1000 & 0.1 & 0.1 & 0.001 & 2 & - & RT \\
\hline $\begin{array}{l}\text { Guderjan et } \\
\text { al. (2005) }\end{array}$ & $\begin{array}{l}\text { Maize } \\
\text { Olive } \\
\text { Soybean }\end{array}$ & $\begin{array}{l}\text { Ground } \\
\text { Uknown } \\
\text { Unknown }\end{array}$ & $P P,-, S S$ & $\begin{array}{l}\text { ED, PurePulse, } \\
\text { USA }\end{array}$ & $\begin{array}{c}0.6 \& 7.3 \\
0.7 \& 1.3 \\
1.3\end{array}$ & $\begin{array}{c}0.6 \\
0.7 \\
\& 1.3 \\
1.3 \\
\end{array}$ & $\begin{array}{c}- \\
- \\
280\end{array}$ & - & - & - & $\begin{array}{c}120 \\
30 \& \\
100 \quad-\end{array}$ & $\begin{array}{c}120 \\
30 \& \\
100 \\
-\end{array}$ & RT \\
\hline $\begin{array}{l}\text { Guderjan et } \\
\text { al. }(2007)\end{array}$ & Rapeseed & - & $\mathrm{PP},-, \mathrm{SS}$ & $\begin{array}{c}\text { ED, PurePulse, } \\
\text { USA }\end{array}$ & 5,7 & $\begin{array}{c}7 \\
\text { (hulled), } \\
5 \text { (non- } \\
\text { hulled) }\end{array}$ & 30 & $\begin{array}{l}0.0018- \\
0.0036\end{array}$ & - & - & $\begin{array}{l}60 \\
120\end{array}$ & $\begin{array}{c}120 \\
\text { (hulled), } \\
60 \text { (non- } \\
\text { huled) }\end{array}$ & RT \\
\hline $\begin{array}{c}\text { Jalté et al. } \\
(2009)\end{array}$ & Potato & $26 \times 10$ & $\mathrm{PP}, 0.1, \mathrm{SS}$ & $\begin{array}{l}\text { RB, } 400 \mathrm{~V}-38 \mathrm{~A}, \\
\text { UTC, France }\end{array}$ & 0.4 & - & 100 & 0.0002 & 0.2 & 0.01 & 2 & - & RT \\
\hline $\begin{array}{c}\text { Jemai \& } \\
\text { Vorobiev } \\
(2002)\end{array}$ & Apple & $52 \times 3.8$ & $\begin{array}{c}\text { PP, } 0.019, \\
\text { PL }\end{array}$ & $\begin{array}{l}\mathrm{RM}, 1500 \mathrm{~V}-20 \\
\mathrm{~A}, \mathrm{UTC}, \text { France }\end{array}$ & $0.1-0.6$ & 0.5 & 100 & 0.1 & 10 & - & 1000 & 1000 & RT \\
\hline
\end{tabular}

${ }^{1}$ Unless specified, cuboidal dimensions axbxc represent wxlxh and cylindrical dimensions dxe represent dxh.

${ }^{2}$ Treatment chamber type, electrode gap $(\mathrm{cm})$, electrode type; where $\mathrm{PP}=$ parallel plate, $\mathrm{CF}=\mathrm{co}-$ field, $\mathrm{SS}=$ stainless steel, and $\mathrm{PL}=\mathrm{platinum}$.

${ }^{3} \mathrm{RM}=$ rectangular monopolar, $\mathrm{RB}=$ rectangular bipolar, and $\mathrm{ED}=$ exponential decay. 
Table 3.1 Continued: Summary of PEF treatment for soft-cellular plants

\begin{tabular}{|c|c|c|c|c|c|c|c|c|c|c|c|c|c|}
\hline \multirow[b]{2}{*}{ Reference } & \multirow[b]{2}{*}{ Plant } & \multirow[b]{2}{*}{$\begin{array}{c}\text { Particle } \\
\text { Size }^{1}(\mathrm{~mm})\end{array}$} & \multicolumn{11}{|c|}{ PEF Process Conditions } \\
\hline & & & $\begin{array}{l}\text { Treatment } \\
\text { Chamber }^{2}\end{array}$ & $\begin{array}{l}\text { Pulse Shape }{ }^{3} \& \\
\text { Pulse Generator }\end{array}$ & $\begin{array}{l}\text { E Tested } \\
(\mathrm{kV} / \mathrm{cm})\end{array}$ & $\begin{array}{c}\mathrm{E} \\
\text { Optimal } \\
(\mathrm{kV} / \mathrm{cm})\end{array}$ & $t_{1}(\mu s)$ & $t_{P E F}(s)$ & $\begin{array}{c}\Delta \mathrm{t} \\
(\mathrm{ms})\end{array}$ & $\begin{array}{c}f \\
(H z)\end{array}$ & $\begin{array}{c}\mathrm{N} \\
\text { Tested }\end{array}$ & $\underset{\text { Optimal }}{\mathrm{N}}$ & $\begin{array}{l}\mathrm{T}, \\
{\left[\mathrm{T}_{\text {optimal }}\right]} \\
\left({ }^{\circ} \mathrm{C}\right)\end{array}$ \\
\hline $\begin{array}{c}\text { López et al. } \\
(2009)\end{array}$ & Sugar beet & $25 \times 10$ & $\mathrm{PP}, 1, \mathrm{SS}$ & $\begin{array}{c}\text { RM, self- } \\
\text { constructed }\end{array}$ & $1-7$ & $\begin{array}{c}\text { no } \\
\text { effect }\end{array}$ & $2-5$ & $\begin{array}{c}0.00001- \\
0.0002\end{array}$ & - & $1-10$ & $5-40$ & $\begin{array}{c}\text { no } \\
\text { effect }\end{array}$ & $\mathrm{RT}$ \\
\hline $\begin{array}{l}\text { Phoon et al. } \\
\text { (2008) }\end{array}$ & $\begin{array}{l}\text { Spinach } \\
\text { leaves }\end{array}$ & $30 \times 5 \times 0.6$ & $\mathrm{PP}, 0.06, \mathrm{SS}$ & $\begin{array}{l}\mathrm{RB}, \text { CythorLab, } \\
\text { Sweden }\end{array}$ & 0.58 & - & 25 & 0.2 & - & - & - & - & RT \\
\hline $\begin{array}{l}\text { Schilling et } \\
\text { al. (2007) }\end{array}$ & Apple & Mash & $\mathrm{PP}, 3, \mathrm{SS}$ & $\begin{array}{c}\text { ED, PurePulse, } \\
\text { USA }\end{array}$ & $1,3,5$ & 5 & 400 & 0.012 & - & - & 30 & - & RT \\
\hline $\begin{array}{c}\text { Talwo et al. } \\
(2003)\end{array}$ & Apple & $38 \times 8$ & $\mathrm{PP}, 3, \mathrm{SS}$ & $\begin{array}{c}\text { ED, PurePulse, } \\
\text { USA }\end{array}$ & $0.5,1,2$ & 1 & 400 & $\begin{array}{c}0.0008- \\
0.02\end{array}$ & - & 1 & $2-50$ & $\begin{array}{c}\text { no } \\
\text { effect }\end{array}$ & RT \\
\hline $\begin{array}{l}\text { Zhao et al. } \\
(2008)\end{array}$ & $\begin{array}{c}\text { Green lea } \\
\text { (inactivation } \\
\text { of } E \text {. Coli \& } \\
\text { S. aureus) }\end{array}$ & $<200$ mesh & $\begin{array}{l}\text { CF, } 0.029 \\
\text { SS }\end{array}$ & $\begin{array}{c}\text { RB, } 9310 \\
\text { Quantum } \\
\text { Composer, USA }\end{array}$ & $\begin{array}{l}18.1 \\
27.4 \\
38.4\end{array}$ & 38.4 & 2 & $\begin{array}{c}0.00016 \\
(\text { E. coli }), \\
0.0002 \\
(S . \\
\text { aureus })\end{array}$ & - & 667 & - & - & $\mathrm{RT}$ \\
\hline $\begin{array}{c}\text { Zhao et al. } \\
\text { (2009) }\end{array}$ & $\begin{array}{c}\text { Green tea } \\
\text { (inactivation } \\
\text { of } E . \text { Coli) }\end{array}$ & $<200$ mesh & $\begin{array}{l}\text { CF, } 0.029 \\
\quad \text { SS }\end{array}$ & $\begin{array}{c}\text { RB, OSU-4L } \\
\text { Ohio State } \\
\text { University, USA }\end{array}$ & $\begin{array}{c}20,30 \\
40\end{array}$ & 40 & 2 & 0.0002 & - & 667 & - & - & RT \\
\hline
\end{tabular}

${ }^{T}$ Unless specified, cuboidal dimensions axbxc represent wxlxh and cylindrical dimensions dxe represent dxh.

${ }^{2}$ Treatment chamber type, electrode gap $(\mathrm{cm})$, electrode type; where $\mathrm{PP}=$ parallel plate, $\mathrm{CF}=\mathrm{co}$-field, $\mathrm{SS}=$ stainless steel, and $\mathrm{PL}=\mathrm{platinum}$.

${ }^{3} \mathrm{RM}=$ rectangular monopolar, $\mathrm{RB}=$ rectangular bipolar, and $\mathrm{ED}=$ exponential decay. 
Table 3.2: Summary of results from PEF treatment of soft-cellular plants

\begin{tabular}{|c|c|}
\hline Reference & Results \\
\hline Amami et al. (2008) & Osmotic dehydration rate enhanced \\
\hline Amami \& Vorobiev (2005) & Enhanced dehydration with $50 \%$ increase of water loss, $6 \%$ increase of solid gain \\
\hline Arevalo et al. (2004) & $\begin{array}{l}\text { Compressive strength of apple reduced } \& \text { drying of potato enhanced (diffusion coefficient up } \\
\text { to } 40 \% \text { ) }\end{array}$ \\
\hline Bazhal et al. (2001) & Juice yield enhanced \\
\hline Bazhal et al. (2003) & Obtained optimal PEF parameters for varying plants to achieve maximum disintegration \\
\hline Brodelius et al. (1988) & Secondary product release achieved via PEF treatment \\
\hline Chalermchat \& Dejmek (2005) & Liquid yield doubled \\
\hline Corrales et al. (2008) & Two-fold increase in extraction of phenolic content \\
\hline De Vito et al. (2007) & $\begin{array}{l}\text { Enhanced PEF disintegration of apple cells, did not consider qualitative effects on material, } \\
\text { only amount of disintegration. }\end{array}$ \\
\hline El-Belghiti et al. (2008) & $\begin{array}{l}98 \% \text { extraction of antioxidants achieved, reaching amount obtained thermally and those more } \\
\text { intensely fragmented. }\end{array}$ \\
\hline Eshtiaghi \& Knorr (2002) & 2-3 times faster extraction rate than control \\
\hline Fincan \& Dejmek (2002) & Observed increased conductivity \\
\hline Gachovska et al. (2006) & Juice extraction enhanced by $38 \%$, improved protein separation \\
\hline Grimi et al. (2009) & $\begin{array}{l}\text { Quicker pressing time, reduced level of pressure required and increased yield from } 67 \text { to } \\
75 \% \text {, higher quality with lower turbidity juice, higher polyphenol content }\end{array}$ \\
\hline Guderjan et al. (2005) & Increase in oil yield, phytosterol content \\
\hline Guderjan et al. (2007) & Increase in oil yield, increased oil quality with higher antioxidant content \\
\hline Jalté et al. (2009) & $\begin{array}{l}\text { Improved rate of freeze-drying with smaller crystal formation hence enhanced quality upon } \\
\text { rehydration of potato }\end{array}$ \\
\hline Jemai \& Vorobiev (2002) & Enhanced diffusion coefficient and thus higher diffusion rate \\
\hline Knorr \& Angersbach (1998) & $1 / 3$ reduction in drying time \\
\hline
\end{tabular}


Table 3.2 Continued: Summary of results of from PEF treatment of soft-cellular plants

\begin{tabular}{|l|l|}
\hline López et al. (2009) & PEF extracted higher sucrose than control \\
\hline Phoon et al. (2008) & Improvement of freeze tolerance, allowing for fresh-like quality upon thawing \\
\hline Schilling et al. (2007) & Enhanced juice yield by up to 7.7\% \\
\hline Taiwo et al. (2003) & $\begin{array}{l}\text { Improved water loss, shorter drying time, physical deterioration of product avoided without } \\
\text { use of high temperatures (browning, shrinkage, vitamin destruction) }\end{array}$ \\
\hline Zhao et al. (2008) & 5.6 and 4.9 log reduction, respectively, extending shelf life by over 6 months \\
\hline Zhao et al. (2009) & $\begin{array}{l}6.0 \text { log reduction, maintained quality of tea polyphenols, catechins, colour while increasing } \\
\text { beneficial amino acids }\end{array}$ \\
\hline
\end{tabular}




\subsection{EFFECT OF ELECTRICAL FIELD STRENGTH}

\subsubsection{Dehydration Rate}

Amami et al. (2005) investigated the effect of PEF as a pretreatment process for the osmotic dehydration of apples. The objective of the study was to maximize the rate of osmotic dehydration while maintaining the integrity of the apple material from any physical damage that would normally occur from other processes such as drying with thermal treatment. Various electric field strengths of PEF were tested to examine the outcome on osmotic dehydration of the apple material, which consequently revealed the structural damage induced by PEF on the apple material. Hypothetically, it was expected that as the electric field strength was increased, further damage would be created in the cellular wall of the apple cells and increased transfer of water and solutes would result in a lower ${ }^{\circ}$ Brix value of the osmotic solution. While maintaining other process parameters at a constant value, the electrical field strength was increased with values ranging from $0.1 \mathrm{kV} / \mathrm{cm}$ to $1.1 \mathrm{kV} / \mathrm{cm}$. As a result of PEF treatment, the ${ }^{\circ}$ Brix of the osmotic solution decreased, inferring that the intracellular water was indeed transferred from the apple and into the hypertonic solution while solutes left the hypertonic solution and transferred into the apple. For the control sample, the concentration of the osmotic solution was $41.1 \%$ ${ }^{\circ}$ Brix. As electric field strength increased from $0.65,0.90$, to $1.1 \mathrm{kV} / \mathrm{cm}$, the ${ }^{\circ}$ Brix measured to be $39.9(-1.2 \%), 39(-2.1 \%)$, and $38.5 \%(-2.6 \%)$, respectively. Water loss was not the only factor affected by increasing electric field strength, as solid gain within the apple material was also affected. Enhanced solid gain was noted with increasing electric field strength, but to a smaller extent when compared to water loss. Overall, PEF treatment prior to osmotic dehydration caused a significant increase in water loss with 
approximately $50 \%$ increase in comparison to a slight increase of $6 \%$ in solid gain (Amami et al. 2005).

Bazhal et al. (2003) further revealed the dependency of cell disintegration on electric field strength during PEF treatment of apple tissue for enhancement of osmotic dehydration. The cell disintegration index was estimated at different values of electric field strength and in correlation with current literature, the results confirmed the linear relationship between both variables. For the higher values of electric field strength $(E>0.5$ $\mathrm{kV} / \mathrm{cm}$ ), the disintegration of the cell linearly increased as time increased, and eventually reached a cell disintegration saturation level at which the apple tissue ceased to experience damage to its cells and changes no longer occurred in the observed effects. Past this saturation point, any increase in electric field strength contributed no effect to the dehydration rate of the apple. The destructive force of PEF at high electric field strength was immediate, leaving the apple cells with no possibility of restructuring. In the case of low field strength values $(\mathrm{E}<0.45 \mathrm{kV} / \mathrm{cm})$, a distinct occurrence emerged, where more than one cell disintegration saturation level appeared for varying field intensities. In this situation, the disintegration of the cells increased with time until hitting a saturation level where the slope reached a plateau, until it began to rise again and hit another saturation level, and so forth (Figure 3.1). The authors asserted that at low values of electric field strength, the damage imposed by PEF was reversible since the cells were capable of resealing and regaining functionality. This remained true until the ongoing PEF treatment further induced cell damage, whereby complete cellular collapse was eventually achieved. Therefore with increasing field strength, the restructuring of the 
cells becomes less pronounced and at values of higher electric field strengths, the process of resealing is restricted, or is simply nonexistent.

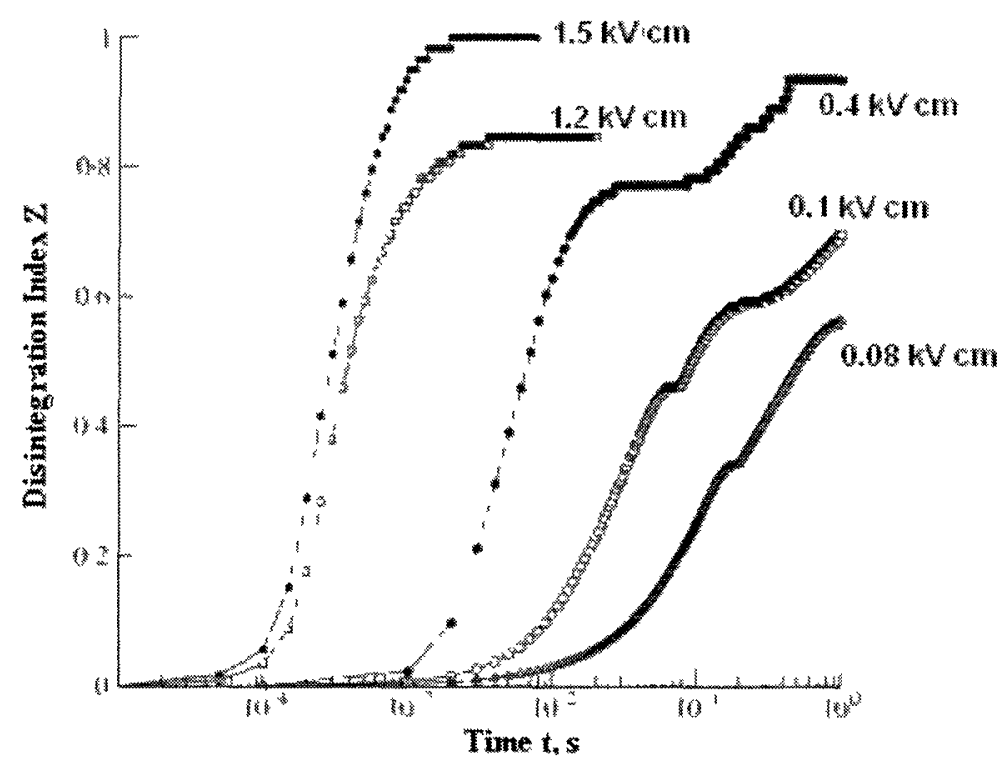

Figure 3.1: Disintegration index vs time for PEF treatment of apple tissues at different values of electric field strength (Bazhal et al. 2003)

The concept of a saturation point in PEF treated apple was also observed by Taiwo et al. (2003). Increasing field strength from 0.5 to $1.0 \mathrm{kV} / \mathrm{cm}$ resulted in improved water loss, however, for $2.0 \mathrm{kV} / \mathrm{cm}$ and beyond, the increase of field strength had no pronounced effect on water loss from apple tissue. This finding also contradicted the belief that increasing electrical field strength would also result in increased cell disintegration and osmotic dehydration. Therefore, it is suggested that maximum improvement of mass transfer from cell electropermeabilization is achieved by a certain degree of cellular disintegration, after which further electropermeabilization poses no effect on mass transfer (Taiwo et al. 2003). Similarly, at $1.0 \mathrm{kV} / \mathrm{cm}$, the amount of water lost from the apple tissue was the highest which indicated perhaps that the mass transfer properties 
were optimal at this electric field strength despite greater cell disintegration at higher field strength values at $2.0 \mathrm{kV} / \mathrm{cm}$. Essentially, this reveals that higher disintegration of cellular membranes does not necessarily exhibit optimal extraction or dehydration characteristics. Furthermore, the amount of vitamin $\mathrm{C}$ content in apples is essential due to its nutritional attributes and antioxidative properties. Performing PEF with electric field strengths greater than $1 \mathrm{kV} / \mathrm{cm}$ reduced the amount of vitamin $\mathrm{C}$ by $50-60 \%$ compared to control samples (Taiwo et al. 2003). This indicates that not only do increase in electric field strength cause the unnecessary consumption of energy, higher levels of field strength can compromise the viability of biological compounds within the plant.

\subsubsection{Extraction of Solutes}

El-Belghiti et al. (2008) examined the use of PEF to extract solutes from fennel, for the purpose of acquiring natural antioxidants to be utilized for the preservation of food products. With varying electric field strength, the effect of PEF parameters on solute extraction was determined by examining qualitative characteristics of absorbance, turbidity, and concentration of vitamins $\mathrm{C}$ and $\mathrm{E}$. Holding all other parameters at fixed values, the coarsely grated fennel termed "GR6" was pretreated at electric field strengths ranging from 0 to $0.6 \mathrm{kV} / \mathrm{cm}$. As the electric field strength increased to $0.45 \mathrm{kV} / \mathrm{cm}$, solute yield also increased from 60 to $98 \%(+38 \%)$ due to the PEF treatment imposed on the fennel sample. Beyond $0.45 \mathrm{kV} / \mathrm{cm}$, there was no effect of electric field strength on the extract yield and the threshold had been reached. Using an electric field strength higher than this value will prove to be ineffective and an unnecessary cost of energy. This threshold level is analogous to the saturation levels described in previous results. This 
concept is continuously demonstrated throughout many PEF applications. Knorr \& Angersbach (1998) similarly reported that a threshold electrical field strength of 1.1 $\mathrm{kV} / \mathrm{cm}$ was reached, after which a further increase beyond this value did not lead to improved thermal drying rates of potato slabs.

PEF pretreatment of sugar beets was performed by Eshtiaghi \& Knorr (2002) to electropermeabilize the cell walls of the plant and enhance the release of sucrose into the extracting solution during pressing and solid-liquid extraction. The findings of the study then made it possible to extract sugar beet juice after PEF treatment at ambient temperatures rather than performing the conventional thermal processing at a high temperature of $75-80^{\circ} \mathrm{C}$, which could degrade the quality of the sugar beet. The cell disintegration occurred at a slow pace initially as field strength increased from 1.2-2.4 $\mathrm{kV} / \mathrm{cm}$ and then the pace increased dramatically as field strength was increased beyond $2.4 \mathrm{kV} / \mathrm{cm}$ up till $3.6 \mathrm{kV} / \mathrm{cm}$. The degree of cell disintegration most likely rose dramatically after $2.4 \mathrm{kV} / \mathrm{cm}$ as the threshold transmembrane potential of the plant was surpassed causing widespread disruption to the plants structure. With PEF treatment and then three-step pressing, sugar extraction was achieved 2-3 times faster than the conventional method, allowing for a $70-90 \mathrm{~min}$ process to be decreased to $30 \mathrm{~min}$. Additionally, the percent of dry matter in the pressed pulp was higher at approximately $30 \%$ dry matter as opposed to conventional treatment with around $15 \%$ dry matter. This translated into the existence of less water in the pressed sugar beet, therefore reducing the amount of energy required for subsequent dehydration processes. 
The critical electric field strength as demonstrated by Eshtiaghi \& Knorr (2002), was associated with the transmembrane potential of the cell. When PEF treatment was applied to apple prior to osmotic dehydration, the recognition of critical electric field strength was provided by Jemai \& Vorobiev (2002). According to analysis, the diffusion coefficient rises abruptly at $0.1 \mathrm{kV} / \mathrm{cm}$, indicating that the transmembrane potential had been surpassed and increased electropermeabilization. As electric field strength increased, the rate of diffusion continued to increase, as indicated by the rising coefficient of diffusion.

\subsubsection{Solid-Liquid Extraction}

Guderjan et al. (2007) pretreated rapeseed with PEF prior to seed pressing and solvent extraction to increase the oil yield and enhance the quality of oil expressed from hulled and non-hulled rapeseed. Compared to the control samples, oil yield from hulled and pressed rapeseed linearly increased from 37 to $43 \%(+6 \%)$ with field strength increasing up to $7 \mathrm{kV} / \mathrm{cm}$. A similar linear trend was observed after applying solvent extraction, where oil yield in hulled and pressed rapeseed followed by hexane extraction increased from 48 to $51 \%(+3 \%)$ with field strength increasing up to $7 \mathrm{kV} / \mathrm{cm}$. However, in the case of non-hulled rapeseed, no clear trend was observed between the electrical field strength and oil yield. The authors attributed the more coherent results for hulled rapeseeds to' the fact that the hulled material is more homogeneous and therefore electrical conductivity is higher and more efficient during PEF treatment. A similar theory regarding the homogeneity of maize germ versus maize kernel was expressed when applying PEF on both forms of maize for enhanced oil yield, indicating that the germ experienced greater 
cell disintegration from the enhanced conductivity in the more homogeneous germ (Guderjan et al. 2005). However, in the experimental design of the rapeseed experiment, it is noted that as electric field strength is increased, the pulse number is also increased. Therefore, the research lacks investigating which variable, or if both variables simultaneously cause the increase of oil yield. In terms of oil quality, as PEF electric field strength was increased, higher quality oil was obtained. This was examined by tracking the content of functional food ingredients such as the antioxidants named tocophyerol and polyphenol. The amount of antioxidants present in the expressed oil increased from 58 to $67 \%(+13 \%)$ in hulled rapeseed and from 45 to $50 \%(+11 \%)$ in nonhulled rapeseed, when compared with control samples.

Unlike the study conducted by Guderjan et al. (2007), the experiments performed by Fincan \& Dejmek (2002) illustrated that electric field strength, and no other confounding variable was clearly effective in manipulating the conductivity of onion epidermal cells. In this case, the confounding variable of pulse number was eliminated, as only one pulse was applied to conduct PEF treatment. The effects of increasing electric field strength were evident by observing colour changes of the vacuole by applying a dye. With increased field strength and in turn enhanced permeability, the dye was able to diffuse through the cell wall and enter the plant vacuole. As the dye accumulate within the vacuole, it changed the colour of the vacuole due to the distinct $\mathrm{pH}$ of the vacuole environment. The change in colour was more prominent with increasing electric field strength, which indicates that more dye was allowed to enter the cell and accumulate within the vacuole. 


\subsubsection{Mechanical Pressing}

Potatoes were pretreated by Chalermchat \& Dejmek (2005) with PEF technology prior to mechanical pressing, to determine the effect of varying electric field strength on liquid yield. In accordance with past studies, results revealed that increasing electric field strength enhanced the yield of liquid from potatoes. With field strength ranging from $0.13-0.68 \mathrm{kV} / \mathrm{cm}$, the liquid yield from the potatoes also increased during mechanical compression. In some instances, the combination of PEF and mechanical pressing resulted in double the control yield (Chalermchat \& Dejmek 2005).

Bazhal et al. (2001) combined the use of PEF treatment and mechanical pressing to increase the kinetics of juice yield from apple. However, unlike experiments performed by Chalermchat \& Dejmek (2005), PEF was not used as a form of pretreatment and instead was used simultaneously with pressing. The process of juice yield from combined PEF and pressing treatment was described in three phases. Phase I compression was characterized by the release of extraparticle air and liquid surrounding the particles of apple, phase II illustrated that cells begin to rupture and extracellular fluid between cells is released, and finally phase III indicates that any remaining fluid from the extraparticle and extracellular regions are released in addition to the intracellular fluid inside the cells. Although PEF was applied simultaneously with pressing from phase I to phase III, it was not until $300 \mathrm{~s}$ after initial treatment that the influence of electric field strength was observed in phase III (Bazhal et al. 2001). In this phase, juice yield increased rapidly with increasing electric field strength. For phases I and II, the independence of electric field strength was attributed to the release of extraparticle fluid, which resulted in high juice 
yield rate simply due to mechanical pressing and therefore the influence of PEF was undermined. Moreover, the observation of the micrograph images revealed damage to the apple cells, where approximately $0.25-0.5 \mathrm{kV} / \mathrm{cm}$ revealed only several remaining intact cells and increased electric field strength of $0.5 \mathrm{kV} / \mathrm{cm}$ revealed complete degradation of the cells (Bazhal et al. 2001). Comparable to these results, De Vito et al. (2008) claimed that the characteristic damage time, or in other words, the time it takes to reach complete cellular damage of apple is decreased with the increase of electric field strength.

\subsection{EFFECT OF PULSE NUMBER}

To examine the effect of the number of pulses applied on the osmotic dehydration of PEF treated apple material, Amami et al. (2005) maintained a constant electric field strength of $0.90 \mathrm{kV} / \mathrm{cm}$ while increasing pulse number from 100 to 1000 . Results displayed that the osmotic dehydration of the apple material was enhanced such that the water loss and solid gain increased as pulse number increased. However, there was a limit to the trend exhibited, such that once the threshold was reached, there was no marked effect on the osmotic dehydration rate as the number of pulses increased. In this case, the increase from 0 to 750 pulses led to a $40 \%$ increase in water loss meanwhile from 750 to 1000 led to only $2 \%$ increase. Therefore, it is not feasible to expend further energy for breaching the 750 pulse number to achieve such a small effect of $2 \%$ increase in water loss, hence, 750 was chosen to be the optimal pulse number (Amami et al. 2005). Comparable to this study, Knorr \& Angersbach (1998) further demonstrated that beyond a pulse number of 25 , no improvement was evident on the drying rate of potato slabs, indicating that the threshold pulse number was attained. For the fennel plant, PEF treatment was introduced 
to enhance solute extract yield in the study performed by El-Belghiti et al. (2008). While testing on coarsely grated fennel (particle size GR6), the increase of pulse number also caused an increase in extract yield. Electric field strength was held constant at 0.45 $\mathrm{kV} / \mathrm{cm}$, and pulse number was increased up to 850 pulses. Similar to previous findings, the pulse number was effective up till 650 pulses, after which there was no longer a significant change in extract yield from PEF treated fennel (El-Belghiti et al. 2008).

Eshtiaghi \& Knorr (2002) attempted PEF treatment on sugar beets to replace conventional thermal treatment to extract the juice for the purpose of sugar beet dehydration. PEF was performed prior to pressing and varying pulse numbers were tested while maintaining the electric field strength at $2.4 \mathrm{kV} / \mathrm{cm}$. The initial increase of pulse number from 1-5 led to a high increase in the disintegration of the cell wall of the sugar beet tissue (Eshtiaghi \& Knorr 2002). However, increase in pulse number past 5 did not have a noticeable effect on the disintegration of the tissue. Considering the relatively high electric field strength for the PEF treatment of the plant with respect to other treated plants, it can be expected that a high number of energy dense pulses will not be required to induce detrimental effects on the plant cells. The electric field strength of $2.4 \mathrm{kV} / \mathrm{cm}$ is considered to be high when taking into perspective the commonly used electric field strength values used for other vegetables in Table 3.1. Hence, it is presumed that a high pulse number is not necessary, which is reflected within the results of the experiment.

In the experiment conducted by Brodelius et al. (1988), cells of plants named Thalictrum rugosum and Chenopodium rubrum were cultured to obtain the secondary products stored 
within the cell vacuole. PEF treatment was applied with all variables held constant except for pulse number. As opposed to the trends observed extensively throughout literature, the pulse number of 3 and 10 did not have a significant effect on the amount of product released by the cells (Brodelius et al. 1988). However, this might be attributed to the fact that the amount of energy per applied pulse was sufficient enough to cause detrimental damage to the cells in under 3 pulses and therefore the increase of the number of pulses did not produce a significant effect on the product release. In addition, the experimenters only tested a minute range of pulse numbers. Results might have differed, had they chosen a more widely distributed range of numbers that exceed 10 pulses. Furthermore, the choice and rationalization of these pulse numbers was not discussed within the context of the research.

For the osmotic dehydration of apples performed by Taiwo et al. (2003), the cell disintegration of PEF treated apples increased as the number of pulses applied also increased by determination of the disintegration index. It is then expected that similar effects would be demonstrated for the amount of water loss from the apple tissue. Instead, there was a lack of impact on water loss with varying pulse number. Nonetheless, it was demonstrated that the effect of increasing field strength on the disintegration of cells and the release of water was more pronounced than the use of higher number of pulses. If there is indeed no effect of pulse number on PEF treatment of plant material, then it would not be feasible to increase pulse number unnecessarily to a high number, as it would only translate into increasing energy expenditure and rising costs. 
Contrary results were observed by Arevalo et al. (2004), where the number of pulses greatly affected the compressive strength of apple, meanwhile the electric field strength did not seem to cause a significant effect. In this case, the compressive strength was analyzed to deduce the effects of PEF on the structural integrity of the plant tissue. The compressive strength of apple was decreased by $20-30 \%$ for a pulse number of 5 and further decreased up to $47 \%$ for a pulse number of 60 , for fixed electric field strengths of either 0.75 or $1.5 \mathrm{kV} / \mathrm{cm}$ (Arevalo et al. 2004). When the same compressive strength experiment was tested for potato, the results were not consistent with those obtained in the apple experiment and the pulse number no longer cause any effect. The characteristics observed for the compressive strength of apple could be limited to plant materials that have cells with high fluid content, and therefore the rigidity of the structure is reliant on the turgor pressure exerted by the fluid-filled cell. Therefore, when electropermeabilization occurs, turgor pressure is reduced dramatically due to the loss of moisture resulting in decreased compressive strength of the material. In the case of potato, the cells are more compactly filled with solids such as large starch granules, rather

than fluid (Arevalo et al. 2004). Hence, the release of turgor pressure due to electropermeabilization is not enough to create a dramatic decrease in compressive strength.

\subsection{EFFECT OF PARTICLE SIZE}

In existing literature, the majority of studies investigate the effect of electric field strength and pulse number on PEF treatment of plants, however, seldom do investigators analyze or discuss the effect of varying particle size and the outcome of PEF treatment. Despite 
the lack of literature, El-Belghiti et al. (2008) performed a series of investigations on the fennel plant. Seven fennel grating sizes were examined to determine the effect of particle size on the amount of valuable antioxidant solutes extracted from fennel by PEF. In order of increasing coarseness, two thin gratings (GR 1 and GR2) and five coarse gratings (GR3 to GR7) were used.

Initially, testing to determine the concentration yield of various fennel gratings did not include PEF treatment. Rather, the different grating sizes were soaked in distilled water and the concentration of the solutes was measured in ${ }^{\circ}$ Brix. For the coarsest grating size, GR7, the final amount of solutes obtained from the fennel was $45 \%$. As the material became finer, the solute yield obtained increased. The thin gratings GR1 and GR2 both yielded $98 \%$ solutes from the crushed fennel (El-Belghiti et al. 2008). It was evident that the smaller the grating size, the higher the extraction rate and final yield of the solute. This can be contributed to the fragmentation of the plant material in preparation for the PEF treatment. The finer the material was grated, the more likely the cells experienced mechanical damage and therefore released more solute readily as compared to a coarsely fragmented material where cells were more predominantly intact.

PEF was then used to enhance the permeability of the cells of the coarsely grated fennel that yielded the least amount of solutes. It was established that with each fennel grating, PEF treatment was able to enhance solute yield to the maximum $98 \%$ that was present in the case of the thin fennel gratings. The only difference that was evident between the varying grating sizes upon PEF treatment, was that thinner gratings rose to the maximum 
98\% yield at a faster rate than the coarse gratings (El-Belghiti et al. 2008). The exact amount of solutes transferred due to the mechanical fragmentation prior to PEF or the actual amount of solute transferred due to electropermeabilization during PEF treatment is unclear, however, it is known that both contributed to the enhancement of solute extraction.

Since the quantity of mechanically destroyed fennel cells is higher in thin gratings than coarse gratings, the amount of energy required to transfer the maximum amount of solute out of the cell and into the solution is less than the coarse gratings. Therefore, there is more energy required to treat the coarse gratings with PEF to achieve a high solute yield. However, the coarse gratings compensate their shortcomings by producing a higher quality solute yield (El-Belghiti et al. 2008). This was determined by examining the turbidity and absorbance of the extracts obtained from coarse and thin fennel gratings. The coarse fennel gratings produced less turbid and colored extracts, which translates to high quality extract with fewer impurities, compared to thin gratings. This is beneficial later on during the processing of the extracts when clarification and purification are performed. The optimal particle size for PEF treatment should encompass a balance of factors, taking into consideration the rate of solute extraction required, the quality of extract desired, and the amount of energy consumption.

Eshtiaghi \& Knorr (2002) successfully employed PEF treatment on sugar beet as a complimentary process to solid-liquid extraction. PEF treated sugar beet provided significant increase in concentration compared to the control samples. However, as the 
slices of beet root decreased in size, the effect that PEF exhibited on sucrose extract became less pronounced. This relates back to the results from El-Belghiti et al. (2008), which claimed that the high degree of mechanical fragmentation dominated the transfer of extracts and thereby diminished the profound effects of PEF.

\subsection{EFFECT OF TEMPERATURE}

Similar to particle size, the literature does not extensively investigate the effect of varying temperature conditions while applying PEF treatment on plant tissues. Traditionally, PEF treatment is performed at ambient temperature. However, according to basic heat and mass transfer theory, kinetics are increased with increasing temperature, speeding up various heat and mass transfer processes. Furthermore, Amami et al. (2005) verifies that application of PEF processing will produce different results when applying it to heated and unheated plant tissue due to the alteration of internal mass transfer upon the introduction of thermal energy. Additionally, the breakdown potential of plant cells decreases with increasing temperature, thus making cell walls of plants more sensitive to an electric field at higher temperatures (Sensoy \& Sastry 2004). Therefore, in comparison to unheated plant tissue, the PEF treated materials performed at higher levels will require lower electric field intensities to produce marked effects on the plant material (Jemai \& Vorobiev 2002).

In the experiments of El-Belghiti et al. (2008), the fennel sample was subjected to thermal extraction with temperatures varying between $60-90^{\circ} \mathrm{C}$ and compared to PEF treated fennel performed at room temperature. In both cases, the thermal treatment and 
the PEF treatment both achieved a final solute yield of $98 \%$ (El-Belghiti et al. 2008). However, as temperature increased in the thermal experiments, the rate at which this maximum solute yield was increased. Hence, higher temperatures mainly caused an increase in the kinetics of the extraction of solutes from fennel. The disadvantage with thermal treatment was that the extracts obtained were more turbid and coloured than the PEF treated material and therefore quality is compromised when high temperatures are used to obtain faster solute yield (El-Belghiti et al. 2008). In addition, vitamin A and C were best preserved with PEF treatment as opposed to higher temperature extractions, which degrade vitamins and other valuable constituents.

The introduction of high thermal energy to a PEF system can enhance the mass transfer of substances in and out of the cell. However, the benefits do not entirely outweigh the issue of reduced quality during thermal treatment. This issue should be considered when introducing thermal treatment as a complimentary treatment to PEF processing. The question of quantity versus quality arises and the answer should be based on the requirements of the specific application. Another issue is that with thermal treatment, high-energy consumption could exceed the energy pertaining to PEF treatment (ElBelghiti et al. 2008).

De Vito et al. (2008) also investigated the effect of increased temperature on PEF treated apple, stating that PEF efficiency increased at higher temperatures. Temperatures of up to $50^{\circ} \mathrm{C}$ were tested to estimate the disintegration index of PEF treated apple. It was observed that the critical transmembrane potential was decreased at $50^{\circ} \mathrm{C}$. In addition, the 
authors suggested that pores were more easily formed in elevated temperatures, and therefore electroporation could occur at lower electric field strengths. The use of thermal and PEF treatment was deemed to have a positive effect on the electropermeabilization of soft-cellular plant material with regards to disintegration. However, the authors did not comment on the effect of PEF and thermal treatment on the physical and nutritional quality of the material.

\subsection{EFFECT OF PULSE DÜRATION AND SHAPE}

Limited articles are available that discuss the effect of pulse shape and width on PEF treatment of plant cells, and none were found to perform experimentation to investigate effects. However, it is well established that exponential and rectangular pulses are the most utilized pulse shapes for the treatment of plant tissues, which is consistent with the methodology chosen for all the experimentations in Table 3.1.

In terms of pulse shape, rectangular pulses have wider pulse duration, and according to Knorr \& Angersbach (1998), are more effective in causing PEF damage to the cell wall of plants. This conclusion is reasonable since the cell wall is exposed to a large potential for a longer period of time, causing extended damage and preventing the cell membrane to undergo resealing processes. In addition, to achieve the same amount of power and cell disintegration using a shorter pulse duration, such as in the case of exponential, will require higher amounts of energy (De Vito et al. 2008). Furthermore, De Vito et al. (2008) observed increased PEF efficiency with increased pulse durations and suggested that shorter pulse durations were not enough to complete the charging process of the cells 
to induce damage. Therefore, the effects of PEF on the plant cell were suppressed. In addition, De Vito et al. (2008) found that less time is required for apple cell damage with increase in pulse width. This effect was more noticeable at lower electric field strengths.

Results obtained from Jemai \& Vorobiev (2002) correlate with those of De Vito et al. (2008). It was determined that the efficiency of PEF rectangular pulse treatment was enhanced with increasing pulse duration from $50 \mu \mathrm{s}$ to $100 \mu \mathrm{s}$, and although less pronounced, from $100 \mu$ s to $200 \mu$ s. However, this rise in pulse duration was associated with a rise in electrical energy input, with $200 \mu$ s pulse duration requiring 2.5 times more energy than $100 \mu$ s. In addition, pulse duration of $200 \mu$ s resulted in a higher temperature elevation (Jemai \& Vorobiev 2002). Therefore, increasing the pulse duration enhances PEF efficiency to a certain extent, when other factors such as energy requirements and ohmic heating outweigh the benefits of increasing pulse duration. 


\section{RESEARCH OBJECTIVE}

The review of current literature has exposed gaps of knowledge in several areas related to the proposed research of podophyllotoxin extraction from Podophyllum peltatum using pulsed electric field technology. In the field of pulsed power technology, successful research advancements have been broadly achieved for PEF treatment to enhance conventional processing of liquid food systems. PEF treatment in this industry is innovative and its uniform treatment of the food product, short treatment time, and nonthermal approach makes it an attractive process. The PEF pasteurization or sterilization procedure entails the use of electropermeabilization to inactivate microbial populations while maintaining food quality to meet the demands of consumers. Nonetheless, it was established that the cellular structure of microorganisms differs from that of plant cells due to the existence of a thick cell wall in the latter.

The focus of researchers has recently shifted towards PEF applications of soft-cellular plants, namely, fruits and vegetables. Progress has been made in this area, but not to the extent of industrial-scale implementation. Research is ongoing and the methods of PEF optimization are inconsistent and inconclusive with respect to obtaining firm guidelines outlining the optimal PEF process for all plant types. Depending on the electrical exposure of the PEF treatment, a wide variety of effects can result in biological cells (Sensoy \& Sastry 2004). Therefore, it is important to distinguish that fruits and vegetables are considered to be soft-cellular plants, and hence, differ from tougher plants such as $P$. peltatum. 
Up to date, no research has been undertaken for plants of this nature. Furthermore, PEF application has been researched to benefit the food industry and the use of PEF treatment has not yet been indulged for the pharmaceutical industry. Hence, the use of PEF treatment for the extraction of podophyllotoxin is a novel approach in the realm of pharmaceutical biotechnology.

Relative to other plants and chemicals, limited studies and information exists for $P$. peltatum and its valuable constituent, podophyllotoxin. It is known that the chemical is stored within the plant interior in the vacuole as an inactive glucoside, and is activated once exposed to the cytoplasmic fluid (Moraes et al. 2004). According to Corrales et al. (2008), compounds that exist within an enclosed organelle such as the vacuole are difficult to extract and further complicate processes involving PEF extraction. With respect to information regarding the cell composition, only general information exists which discusses the compositions of powdered $P$. peltatum. Unfortunately, there is no information regarding the cellular constituents of the plant. Furthermore, it is not yet understood how the PEF treatment will affect podophyllotoxin in the plant. With this in consideration, the main objective of this research is to use PEF treatment to electropermeabilize the cell wall, cytoplasmic membrane and tonoplast of $P$. peltatum to release podophyllotoxin. To achieve the objective of cell barrier breakage of $P$. peltatum, PEF treatment must be fine-tuned to attain sufficient damage for electropermeabilization and enhanced extraction. This primary achievement will initiate the path for attaining long-term objectives. 
If the research results demonstrate that PEF does indeed break the cell barriers of $P$. peltatum and podophyllotoxin extraction is enhanced due to electropermeabilization, the high cost of podophyllotoxin production can be decreased. This in turn can reduce the cost of cancer treatment for patients and the burden on the health care system. Among the plethora of medicinal activities that this chemical possesses, its anticancer characteristics are vital for the treatment of the wide-spread disease of cancer, in addition to venereal warts, rheumatoid arthritis, and malaria. The pharmaceutical industry recognizes the need for alternative methods for production as the chemical synthesis of podophyllotoxin is very costly (Farkya et al. 2004). The major issue of natural podophyllotoxin is that the demand outstrips the supply (Haijun et al. 2004). Foremost, the concentration of the chemical is minute within the plant (Eyberger et al. 2006), and secondly, the primary source, $P$. emodii has been declared as an endangered species (Liu et al. 2007). Accomplishing the objective of the research will maximize the amount of podophyllotoxin from $P$. peltatum, battle dwindling supplies, source the increasing demand of podophyllotoxin and possibly deter $P$. peltatum from experiencing the same fate of $P$. emodii and its endangerment. 


\section{MATERIALS AND METHODS}

\subsection{OVERVIEW}

To achieve damage to the cell barriers that inhibit the diffusion of podophyllotoxin, ground $P$. peltatum rhizomes were subjected to PEF treatment in a parallel-plate treatment chamber. A series of experiments were completed in 4 phases. Experiments were performed with numerous variables to determine which combination, if any, was successful in breaking the cell barriers. Phases I and II employed instant charge reversal pulses and Phases III and IV employed rectangular pulses for PEF treatment. For each sample of $P$. peltatum prepared and tested with PEF treatment, a control sample was acquired. Figure 5.1 briefly outlines the methodology of this research.

\subsection{PREPARATION OF PODOPHYLLUM PELTATUM SAMPLES}

P. peltatum was obtained from Richters Herbs (Goodwood, Ontario). Each package contained $1 \mathrm{~kg}$ of dried rhizomes of $P$. peltatum (Product Code H3960). The rhizomes were ground into various particle sizes using a grinder (Model 80374, Hamilton Beach Custom Grind Deluxe). Using ASTM standardized sieves with different mesh sizes (Table 5.1), particles of $P$. peltatum samples were obtained. The mesh number represents the number of apertures in 1 inch of linear measurement. The greater the mesh number, the higher the number of apertures and therefore the smaller the size of the particles that are able to pass through the sieve. 


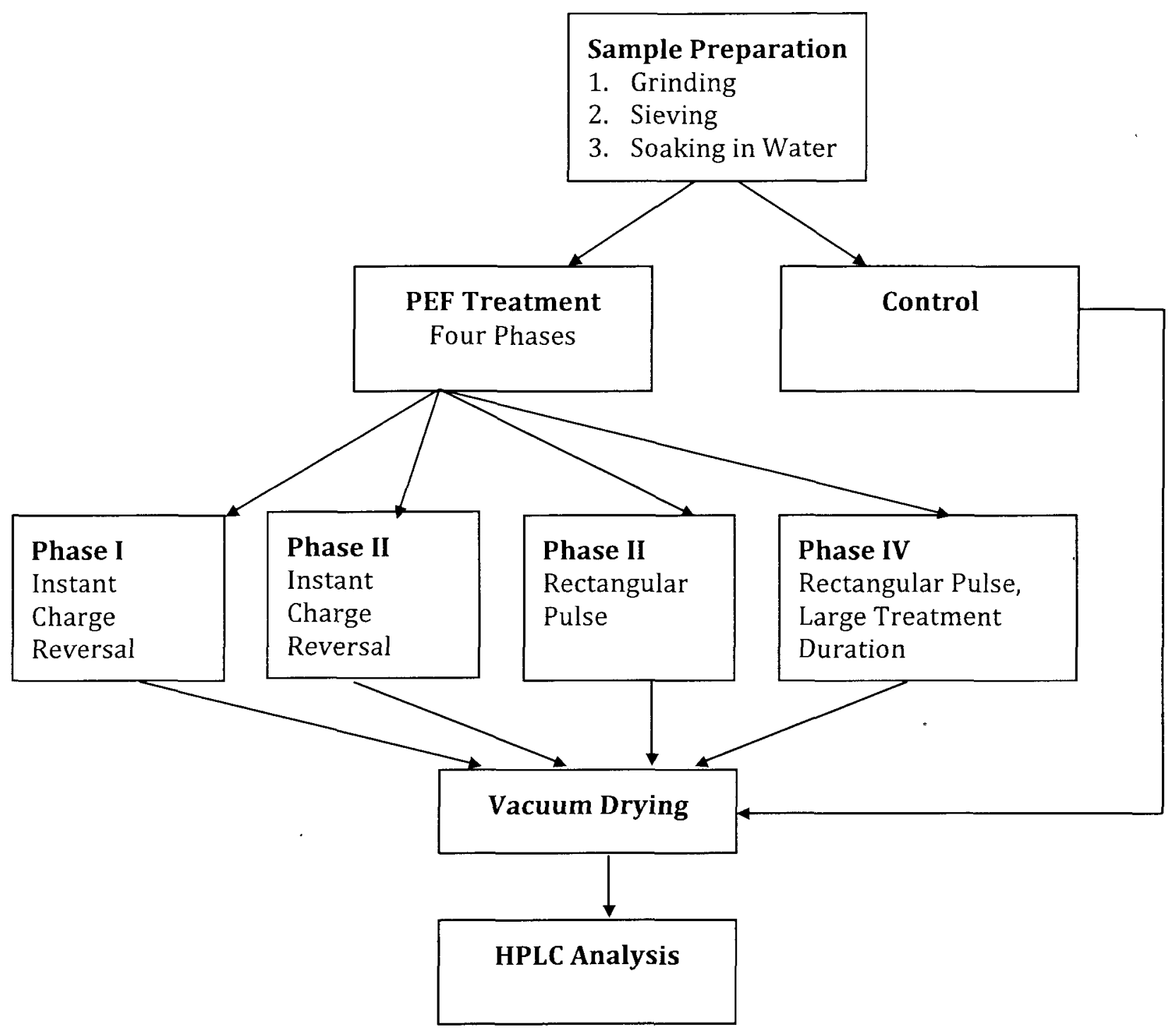

Figure 5.1: Flow diagram of experimental procedure

Particles that were filtered through the mesh sieve and into the collection pan, had a particle size smaller than the mesh apertures, and were termed either $<60$ or $<48$. Particles that did not pass through the mesh were greater than the size of the apertures, 
and were labeled $>48$. Different $P$. peltatum particle sizes of $<60,<48$ and $>48$ were used at various stages of the research.

Table 5.1: Size of $P$. peltatum particles after grinding and sieving

\begin{tabular}{|c|c|c|c|}
\hline Mesh & Opening $(\mu \mathrm{m})$ & Particle Size & Relative Size \\
\hline 60 & 250 & $<250 \mu \mathrm{m}$ & Fine, Powder \\
\hline 48 & 295 & $<295 \mu \mathrm{m}$ & Medium \\
\hline 48 & 295 & $>295 \mu \mathrm{m}$ & Large \\
\hline
\end{tabular}

After sieving and collection, the ground $P$. peltatum samples were soaked with deionized water. This soaking treatment rehydrated the cells and restored the mobility of the cell constituents. Unused ground $P$. peltatum samples were stored for future experiments in a chamber containing Indicating Drierite (anhydrous calcium phosphate, Stock \# 24005, Fischer Scientific), which was used to maintain a dry environment.

\subsection{PULSED POWER GENERATOR}

The laboratory scale pulsed power systems used for the treatment of $P$. peltatum rhizomes were formerly constructed for past research at the University of Guelph, School of Engineering.

\subsubsection{Instant Charge Reversal Pulse Generator}

Instant charge reversal pulses were applied in Phase I and II of the experiments. Figure 5.2 is a flow diagram briefly outlining the method of instant charge reversal pulse generation. 


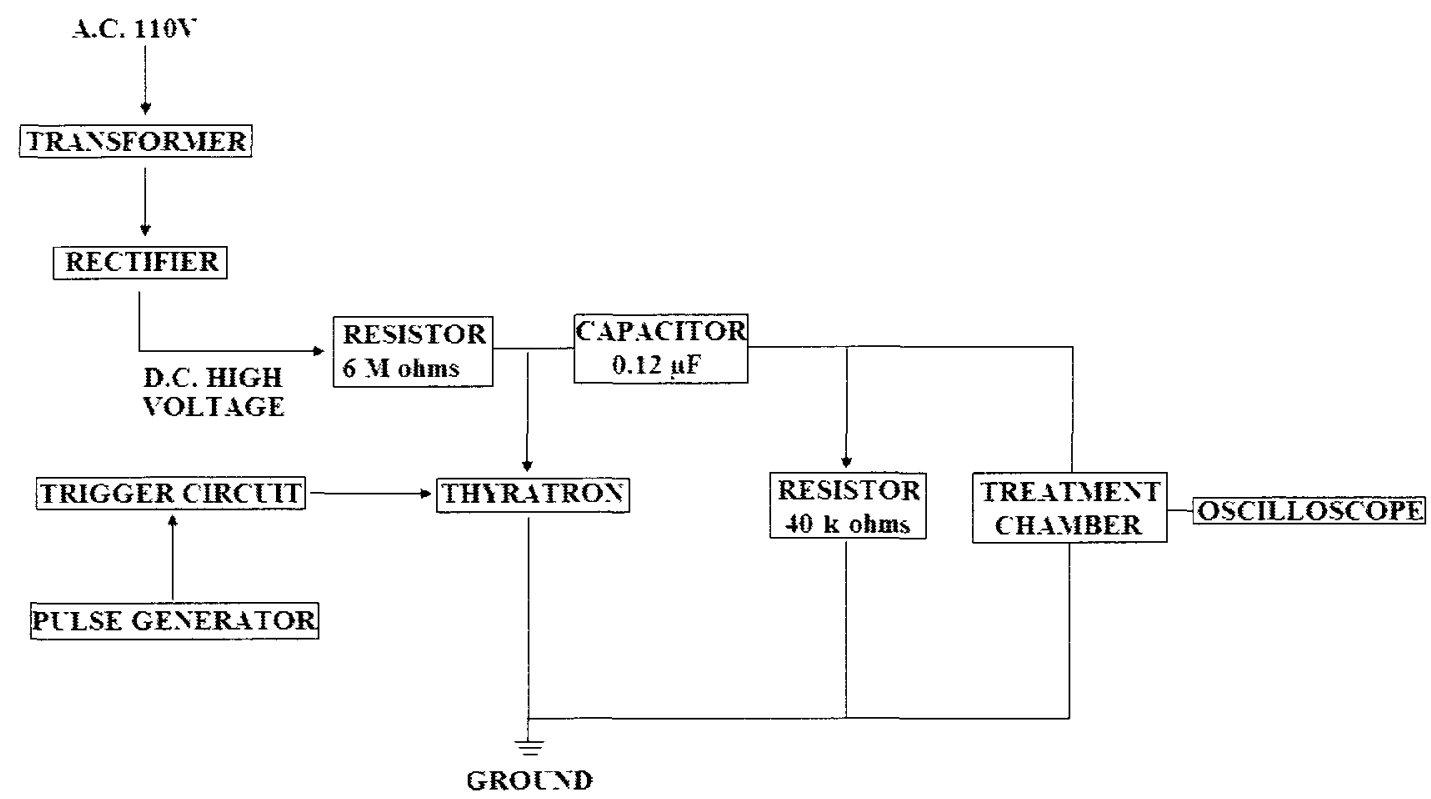

Figure 5.2: Flow diagram of instant charge reversal pulse generation in PEF system used in Phases I and II (Ho et al. 1997)

A voltage was initially fed to the system from a $110 \mathrm{~V}$ A.C. source. The transformer stepped up the incoming voltage and the rectifier converted the voltage from A.C. to D.C. The transformed D.C. voltage was used to charge the capacitor (Model 31885, Maxwell) for energy storage. Throughout this process, the circuit was open due to the open switch, which in this case was the thyratron. However, once the capacitor was sufficiently charged, the system was ready for pulse initiation. The power supply (230-6P-R\&D, Sorensen D.C. Power Supplies) then released a train of low voltage pulses that were converted to high voltage pulses by the trigger circuit. This series of pulses caused the thyratron switch to close and the circuit was completed. Electrical current was then able to flow through the circuit due to the high voltage potential difference. Hence, energy stored in the capacitor was released in the form of pulses. The resultant generated pulse was exposed to the material within the treatment chamber in the form of an electrical 
field from the stainless steel electrodes (Section 5.4). Current travels from the anode to the cathode, hence causing the anode to be positively charged and the cathode to be negatively charged. Any charged particles between the electrodes were then attracted to the oppositely charged electrode. Hence, due to the design of the PEF system, the duration and frequency were fixed at $2 \mu$ s and $0.5 \mathrm{~Hz}$, respectively.

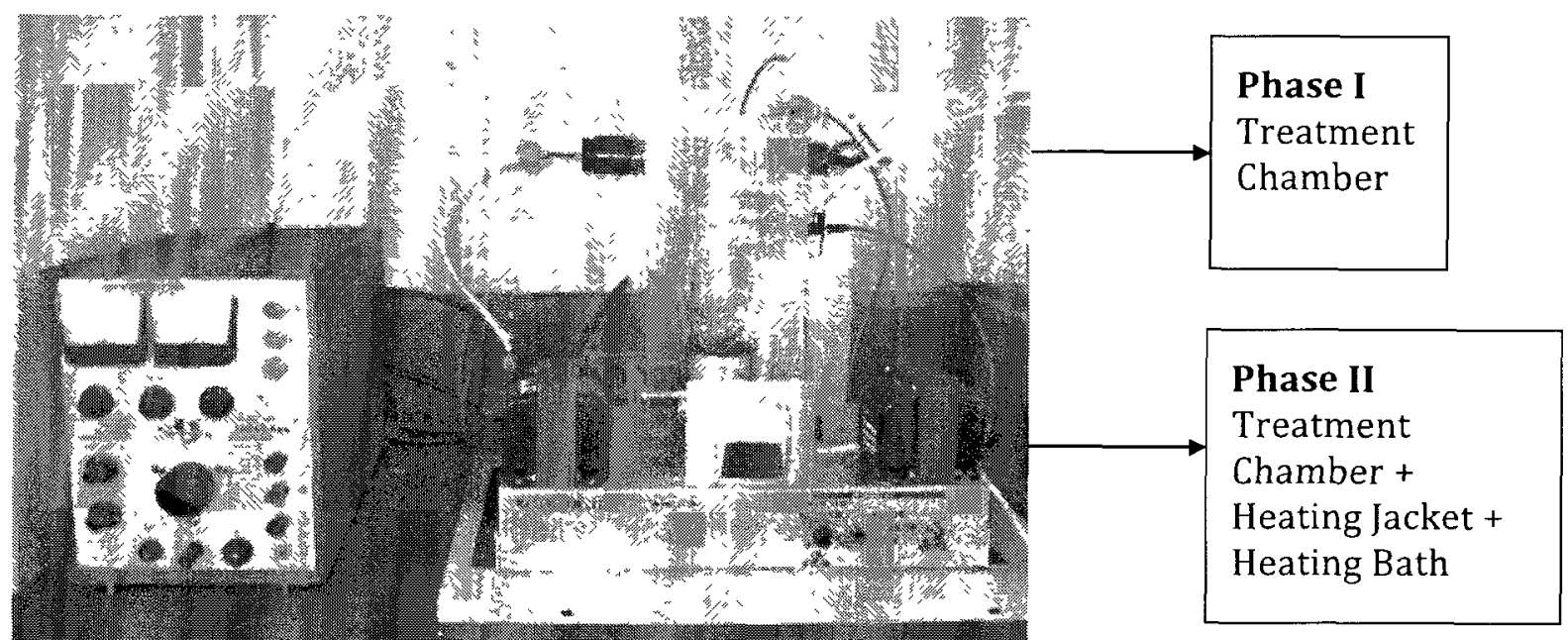

Figure 5.3: PEF system set-up for instant charge reversal pulses for Phases I and II

Figure 5.3 presents the physical set up of the PEF system for instant charge reversal pulses that were implemented in Phase I and II. Each electrode terminal in the treatment chamber was connected to the pulse generator. The chambers were varied depending on the experimental phase (Section 5.4). A voltage probe (Model 2230, Tektronix) was used to measure the voltage in the treatment chamber. A digital real-time oscilloscope (TDS 340, Tektronix) was also connected to the system to monitor the pulses. An instant charge reversal pulse captured by the oscilloscope is demonstrated in Figure 5.10. 


\subsubsection{Rectangular Pulse Generator}

Rectangular monopolar pulses were applied in Phase III and IV of the experiments. The details of this generator are not discussed, as the inventors have not yet patented it. The physical set up of the system is shown in Figure 5.4. A rectangular pulse generated by the system is demonstrated in Figure 5.12.

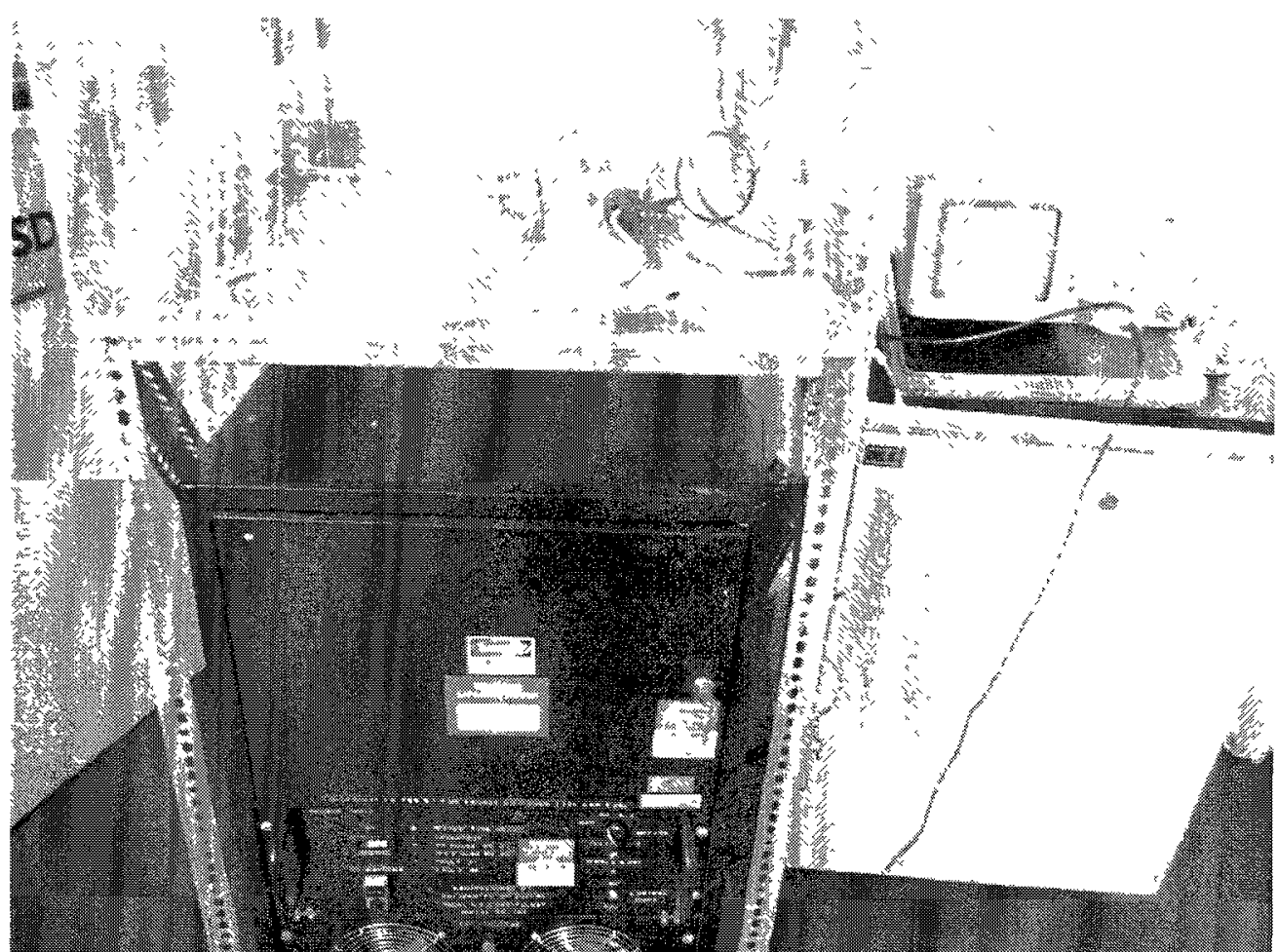

Figure 5.4: PEF system set-up for rectangular pulses for Phases III and IV

\subsection{TREATMENT CHAMBER}

Different treatment chambers were used depending on the phase of experimentation. All the treatment chambers contained parallel plate disc electrodes and performed batch treatment. The treatment chamber used in Phase I is illustrated in Figure 5.5. 


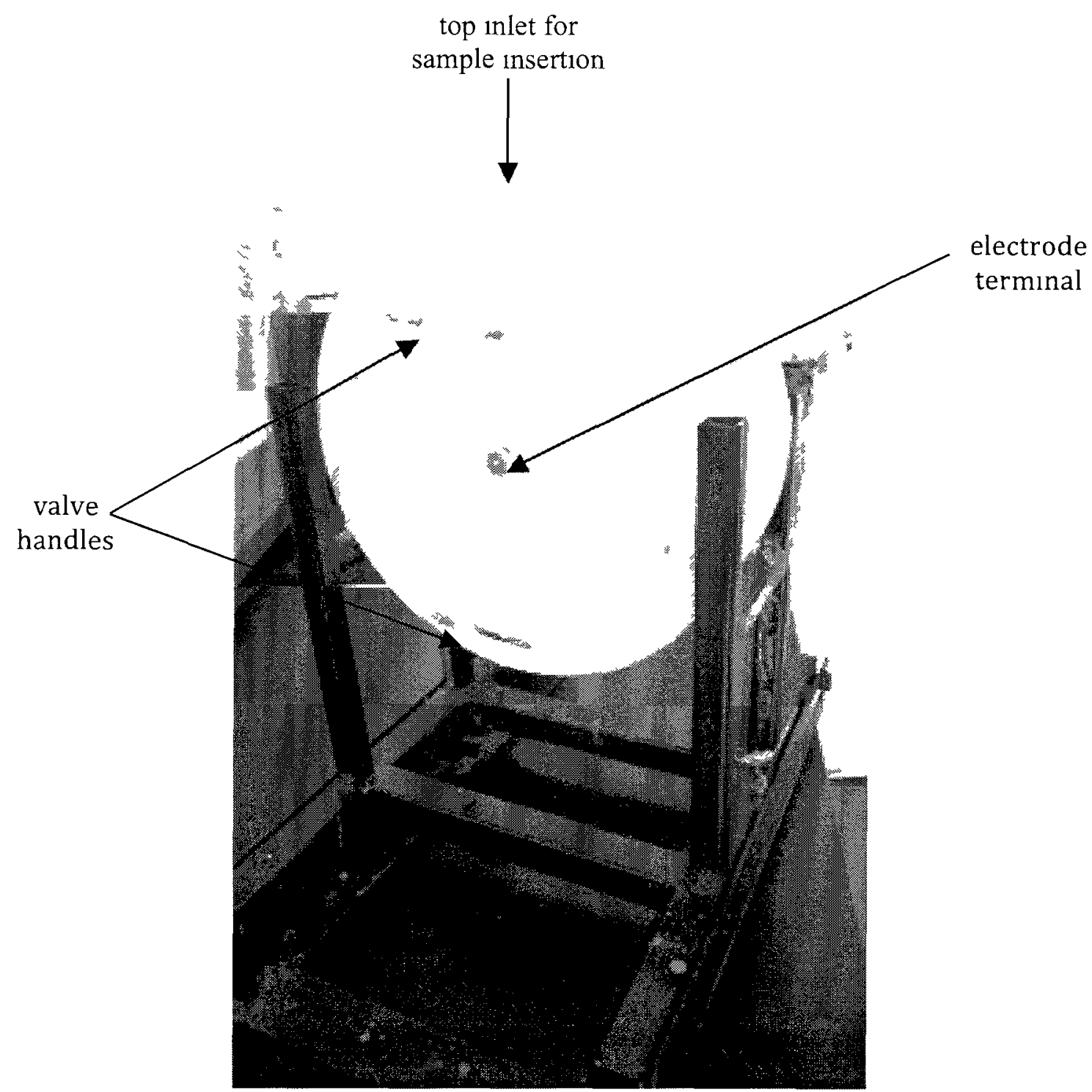

Figure 5.5: Parallel electrode treatment chamber used in Phase I, set in vertical position on a hingejointed frame

The two parallel plate disc electrodes were made of stainless steel and had a diameter of $165 \mathrm{~cm}$ Although the gap was adjustable to 03,06 or $09 \mathrm{~cm}$ thickness, an electrode gap of $03 \mathrm{~cm}$ was used for the experiments to obtain a higher electric field strength The gap was adjustable by the insertion of 03,06 , or $09 \mathrm{~cm}$ thick Derlin circular plates of $145 \mathrm{~cm}$ diameter between the two electrodes Figure 5.6 illustrates the components of 
the unassembled treatment chamber. Hence, the volume of the treatment chamber in the experiments was $45 \mathrm{~mL}$, although the capacity of the treatment chamber could be adjustable up to $\leq 148 \mathrm{~mL}$. Both the inlet and outlet openings were $0.8 \mathrm{~cm}$ in diameter.

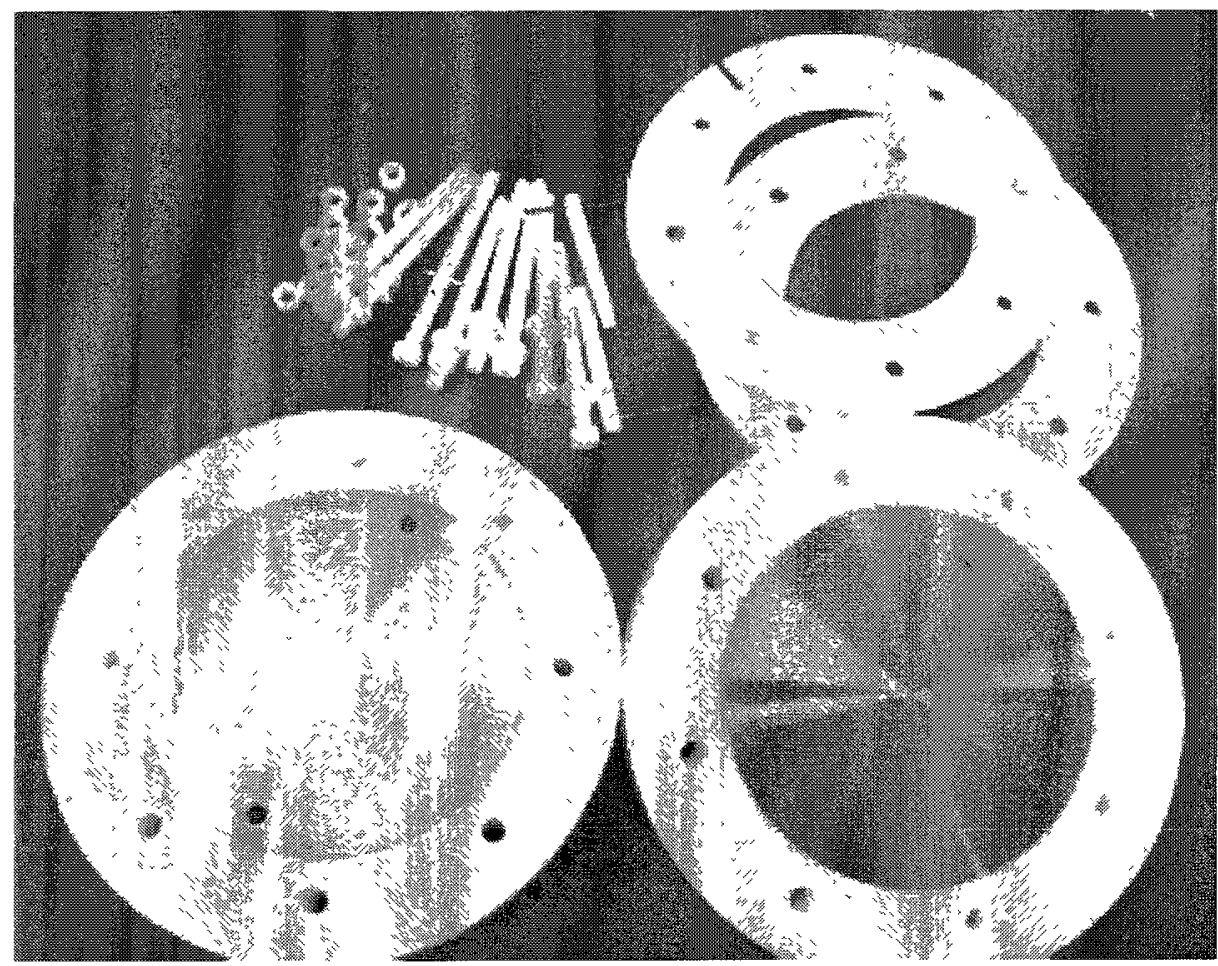

Figure 5.6: Components of the unassembled parallel-plate treatment chamber used in Phase I

In Phase II, a treatment chamber insulated with acrylic was used (Figure 5.7). The outer diameter of the treatment chamber with insulation was $15 \mathrm{~cm}$ and the total height of the chamber was $5.6 \mathrm{~cm}$. 


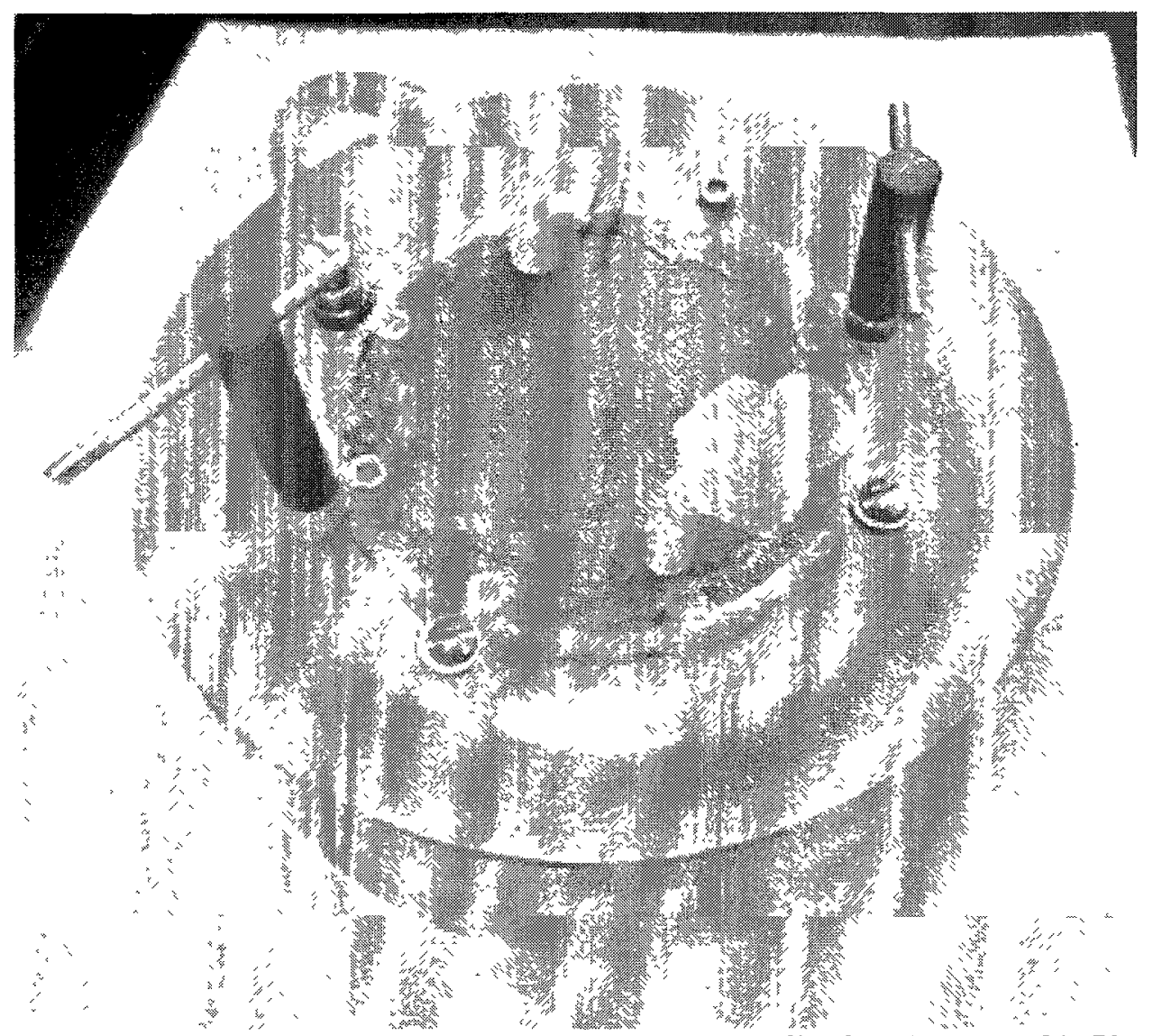

Figure 5.7: Parallel electrode treatment chamber with a surrounding heat jacket used in Phase II

The two parallel plate disc electrodes were made of stainless steel with diameters of 10.5 $\mathrm{cm}$ and electrode gap of $0.3 \mathrm{~cm}$. The electrode gap was not adjustable; hence, the volume of the treatment chamber was approximately $26 \mathrm{~mL}$. Both the inlet and outlet openings were $0.65 \mathrm{~cm}$ in diameter. The set-up of the treatment chamber is demonstrated in Figure 5.8. The treatment chamber was set up in vertical position during PEF treatment. Water was circulated through the heating jacket at approximately $50^{\circ} \mathrm{C}$ by connecting the jacket tubes to the heating bath. 


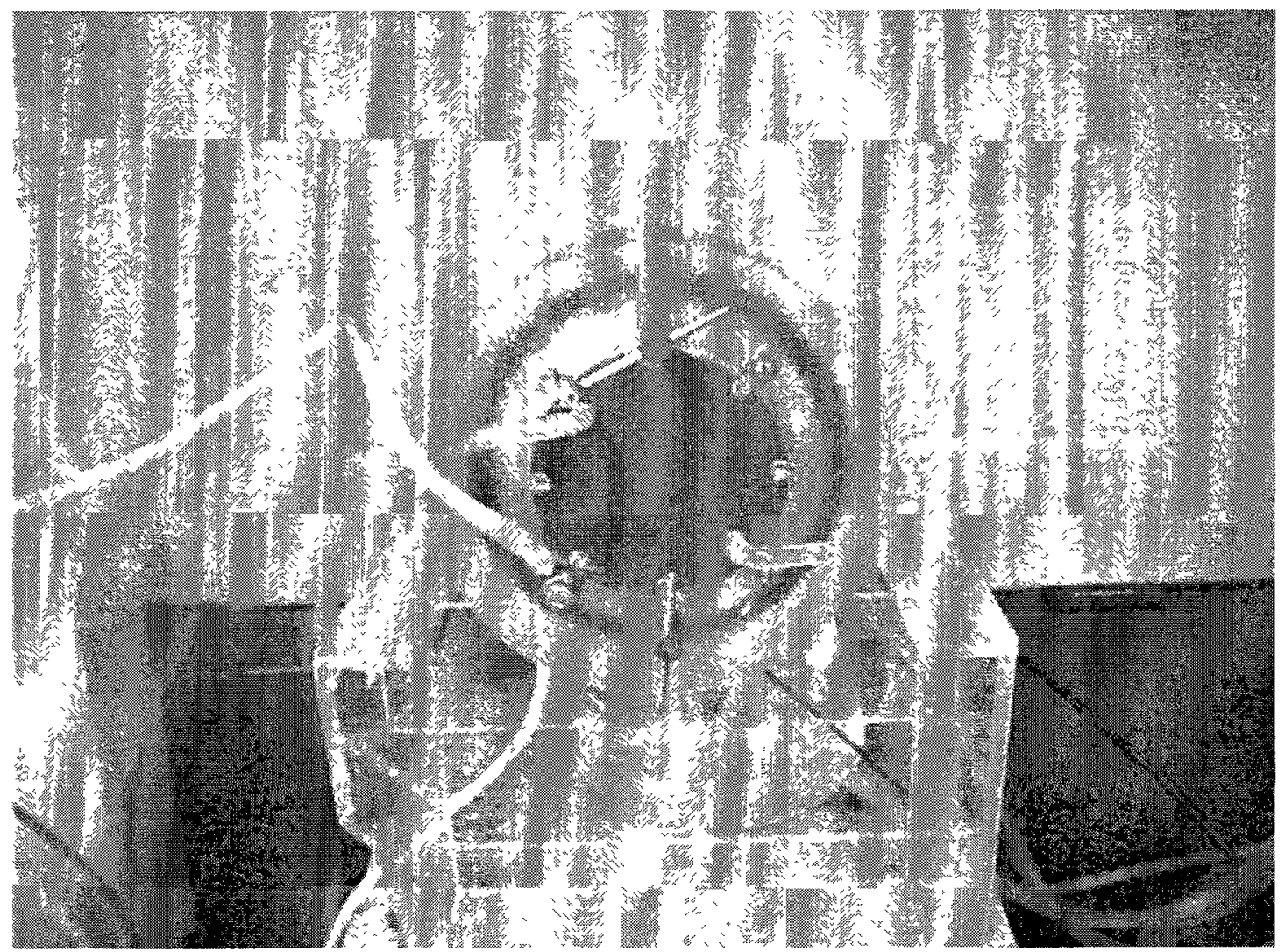

Figure 5.8: Parallel electrode treatment chamber used in Phase II with a surrounding heating jacket, set up in vertical position while connected to PEF system and heating bath

In Phases III and IV, the same treatment chamber was used and is illustrated in Figure 5.9. The treatment chamber was insulated with acrylic and the outer diameter of the treatment chamber including the insulation was $7.7 \mathrm{~cm}$. The total height of the chamber was $7.5 \mathrm{~cm}$. The two parallel plate disc electrodes were made of stainless steel and had diameters of $6.4 \mathrm{~cm}$ and electrode gap of $0.7 \mathrm{~cm}$. The electrode gap was not adjustable, resulting in a treatment chamber volume of approximately $22 \mathrm{~mL}$. The inlet was $1 \mathrm{~cm}$ in diameter. 


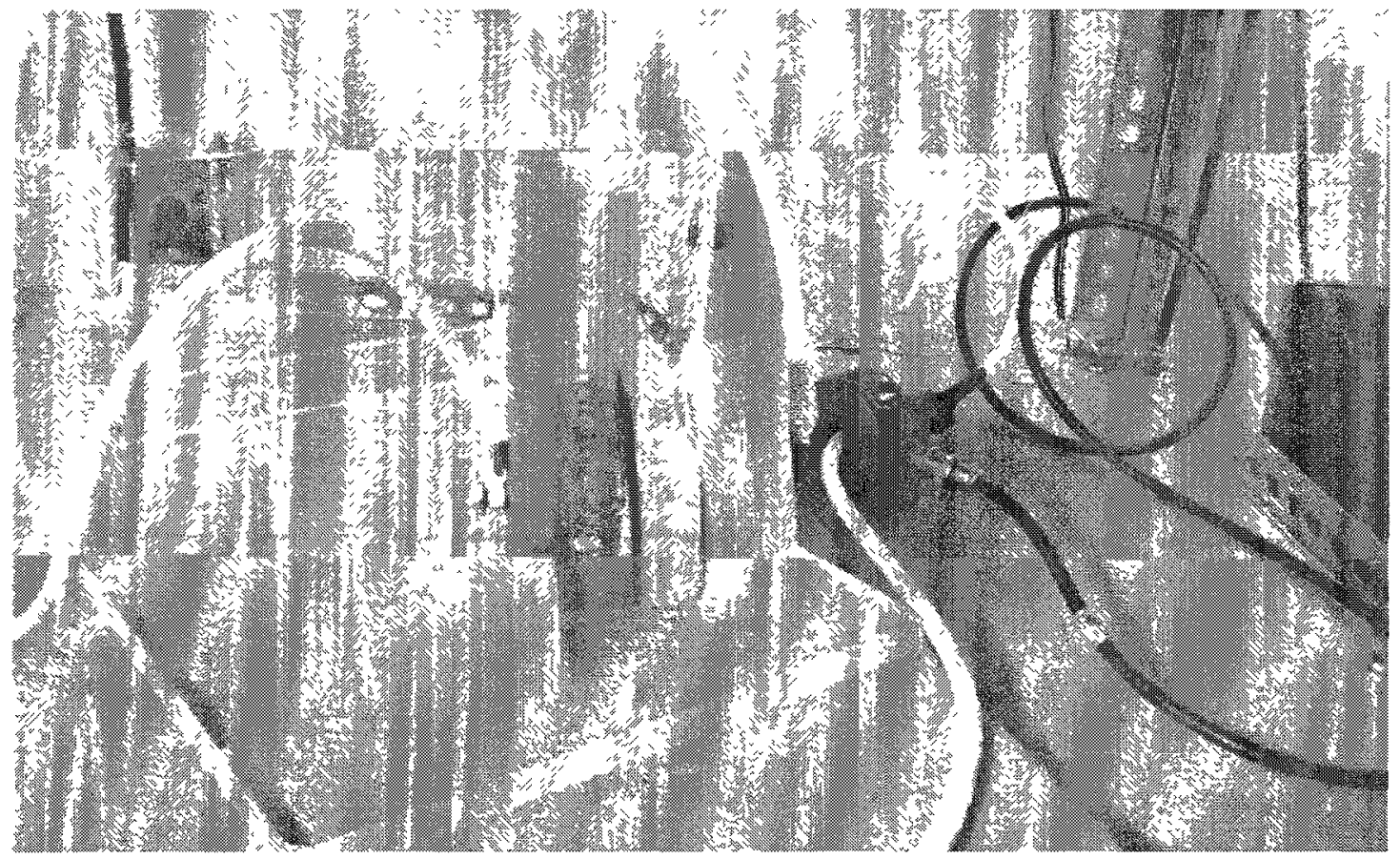

Figure 5.9: Parallel electrode treatment chamber used in Phases III and IV with current meter surrounding the electrode wire.

\subsection{DESIGN OF EXPERIMENTS}

Factorial design experiments were performed with at least two replications for Phases I to III. In all the experiments, the response variable was the concentration of podophyllotoxin extracted from $P$. peltatum. The PEF process variables were used to determine if there was any effect on the cells of $P$. peltatum resulting in a higher yield of podophyllotoxin.

\subsubsection{Phase I}

The instant charge reversal generator was used to treat $P$. peltatum with $\mathrm{PEF}$ at room temperature (Section 5.6.1). Table 5.2 outlines the experimental variables and Table 5.3 presents the factors that were held constant throughout the experiments. In all the 
experiments, the electrical field strength was calculated by dividing the voltage by the electrode gap of the treatment chamber.

Table 5.2: Phase I experiment variables using instant charge reversal pulses

\begin{tabular}{|l|l|}
\hline Variable & Value \\
\hline Particle Size (2) & $<60,<48$ mesh \\
\hline Pulse Number (3) & $20,40,60$ \\
\hline Electric Field Strength (3) & $33.3,50,66.7 \mathrm{kV} / \mathrm{cm}$ \\
\hline
\end{tabular}

Table 5.3: Phase I controlled variables using instant charge reversal pulses

\begin{tabular}{|l|l|}
\hline Constant & Value \\
\hline Temperature & Room temperature $\left(24^{\circ} \mathrm{C}\right)$ \\
\hline Water:P. Peltatum & $4: 1$ \\
\hline Soaking Time & $24 \mathrm{~h}$ \\
\hline
\end{tabular}

\subsubsection{Phase II}

The instant charge reversal generator was used to apply PEF treatment on the $P$. peltatum samples at a high temperature of $45^{\circ} \mathrm{C}$ (Section 5.6.2). Table 5.4 outlines the explanatory variables and Table 5.5 presents the factors that were held constant during PEF treatment.

Table 5.4: Phase II experiment variables using instant charge reversal puises

\begin{tabular}{|l|l|}
\hline Variable & Value \\
\hline Pulse Number (3) & $20,40,60$ \\
\hline Electric Field Strength (3) & $33.3,50,66.7 \mathrm{kV} / \mathrm{cm}$ \\
\hline
\end{tabular}

Table 5.5: Phase II controlled variables using instant charge reversal pulses

\begin{tabular}{|l|l|}
\hline Constant & Value \\
\hline Particle Size & $<48$ mesh \\
\hline Water:P. Peltatum & $4: 1$ \\
\hline Soaking Time & $24 \mathrm{~h}$ \\
\hline Temperature & $45^{\circ} \mathrm{C}$ \\
\hline
\end{tabular}


To determine the effect of temperature on PEF treatment of $P$. peltatum, statistical analysis was performed using the results obtained for the PEF treatment of $<48$ mesh $P$. peltatum at $45^{\circ} \mathrm{C}$ and $24^{\circ} \mathrm{C}$ from Phase I.

\subsubsection{Phase III}

The rectangular monopolar pulse generator was used to treat $P$. peltatum with PEF (Section 5.6.3). Table 5.6 presents the PEF process variable and Table 5.7 illustrates the factors that were held constant throughout the experiments. Due to the manufacture and settings of the rectangular pulse generator, the PEF generator was operated by adjusting voltage and pulse frequency. To maintain consistency with the experimental variables of Phases I and II, the pulse number was calculated by multiplying frequency by PEF treatment time.

Table 5.6: Phase III experiment variables using rectangular monopolar pulses

\begin{tabular}{|l|l|}
\hline Variable & Value \\
\hline Frequency (2) & $84,840 \mathrm{~Hz}$ \\
\hline PEF Treatment Time (6) & $120,150,180,240,300,360 \mathrm{~s}$ \\
\hline
\end{tabular}

Table 5.7: Phase III controlled variables using rectangular monopolar pulses

\begin{tabular}{|l|l|}
\hline Constant & Value \\
\hline Particle Size & $>48$ mesh \\
\hline Water:P. Peltatum & $2: 3$ \\
\hline Temperature & Room temperature $\left(24^{\circ} \mathrm{C}\right)^{*}$ \\
\hline Electrical Field Strength & Maximum possible by PEF generator \\
\hline Soaking Time & $1 \mathrm{~h}$ \\
\hline
\end{tabular}

*Temperature of $P$. peltatum inside treatment chamber increased due to energy input and was not measured

The maximum electric field strength possible by the PEF generator was desired. However, due to operational limitations and the uncontrollable nature of the $P$. peltatum 
sample, the electric field strength varied. This factor was taken into account during statistical analysis by assigning electric field strength as an explanatory variable.

\subsubsection{Phase IV}

Table 5.8 outlines the experimental variables and Table 5.9 presents the factors that were held constant throughout the experiments. The experiments in Phase IV were conducted using the knowledge obtained from Phases I to III regarding the effect of PEF treatment variables on podophyllotoxin concentration.

Table 5.8: Phase IV experiment variables using rectangular monopolar pulses

\begin{tabular}{|l|l|}
\hline Variable & Value \\
\hline PEF Treatment Time (3) & $300,360,480 \mathrm{~s}$ \\
\hline
\end{tabular}

In Phase IV, intermission periods were carried out in between the total PEF treatment time. Initially, PEF was applied for $120 \mathrm{~s}$, paused until temperature was reduced to approximately $30^{\circ} \mathrm{C}$. PEF treatment was then continued at $60 \mathrm{~s}$ intervals until the required total $\mathrm{PEF}$ treatment time was achieved.

Table 5.9: Phase IV controlled variables using rectangular monopolar pulses

\begin{tabular}{|l|l|}
\hline Constant & Value \\
\hline Particle Size & $>48$ mesh \\
\hline Water:P. Peltatum & $2: 3$ \\
\hline Soaking Time & $1 \mathrm{~h}$ \\
\hline Temperature & Room temperature $\left(24^{\circ} \mathrm{C}\right)^{*}$ \\
\hline Electrical Field Strength & Maximum possible by PEF generator \\
\hline Frequency & $840 \mathrm{~Hz}$ \\
\hline
\end{tabular}

*Temperature of $P$. peltatum inside treatment chamber increased due to energy input, maximum temperature recorded was $53.7^{\circ} \mathrm{C}$ 


\subsection{PULSED ELECTRIC FIELD TREATMENT OF PODOPHYLLUM PELTATUM}

\subsubsection{Phase I}

A $P$. peltatum suspension was made by adding $320 \mathrm{~g}$ of deionized water to $80 \mathrm{~g}$ of $<60$ or $<48$ mesh $P$. peltatum powder. The suspension was then placed in a refrigerator for $24 \mathrm{~h}$ in a $500 \mathrm{~mL}$ beaker covered with cellophane. After removing the sample from the refrigerator, it was mixed thoroughly with a spoon to suspend the particles that have settled at the bottom of the beaker. This was repeated prior to removing a sample for each experiment. The pulse generator was turned on and charged for $10 \mathrm{~min}$ prior to experimentation.

The treatment chamber was held in place by a hinge-jointed movable frame, allowing the chamber to be set in vertical or horizontal position (Figure 5.5). For the insertion of the $P$. peltatum suspension into the treatment chamber, a plastic syringe was used and the chamber was set vertically. The handles were rotated counter-clockwise to open the top and bottom valves of the chamber. The 4:1 ratio of water to $P$. peltatum was determined to be optimal as it provided no complications when flowing through the syringe and into the chamber. In addition, after PEF treatment, the suspension was released from the chamber by gravity. On several occasions, a minor clog occurred due to the accumulation

of larger $P$. peltatum particles. A small hole was drilled into the top of the treatment chamber, where a syringe was used to pump air into the chamber and force the clogged material to be released, allowing remaining suspension material to exit the chamber. 
To insert the sample, the syringe was filled with $60 \mathrm{~mL}$ of $P$. peltatum suspension, which was slowly injected into the treatment chamber through the top inlet. This was performed at a gradual pace to avoid the introduction of air bubbles into the treatment chamber. The air outlet was kept open during injection of the $P$. peltatum sample into the chamber, this ensured that as the sample was injected into the chamber, air within the chamber was released through the air outlet limiting the amount of trapped air or bubbles in the treatment chamber. The formation of air bubbles led to sparking which can cause operational and safety issues. The chamber was filled till excess sample was observed at the top of the chamber. Rotating the top handle clockwise closed the top valve, the air outlet was plugged using a plastic screw and excess $P$. peltatum sample was wiped from the treatment chamber. For each PEF treatment sample, a corresponding control was acquired from the $P$. peltatum sample. The control was not exposed to PEF treatment, however, it experienced soaking and vacuum drying.

The chamber was placed into horizontal position, and using insulated pliers both wires from the pulse generator were fixed to the electrodes on opposite sides of the treatment chamber. Experiments were performed at room temperature $\left(24^{\circ} \mathrm{C}\right)$. Pressing both the "Lock" and "Hold" knobs together instantaneously turned on the PEF system and the voltage dial was rotated to set the desired voltage value of 10,15 or $20 \mathrm{kV}$. This voltage corresponds to an electric field strength of $33.3,50$ or $66.7 \mathrm{kV} / \mathrm{cm}$ (Table 5.2 ).

A digital real-time oscilloscope (TDS 340, Tektronix) was used to monitor the pulses to ensure that the PEF generator was functioning properly. The voltage probe was 
connected to Channel 1 of the oscilloscope. An image of an instant charge reversal pulse captured by the oscilloscope is illustrated in Figure 5.10.

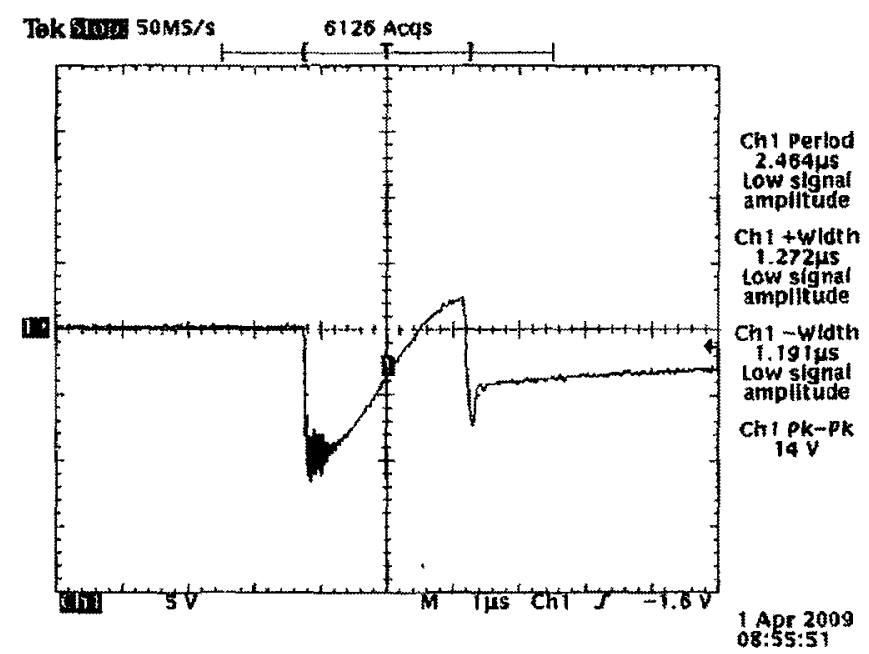

Figure 5.10: Instant charge reversal pulse captured by oscilloscope during Phase II PEF treatment of $<48 P$, peltatum with $50 \mathrm{kV} / \mathrm{cm}$

The time scale of $1 \mu \mathrm{s} /$ square and $5 \mathrm{kV} /$ square were chosen as the settıngs for the oscilloscope. These settings were found to be appropriate to display the entire pulse waveform on the screen.

The pulse number for each experiment was manually counted by monitoring the pulses on the oscilloscope screen. The peak-to-peak voltage of the instant charge reversal pulses was also observed on the oscilliscope (Figure 5.10). Although the pk-pk voltage is displayed in $\mathrm{V}$, in reality, the treatment chamber is exposed to a voltage in the range of $\mathrm{kV}$. This is due to the manufacture of voltage probe as it has an attenuation ratio of 1:1000. After the appropriate number of pulses was completed (Table 5.2), the "OFF/RESET" button was pressed to stop the PEF treatment. For safety reasons, the 
grounding stick was put in contact with the electrode/wire bolt several times to eliminate any residual charge. This ensured that after shutting off the pulse generator, any charge that still existed within the system was brought down to zero by grounding. Using the pliers, both of the electrode wires were unscrewed and the treatment chamber was returned to vertical position. An appropriately labeled ceramic bowl was placed underneath the treatment chamber and the bottom handle was rotated counter-clockwise to release the sample from the treatment chamber. Once the sample was no longer released from the chamber, the air outlet was opened and using an empty syringe, air was injected to ensure that any remaining sample was released into the ceramic bowl. The treatment chamber was thoroughly cleaned with water prior to further experimentation.

\subsubsection{Phase II}

A $P$. peltatum suspension was made by adding $280 \mathrm{~g}$ of deionized water to $70 \mathrm{~g}$ of $<48$ mesh $P$. peltatum powder and refrigerated for $24 \mathrm{~h}$, forming a $4: 1$ ratio. Prior to PEF treatment, the 24 h soaked $P$. peltatum was placed in a heating bath (Model IC-2100, Isotemp 2100, Fisher Scientific) for approximately $1 \mathrm{~h}$ to ensure that both the heating bath and $P$. peltatum sample reached a temperature of approximately $50^{\circ} \mathrm{C}$. The experiments were then conducted in the same manner as Phase I, except a different chamber was used to maintain the high temperature of $P$. peltatum sample (Figure 5.7). The sample temperature was maintained by circulating the heated bath water through the heating jacket of the treatment chamber. The centre of the sample within the treatment chamber was recorded to be approximately $45^{\circ} \mathrm{C}$ before PEF treatment using a digital temperature probe (Model HH21, Omega). Similar to Phase I, the chamber was set-up 
vertically on the hinge-jointed moveable frame to allow for the flow of $P$. peltatum out of the chamber (Figure 5.8). Due to the change of treatment chamber, the syringe was filled with $30 \mathrm{~mL}$ of $P$. peltatum suspension and was slowly injected into the treatment chamber through the top inlet. The control was acquired from the remaining sample in the heating bath. The remaining method (sample insertion/removal, PEF generator operation, oscilloscope settings, etc.) follow the same guidelines as described for Phase I (Section 5.6.1).

\subsubsection{Phase III}

For $>48$ mesh $P$. peltatum, a sample was made by adding $60 \mathrm{~g}$ of $P$. peltatum to $90 \mathrm{~g}$ of water in a $500 \mathrm{~mL}$ beaker, providing a $2: 3$ ratio. This ratio was enough to impregnate the cells without leaving excess water. Since the sample was no longer suspended in water, the particles had to be scooped in and out of the chamber through the inlet, which required approximately 15 min. Hence, the treatment chamber in Figure 5.9 was used for experimentation of $>48$ P. peltatum.

The pulse generator was charged 5 min prior to experimentation by switching on the CONTROL POWER. Once the pulse generator was charged, the vertical LED lights on the PEF generator lit up one by one (Figure 5.10). Once all the lights were lit up, the system was ready for PEF treatment. The pulse rate was set to 84 or $840 \mathrm{~Hz}$. The experiments were performed at room temperature $\left(24^{\circ} \mathrm{C}\right)$. 


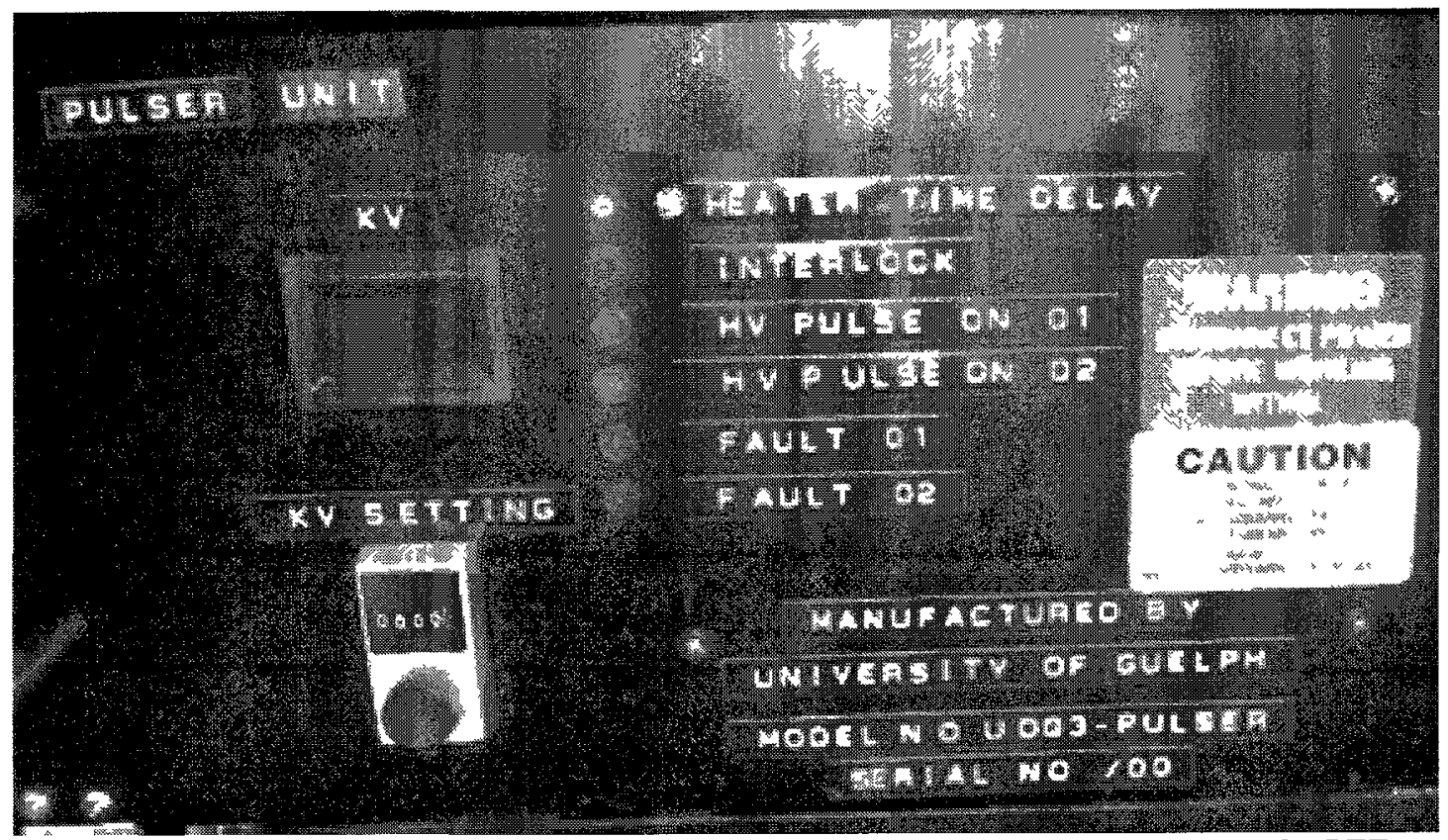

Figure 5.11: LED lights on monitor that indicate that the system is charged and ready for PEF treatment

To fill the treatment chamber with the $>48$ mesh $P$. peltatum sample, a dental spatula was used to insert approximately $30 \mathrm{~g}$ of the sample into the inlet with the assistance of a funnel. The samples were slightly compressed using a wooden paintbrush handle with a rounded end to ensure that no air pockets were present in the treatment chamber. Once the treatment chamber was completely filled, the inlet was closed using a plastic stopper and insulated pliers were used to attach the wires from the generator to the electrodes on opposite sides of the treatment chamber (Figure 5.9).

The PEF treatment was initiated by pressing the POWER ON switch. The voltage was immediately adjusted to $3.02 \mathrm{kV}$. This was the maximum voltage possible prior to sparking occurred. The voltage in the treatment chamber was monitored through the oscilloscope using a voltage probe, and the peak-to-peak voltage for the rectangular pulse was recorded (Figure 5.12). However, due to operational limitations and the 
unpredictable nature of the $P$. peltatum material, it was not possible to achieve a consistent treatment chamber voltage. The PEF treatment time was monitored using a digital stopwatch. Pressing the POWER ON switch turned off the pulse generator and the wires were disconnected from the electrode using insulated pliers. The sample was removed from the chamber using the dental spatula to scoop out the particles.

A voltage probe was connected to Channel 1 of the oscilloscope. A current monitor (Model 6222, Pearson) was surrounding one of the electrode wires and connected to Channel 2 of the oscilloscope. It did not matter which electrode wire it was surrounding since the current running through the system was the same. The monopolar rectangular pulse is illustrated in Figure 5.12 and includes the current and voltage waveforms. A digital temperature probe (Model HH21, Omega) was used to determine the temperature of the sample by inserting it into the centre of the treatment chamber.

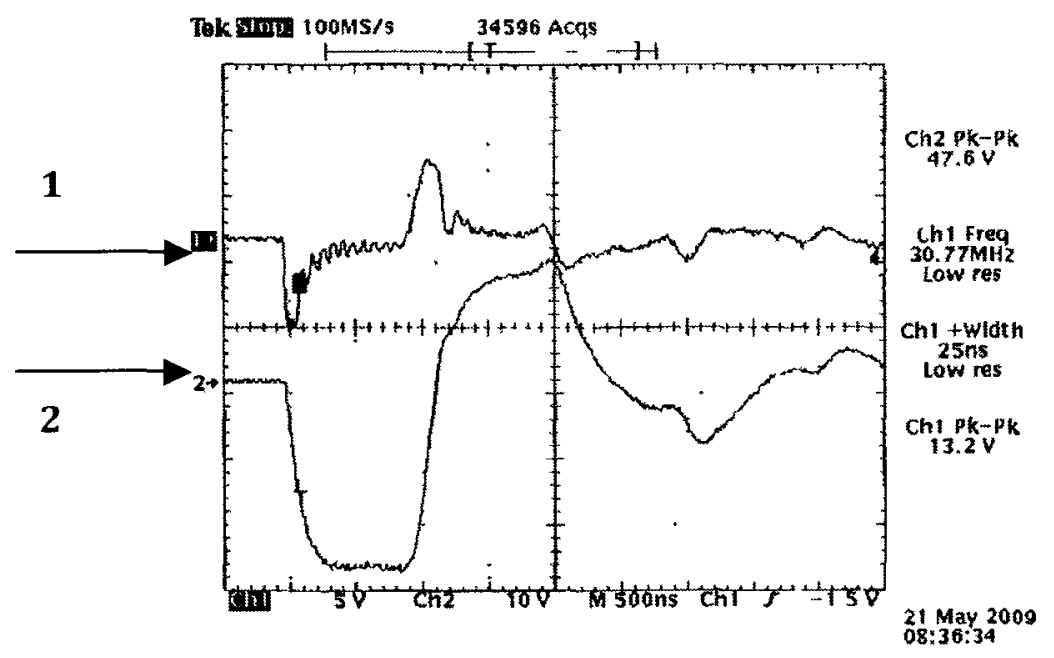

Figure 5.12: Near-rectangular monopolar pulse acquired from oscilloscope displaying (1) voltage waveform and (2) current waveform 
The time scale of $500 \mathrm{~ns} / \mathrm{square}$ and $5 \mathrm{kV} /$ square were chosen as the settings for the oscilloscope. These settings were found to be appropriate to display the entire pulse waveform on the screen. The pk-pk voltage was obtained from the graph and was used to calculate the electrical field strength by dividing the voltage by the electrode gap. Hence, the electrical field strength varied due to the change in treatment chamber and electrode gap. Due to the attenuation ratio of the 1:1000 attenuation ratio of the voltage probe, the voltage in the graph was displayed as $\mathrm{V}$ but was recorded as $\mathrm{kV}$.

\subsubsection{Phase IV}

The experiments follow the same method as Phase III ( $>48$ P. peltatum experiments), however, the $150 \mathrm{~g}$ sample of $2: 3$ ratio water and $P$. peltatum were soaked for $1 \mathrm{~h}$ and the PEF treatment time was paused for intermission periods to allow for the $P$. peltatum temperature to decrease. PEF treatment times tested were 5, 6 and $8 \mathrm{~min}$ (Table 5.8). The samples were treated for $2 \mathrm{~min}$ initially then paused until the temperature was reduced to approximately $30^{\circ} \mathrm{C}$. The PEF treatment was then continued with intermissions between every 1 min of PEF treatment until the desired total PEF treatment time was fulfilled. The frequency was set to $840 \mathrm{~Hz}$. 


\subsection{POST-PEF TREATMENT AND ANALYSIS}

\subsubsection{Vacuum Drying}

PEF treated and control samples were placed in ceramic bowls and allowed to dry in the vacuum oven (Model 282A, Isotemp Vacuum Oven, Fisher Scientific). The power was switched to ON and the purge dial was rotated clock-wise completely. The vacuum pump was also turned on (VacTorr, Precision Scientific). The temperature of the oven was set to $52^{\circ} \mathrm{C}$ and the pressure was set to the minimum value of 0 in- $\mathrm{Hg}$, but was measured to be 0.4 in- $\mathrm{Hg}$. The samples were monitored every $1-2 \mathrm{~h}$ and mixed to avoid granulation of particles and over-drying in some areas. When the sample formed large aggregates, they were broken down using a kitchen knife or ground with a pestle and mortar if the sample was relatively dry. The samples were determined to be dry when they no longer stuck to the surface of the bowl. Once dried, the pump was turned off and the oven ON button was switched off. The samples were mixed, ground to remove aggregates, sealed, labeled accordingly, and sent for HPLC analysis.

\subsubsection{Scanning Electron Microscopy}

\subsubsection{Sample Fracturing}

In some instances, the cross section of the $P$. peltatum particles was examined under the scanning electron microscope. Depending on the particle size, approximately 5-10 particles were fixed on the stub with double-sided adhesive tape. The particles were fragmented under microscope at 10x magnification (Laborlux S Model, Leitz). The $>48$ mesh particles of $P$. peltatum were large enough to be cut in half by placing a thin razor 
blade on the middle of the top flat surface of the particle and pressing down till it was separated into two pieces. This was performed while the particles were held on a stub using double-sided adhesive tape. The newly fragmented pieces were pushed down with the blade to expose the fractured surfaces and set them facing upwards. In some cases, the particles naturally fractured in half once some force was exerted down on the particle. After fracturing, the samples were sputter coated (Section 5.7.2.2). Since the particles were relatively large, it was not difficult to recognize the fractured surfaces under the scanning electron microscope.

Smaller particles of $<48$ mesh were difficult to handle and cut in half. Roughly $2 \mathrm{~g}$ of $P$. peltatum particles were placed in a bowl and approximately $10 \mathrm{~mL}$ of liquid nitrogen was added to the sample. The liquid nitrogen was allowed to fully evaporate until the freezedried $P$. peltatum sample was only left in the bowl. The particles were then fractured under microscope (Laborlux S Model, Leitz) using a thin razor blade as performed for the $>48$ mesh particles. However, this was difficult to achieve as the particles were very small (Table 5.1) and it was challenging to cut the particles exactly in half using the thin razor blade. Furthermore, it was difficult to recognize the interior cells from exterior cells under scanning electron microscope. Sputter coating was then applied to the fractured particles.

\subsubsection{Sputter Coating}

Using tweezers, particles were randomly removed from the $P$. peltatum sample and mounted on a stub with double-sided adhesive tape affixed to the top. Particles of $P$. peltatum were evenly spaced across the entire surface of the stub. Several samples were 
mounted onto the stub at once (maximum 6) as each individual stub placement is numbered. The valve for the argon tank was opened. After opening the lid of the sputter coater (Model K550, Emitech), the stage was taken out and the stubs containing the samples were inserted into the holes of the stage and set into place. The stage was set back into the sputter coater and secured into its proper position. The lid was closed and held down until the START button was pressed. The sputter was set to a coating time of 2 min and a coating thickness of $15 \mathrm{~nm}$. The sample was coated with gold. Gold is a finegrain, conductive material. Relative to other metals, such as chromium, gold does not require a strong vacuum to sputter coat the sample. Once the timer was set off, the lid was opened automatically as the vacuum was purged. The sputter coater was turned off and the argon tank valve was closed.

\subsubsection{Podophyllum peltatum Micrograph Acquisition}

After sputter coating, the sample was prepared for scanning electron microscopy (Model S-570, Hitachi High Technologies). The pressure of the chamber was maintained at $10^{-4}$ $\mathrm{Pa}$. The AIR/EVAC button was pressed and the vacuum was purged to access the chamber. The door was then slid open and the stub with the sputter-coated samples were mounted onto the stage using stub tweezers. After sliding the stage back into the chamber, the door was held shut until the AIR/EVAC button was pressed again and the pump was turned on. After waiting for $5 \mathrm{~min}$ for the pressure to reach approximate vacuum, the Accelerating Voltage $\mathrm{ON}$ button was turned on. The microscope was operated at an accelerating voltage of $10 \mathrm{kV}$. According to the operator manual, this setting is appropriate for most biological samples. The magnification was set to 1000 for LOW and 10,000 for HIGH. 
In order to find the appropriate sample, the LOW button was pressed, and the micrometers were rotated till a stub appeared on the screen. The number on the stub was verified in order to determine which sample was under the microscope. Once the sample was identified, the UP button was pressed to increase magnification to a suitable level and the micrometers were rotated to move the stub around till possible cells were identified on the screen. Once the desired image was observed, focusing was achieved by pressing the HIGH button. This led to a high magnification of $10,000 \mathrm{x}$ of the desired particle, and the FOCUS knobs (fine and control) were adjusted in addition to the STIGMA ( $\mathrm{X}$ and $\mathrm{Y}$ ) knobs. An image was deemed to be in focus when the contour lines were no longer fuzzy. After focusing, pressing LOW returned the image to $1000 \mathrm{x}$ magnification. The desired magnification was achieved by pressing UP or DOWN and the image was then ready to be captured. In some cases, the AUTO button was pressed to focus the micrograph automatically.

Quartz PCI software (Quartz Imaging Corp.) was used to acquire and store the images. To capture an image, the SCANNING SPEED button was set to $3 / 4$. The image acquisition button was selected in the program and the PHOTO button was pressed immediately on the scanning electron microscope keypad. The micrograph then began to display on the computer where it was immediately named and saved. The SCANNING SPEED button was returned to $1 / 2$ and the process was repeated to capture further images. After completing image acquisition, the Accelerating Voltage was turned OFF. The AIR/EVAC button was pressed and the chamber door was opened after pumping of air 
was completed. The samples were removed and the door was held while the AIR/EVAC button was pressed to return to approximate vacuum.

\subsubsection{Solvent Extraction of Podophyllotoxin from Podophyllum peltatum}

A $100 \mathrm{~mL}$ aqueous solvent consisting of $30 \%$ ethanol and $70 \%$ HPLC grade water was prepared for the extraction of podophyllotoxin from $P$. peltatum. This ratio was found to be most effective in extracting the highest concentration of podophyllotoxin from $P$. peltatum (Izadifar \& Baik 2008). The aqueous solvent, a $100 \mathrm{~mL}$ beaker and an agitator were preheated to $50^{\circ} \mathrm{C}$ in a water bath. A sample of $2 \pm 0.001 \mathrm{~g}$ of $P$. peltatum was weighed and placed into the preheated beaker. The warm aqueous ethanol solution was then added to the $P$. peltatum sample. Once the particles were mixed for $30 \mathrm{~s}$ within the solution using a digital hot plate stirrer (RCT basic, Rose Scientific Ltd.), timing was initiated to regulate extraction time. For Phases I to III the extraction time was $2 \mathrm{~min}$. In Phase IV, the extraction parameters were varied to determine the optimal solvent extraction method. The methods tested in Phase IV were:

1. Stir at $50^{\circ} \mathrm{C}$ for $2 \mathrm{~min}$

2. Stir at $50^{\circ} \mathrm{C}$ for $10 \mathrm{~min}$

3. Stir at $50^{\circ} \mathrm{C}$ for $1 \mathrm{~h}$

4. Soaking for $24 \mathrm{~h}$

5. Stir at $50^{\circ} \mathrm{C}$ for $1 \mathrm{~h}$ and soaking for $24 \mathrm{~h}$ 
After solvent extraction was completed, a syringe was used to transfer $1 \mathrm{~mL}$ of the solution into a test tube and centrifuged at $4000 \mathrm{rpm}$ for $4 \mathrm{~min}$. After centrifugation, 0.7 $\mathrm{mL}$ of the supernatant solution was removed from the test tube. The vacuum oven was set to $50^{\circ} \mathrm{C}$ and $24 \mathrm{in}-\mathrm{Hg}$, where the volatile ethanol and water solvent were evaporated.

\subsubsection{High Performance Liquid Chromatography Analysis}

For further refining prior to high performance liquid chromatography (HPLC) analysis, $0.7 \mathrm{~mL}$ of ethyl acetate and $0.7 \mathrm{~mL}$ of HPLC grade water were added to the residual sample obtained (Section 5.7.3) and mixed for $30 \mathrm{~s}$ (VX200 Vortex Mixer, Labnet) to ensure that the solute was dissolved within the aqueous solvent. The sample was then centrifuged for $2 \mathrm{~min}$ at $3000 \mathrm{rpm}$ at room temperature, resulting in water settling at the bottom and ethyl acetate on top of the water. Water was removed and the ethyl acetate solution was evaporated in a vacuum oven set at $50^{\circ} \mathrm{C}$ and 24 in- $\mathrm{Hg}$. Subsequently, 0.7 $\mathrm{mL}$ of methanol was injected into the test tube and shaken mixed (VX200 Vortex Mixer, Labnet) for $30 \mathrm{~s}$ to completely dissolve the sample in the solvent. Using a $1 \mathrm{~mL}$ syringe, the methanol solution was injected into a HPLC vial and subjected to HPLC analysis (G1313A, Hewlett Packard; Hypersil C-18 column, $4.6 \mathrm{~mm} \times 150 \mathrm{~mm} \times 3 \mu \mathrm{m}$, Phenomenex; G1315A, diode array detector). A standard of pure podophyllotoxin was obtained to identify the retention time of podophyllotoxin. For each extraction trial, a duplicate was produced and tested using the HPLC to obtain a mean concentration $(\mathrm{mg} / \mathrm{g})$. 


\subsubsection{Statistical Analysis of Results}

Analysis of variation (ANOVA) and Duncan's multiple range test were performed at 95

$\%$ confidence level. SAS software (Version 9.2, SAS Inc.) was used to perform statistical analysis of the results. 


\section{RESULTS AND DISCUSSION}

\subsection{PODOPHYLLUM PELTATUM PRIOR TO PULSED ELECTRIC FIELD TREATMENT}

To understand and assess the effect of PEF treatment on $P$. peltatum cells, knowledge of the cell structure and constituents is required. No research was found that discusses the precise structure and contents of $P$. peltatum cells, as limited information is available regarding the tissue and cellular constituents of $P$. peltatum (Moraes 2002). Scanning electron micrographs of the $P$. peltatum samples used in this research were acquired to clarify the composition and condition of $P$. peltatum cells.

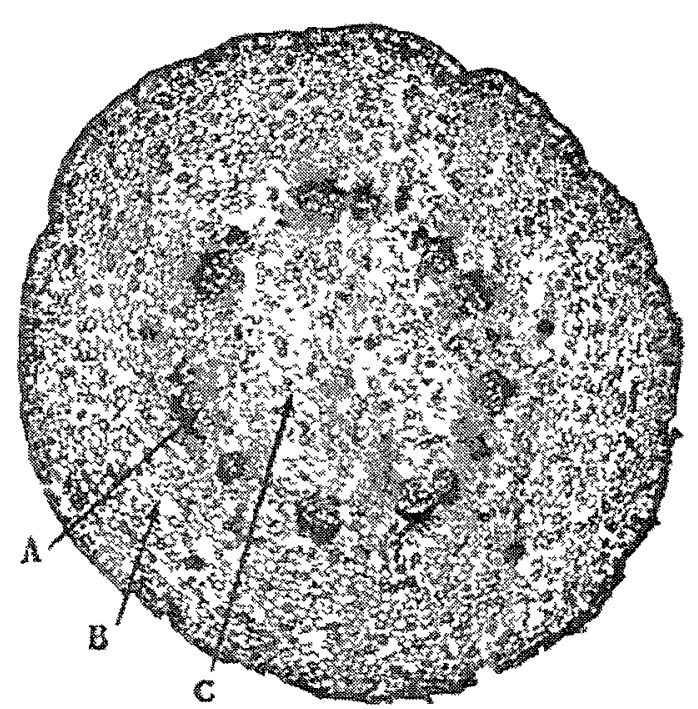

Figure 6.1: Cross-section of $P$, peltatum rhizome: A. Vascular bundle, B. Cortex, C. Medulla (Sayre 1917)

Figure 6.1 is an illustration of the cross-sectional view of a $P$. peltatum rhizome by Sayre (1917). The outermost layers of the rhizome form the tough bark, which typically exists in woody plants. For the most part, the cortex is made up of parenchyma and collenchyma cells that store a high quantity of starch, the latter possessing thicker cell 
walls (Sayre 1917). The vascular bundles circle the rhizome and are the intermediate layer between the cortex and medulla. This vascular system is composed of either xylem or phloem. The medulla is the core of the rhizome and is also made of starch-filled parenchyma cells. Similar structures of the rhizome were observed in the samples of $P$. peltatum under the scanning electron microscope. A micrograph of a sample rhizome is presented in Figure 6.2.

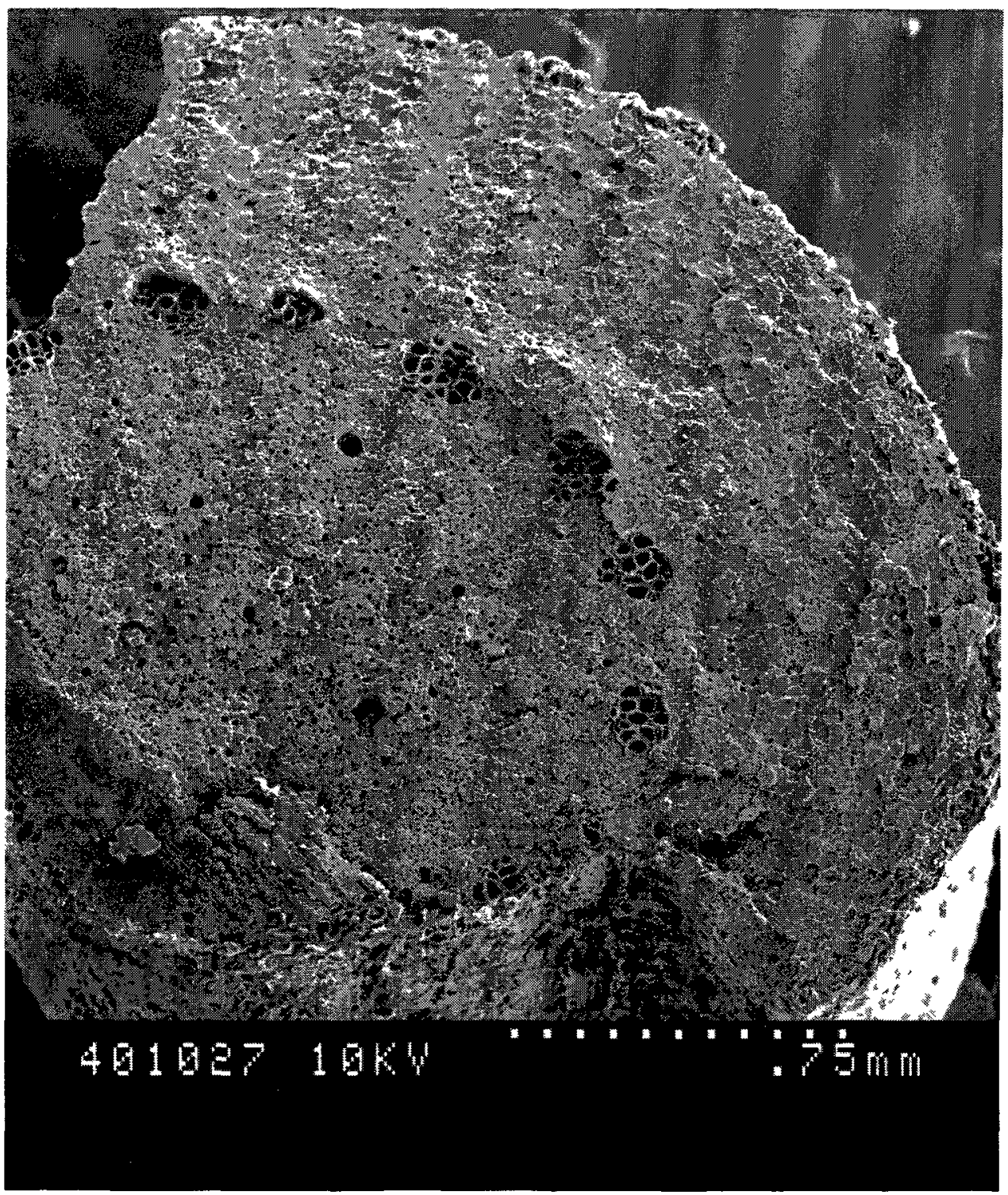

Figure 6.2: Fragment of $P$. peltatum rhizome cross-section (40x) 
Similar to Figure 6.1, the rhizome structure in the micrograph reveals the bark, vascular bundles, the inner medulla core and the outer cortex.

The existence of bark within the ground $P$. peltatum poses the issue of sample homogeneity. Comparably, Guderjan et al. (2007) treated hulled and non-hulled rapeseed with PEF and found that the efficiency of PEF treatment was more predominant for the hulled rapeseed. Similar findings were reported in Guderjan et al. (2005), for PEF treatment of corn germ versus corn kernel. The researchers claimed that hulled rapeseed and corn germ provided a more homogeneous sample for PEF treatment and enhanced electrical conductivity. With respect to $P$. peltatum, there are diverse cells with varying cell wall thickness and composition. Overall, the majority of the tissue is composed of parenchyma cells. However, the bark is composed of cork cells that are essentially dead and chemically inert. In addition, there are collenchyma cells in the cortex and tracheids, sclereids and fibres of the vascular bundles. All of the aforementioned are thick-walled cells containing deposits of lignin, a strengthening chemical compound found in wood plants, and in the case of bark, further impregnated with water-proof suberin (Perumalla et al. 1990). This heterogeneous tissue of P. peltatum, like the hull of rapeseed or the seed coat of corn could have affected the homogeneity of PEF treatment of P. peltatum. Furthermore, only $2 \mathrm{~g}$ of each $P$. peltatum sample was used for solvent extraction and HPLC analysis, therefore it is anticipated that there will be slight variability in the results of the experiments. 
Figure 6.3 illustrates the overall composition of powdered $P$. peltatum, as discovered by Sayre (1917). Numerous starch granules were present in powdered P. peltatum. The starch grains were found in various forms such as small and large spherical, polygonal, or 2- to 6-compound grains.

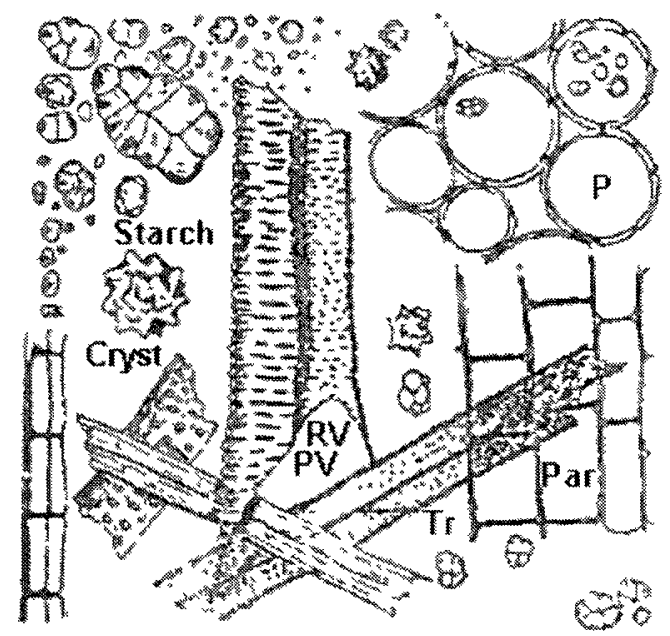

Figure 6.3: Composition of powdered $P$. peltatum: (Cryst) crystals of calcium oxalate, (RV) reticulated vessels, (PV) pitted vessels, (Tr) tracheids, (Par) parenchyma in longitudinal view, and (P) parenchyma in cross-section (Sayre 1917)

The parenchyma cells were also depicted as being circular in cross-section and slightly elongated from the side view. Salts of calcium oxalate were discovered in the powder of $P$. peltatum and resemble crystals. Various components of the vascular system such as tracheids and pitted and reticulated ducts were also identified. The information provided by Sayre (1917) identifies the constituents of powdered $P$. peltatum, however, it does not provide details regarding the general composition of each cell, particularly the abundant parenchyma cells.

Focusing in closer into the medulla core of the rhizome, Figure 6.4 reveals the numerous parenchyma cells. Within a micro-scale, there are numerous plant cells that make up the 
plant tissue. This demonstrates that podophyllotoxin does not only need to cross the barriers of an individual cell, but is also required to diffuse through numerous neighboring cells and barriers for extraction.

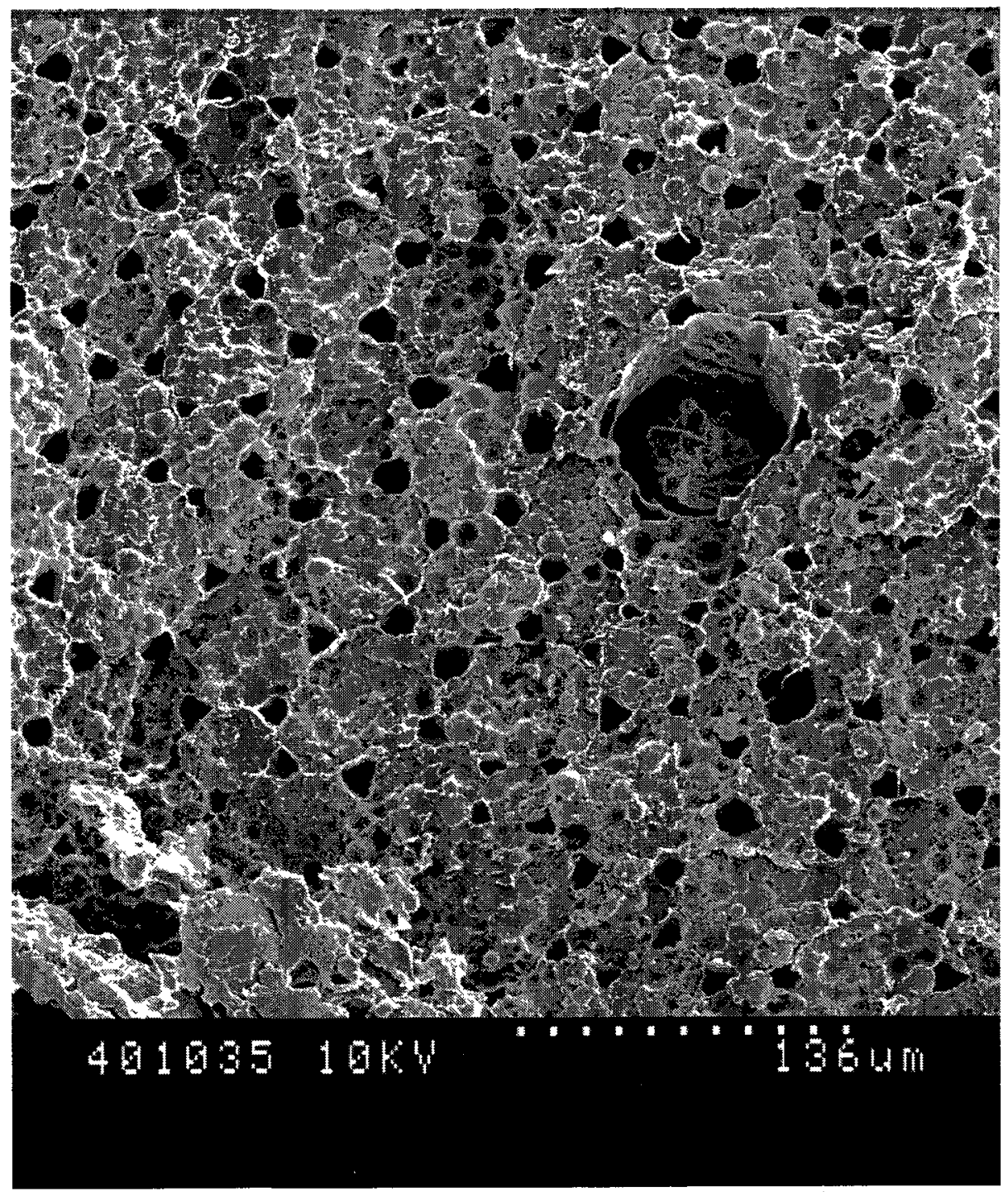

Figure 6.4: Parenchyma cells of $P$. peltatum rhizome (220x)

Compared to low molecular weight solutes such as ions and water, larger molecules such as podophyllotoxin typically travel via the transcellular route rather than the paracellular route (Fahr et al. 2005). Hence, mechanical fragmentation prior to solvent extraction is 
required to reduce the distance that molecules diffuse through. However, there is always a limit in the extent of mechanical fragmentation possible.

Due to dehydration, the cells appear to be compact and resemble a flower-like structure as each cell is surrounded by air gaps. Once the plant is rehydrated, the air gaps are filled with intercellular fluid and the cells expand in volume due to the introduction of water to the cells. The extent of dehydration experienced by the $P$. peltatum samples is crucial to the resultant structure and viability of the plant cells. This will be discussed after further examining the structure of the cell and assessing its apparent condition. The cells of $P$. peltatum are of upmost interest in this research, as the main aim of this research is to cause enough damage to the cell barriers to permit the diffusion of podophyllotoxin from the vacuole and enhance its extraction out of $P$. peltatum tissue.

Figure 6.5 illustrates a single cell of the rhizome tissue. It is difficult to assess exactly what components are present in the micrograph, however, Sayre (1917) indicated that numerous starch grains are present within powdered $P$. peltatum (Figure 6.3). The starch grains are in the form of small and large spherical, polygonal, or 2- to 6-compound grains. The majority of the cell in Figure 6.5 seems to consist of starch granules. 


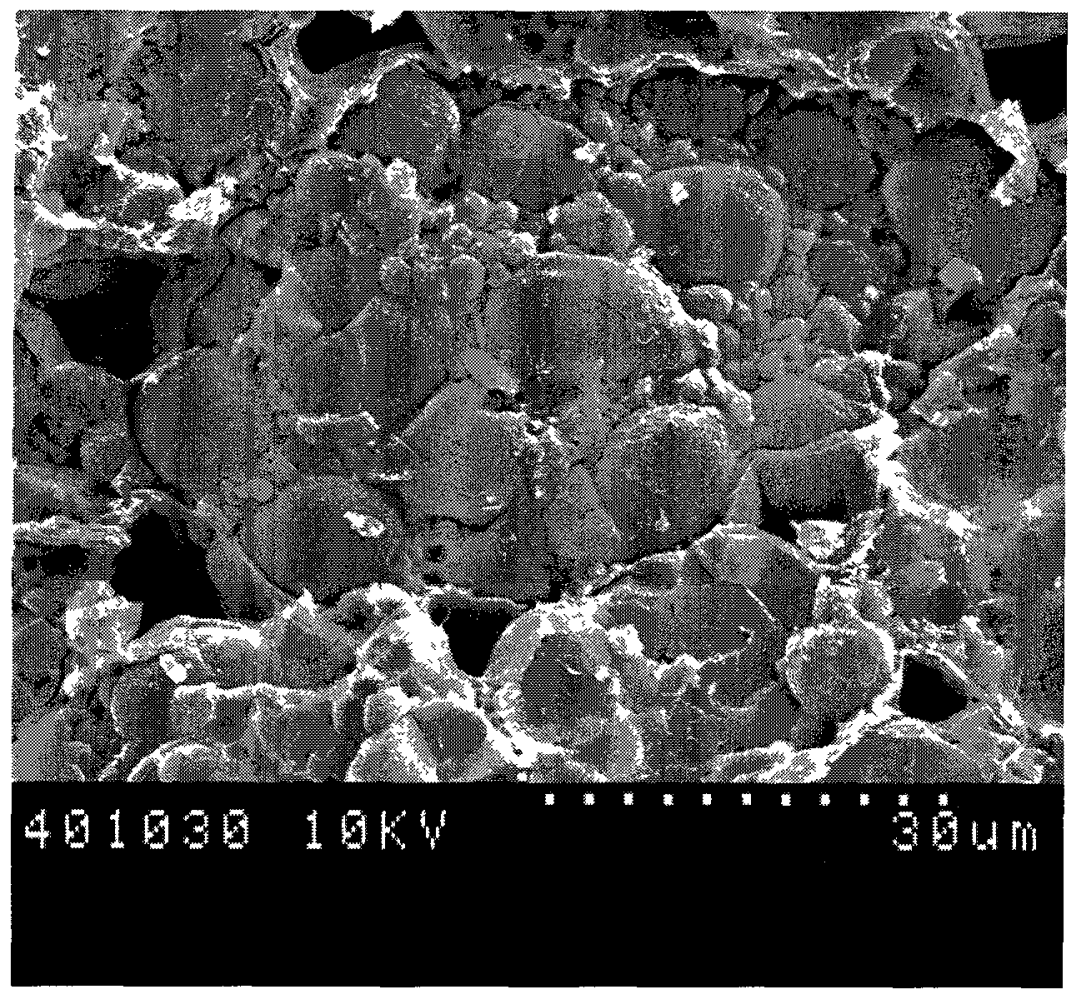

Figure 6.5: Fractured cell of $P$. peltatum rhizome (1000x)

According to Sayre (1917), the starch grains range in size from $3 \mu \mathrm{m}$ to $15 \mu \mathrm{m}$ in diameter, which seems to be a valid size range when measuring the diameters of the large and small sphere-like structures that appear in Figure 6.5. The compactness and high compartmentalization of compounds is typical of cells in higher plants (Kuri-Brena 1992). Aside from the starch granules, the cytoplasm is packed with enzymes, lipids, chloroplasts and other compounds and organelles.

The thick cell wall is also revealed surrounding the cell constituents and appears to be intact. This was observed during the examination of cells from various samples and in all cases it appears that the cell wall remains undamaged after dehydration, except for cells exposed to mechanical fragmentation. The cell membrane is found in the interior of the 
cell wall but is not clear in this micrograph at this scale. These barriers inhibit the transfer of podophyllotoxin out of the cell. The direct examination of $P$. peltatum through scanning electron microscopy suggests that the samples seem to be in acceptable condition, even after dehydration. However, the extent of damage to the cytoplasm and vacuole membranes at the molecular level is unknown. Furthermore, the method through which the $P$. peltatum samples were dehydrated is also unknown. This information is important to determine the viability and response of the cells to PEF treatment, and the severity of damage already experienced by the cells, prior to PEF treatment.

Izadifar \& Baik (2008) determined the average moisture content of the similar dehydrated $P$. peltatum product (Richters, Goodwood, $\mathrm{ON}$ ) used in this research to be $0.01 \mathrm{~g} \mathrm{H}_{2} \mathrm{O} / \mathrm{g}$ dry solid. This critically low moisture content means that the cells of $P$. peltatum in this research are dead and are unable to perform the regular functions of a living plant cell. Under extreme environmental conditions, desiccation tolerant plants are able to survive with moisture contents as low as $0.3 \mathrm{~g} \mathrm{H}_{2} \mathrm{O} / \mathrm{g}$ dry solid. Below this moisture level, mechanisms to maintain cell functionality are inadequate and cells begin to experience structural damage and cell death (Hoekstra et al. 2001). Since P. peltatum is not a desiccation tolerant plant, it is assumed that the cells are no longer considered to be living, yet the extent of damage to the cells at the molecular level is unknown. However, from the direct examination of the $P$. peltatum samples, it is assumed that the cell membranes have not experienced complete degradation, such that they are fully permeable to podophyllotoxin and other solutes. This assumption will be reflected within the results of the experiments, if PEF treatment does indeed enhance podophyllotoxin 
transfer through penetration of the barriers. Furthermore, Canel et al. (2000) found that dry $P$. peltatum tissue has significant protection capabilities from denaturing thermal conditions. No obvious damage of the cell wall (Figure 6.5) is apparent. This is attributed to the flexible nature of the cell wall matrix and its ability to distend and accommodate to the shrinkage of the protoplast due to dehydration (Cosgrove 2000). Conventional extraction of podophyllotoxin from Podophyllum spp. always involves the dehydration of the plant material prior to solvent extraction. If complete membrane and cell wall rupture was possible through dehydration, conventional extraction methods would not be deemed inefficient, and researchers would not investigate methods to enhance podophyllotoxin extraction. This has led researchers to call for the development of processes to enhance the mass transfer of podophyllotoxin due to the low yield after conventional extraction methods (Farkya et al. 2004).

For the extraction of podophyllotoxin in the pharmaceutical industry, P. peltatum is mechanically fragmented following dehydration and solvent extraction is employed (Izadifar \& Baik 2008). The extraction process releases a limited amount of podophyllotoxin (Eyberger et al. 2006). The potential to extract additional amounts are possible, however, not with the sole application of solvent extraction. Mechanical fragmentation of $P$. peltatum enhances the extraction of podophyllotoxin, as previously illustrated in the discussion of Figure 6.4. The exposure of increased amounts of ruptured cells to the solvent further assists in the mass transfer process of podophyllotoxin. 

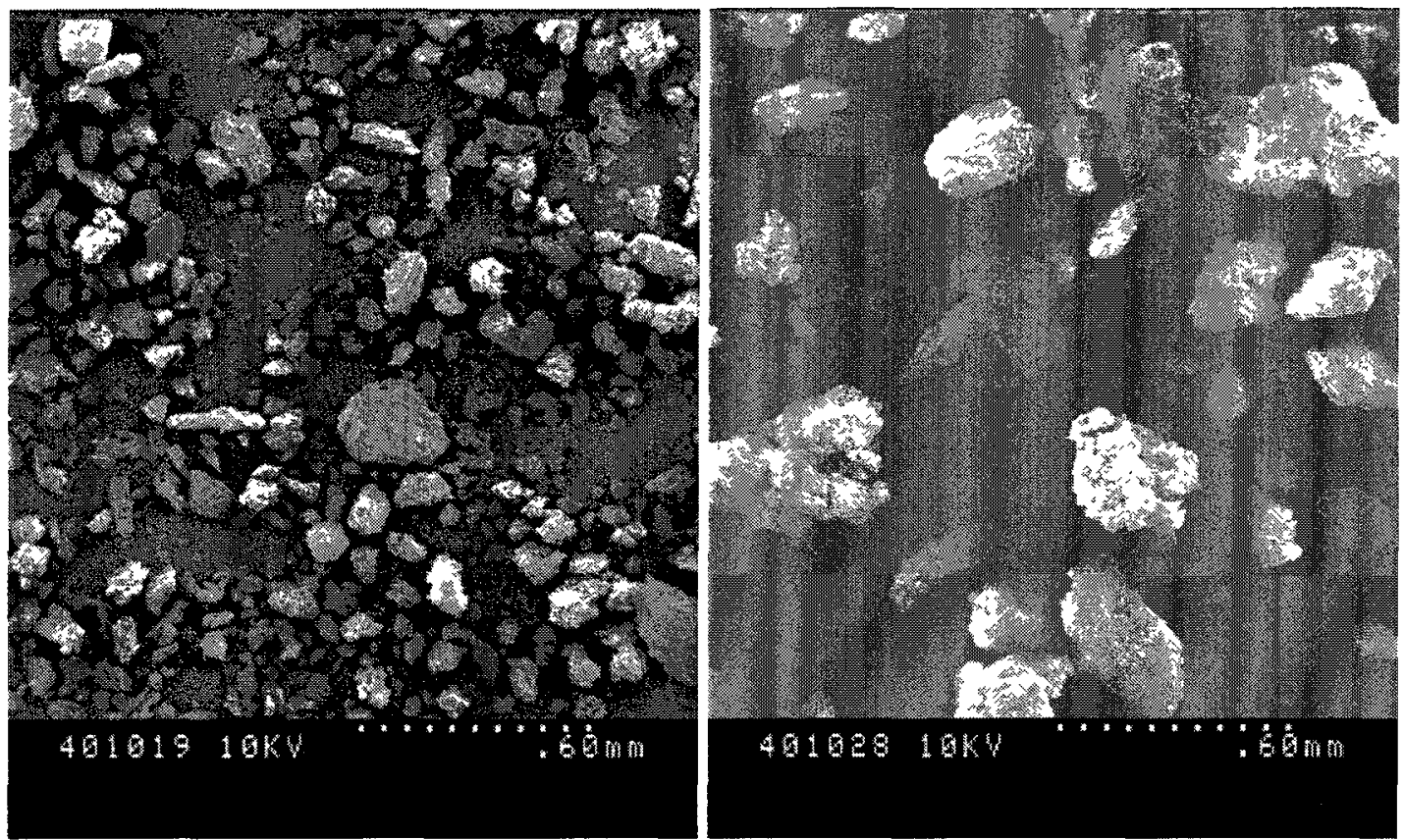

Figure 6.6: Powdered $P$. peltatum roots and rhizomes $(50 x),<60$ mesh (left) and $<48$ mesh (right)

Upon grinding the $P$. peltatum samples, micrographs were obtained for the $<60$ and $<48$ mesh sized particles (Figure 6.6). Although it appears to the eye that particles of powder are extremely small, close examination shows that this is not the case. In fact, there could be hundreds of cells that make up a single powder particle. These hidden and intact cells are the main implication hindering the mass transfer of podophyllotoxin upon solvent extraction, and the reason why PEF was implemented in this research to target the cells within the interior of each particle. The cell membranes and wall of the intact cells in the interior of the powder particles remain undisrupted by mechanical fragmentation. Breaking the barriers that delay or even prevent the diffusion of podophyllotoxin through the cells could potentially enhance the extraction of podophyllotoxin. 


\subsection{PULSED ELECTRIC FIELD TREATMENT}

Numerous experiments were performed taking many variables into account in order to find if PEF causes cell wall and membrane breakage and which factor(s) contribute to this damage. Various PEF treatments were applied to $P$. peltatum and the concentration of podophyllotoxin was analyzed. The results are discussed according to each phase of the research.

\subsubsection{Phase I}

In the initial stages of the research experiments, $P$. peltatum was treated with instant charge reversal pulses at room temperature. The $P$. peltatum samples had a particle size of either $<60$ or $<48$ mesh. The PEF variables were electric field strength with 33.33 , 50.00 , or $66.67 \mathrm{kV} / \mathrm{cm}$ and pulse number with 20,40 , or 60 pulses. The pulse frequency, pulse duration and soaking time were constant at $0.5 \mathrm{~Hz}, 2 \mu \mathrm{s}$, and $24 \mathrm{~h}$, respectively.

Figure 6.7 presents the mean concentration of podophyllotoxin extracted from $<60$ and $<48$ mesh $P$. peltatum exposed to instant charge reversal pulses. A clear observation is that higher concentrations of podophyllotoxin were obtained from the $<60$ mesh compared to $<48$ mesh $P$. peltatum. The mean concentration of podophyllotoxin extracted from $<60$ mesh $P$. peltatum was $9.21 \pm 0.20 \mathrm{mg} / \mathrm{g}$ and $<48$ mesh $P$. peltatum was $7.59 \pm 0.19 \mathrm{mg} / \mathrm{g}$. 


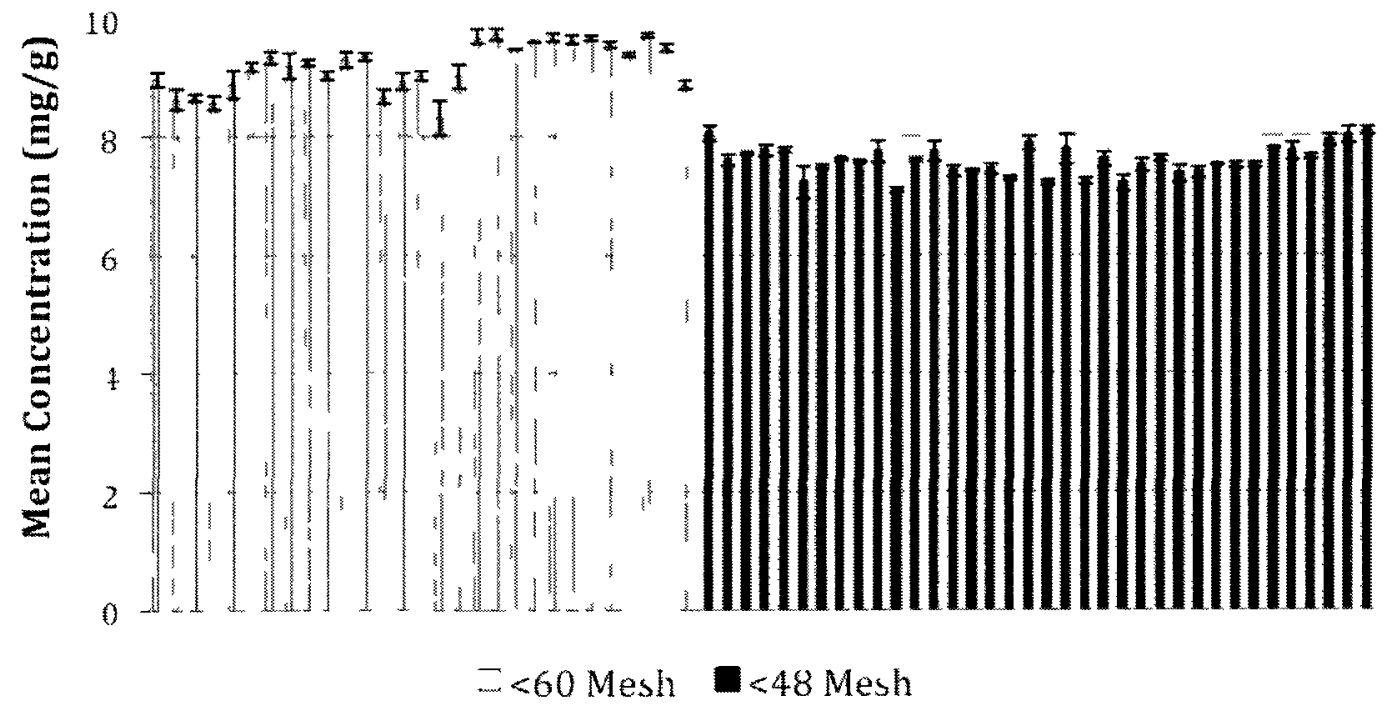

Figure 6.7: Effect of varying particle size on the extraction of podophyllotoxın (mg/g) from PEF treated $P$. peltatum using instant charge reversal pulses

The statistical analysis of these results is presented in Table 61 This indicates that the maximum amount of podophyllotoxin was extracted from finer particles of $P$ peltatum As particle size decreased, the amount of podophyllotoxin extracted increased

The range of electric field strength of 3333 to $6667 \mathrm{kV} / \mathrm{cm}$ used is substantially higher relative to the electric field strength values of previous research (Table 3.1) In Table 3.1, varıous plant tissues were PEF treated with electric field strengths ranging from 01 to a maximum of $73 \mathrm{kV} / \mathrm{cm}$ using exponential decay or rectangular pulses Given the nature of $P$ peltatum and the fact that it is not a soft-cellular plant like fruits and vegetables, the use of instant charge reversal pulses at high electric field strengths of up to $667 \mathrm{kV} / \mathrm{cm}$ might induce cellular damage enough to permeate the cells and enhance podophyllotoxin extraction This assumption was not supported by the statistical analysis in Table 6.1 
Table 6.1: Statistical analysis for the effect of varying particle size and PEF process variables on the extraction of podophyllotoxin (mg/g) from $P$. peltatum using instant charge reversal pulses.

\begin{tabular}{|l|l|l|l|l|}
\hline \multirow{2}{*}{$\begin{array}{l}\text { Particle Size } \\
\text { (Mesh) }\end{array}$} & $<60$ & $<48$ & & \\
\cline { 2 - 5 } & $9.19^{\mathrm{A}}$ & $7.59^{\mathrm{B}}$ & & \\
\hline $\begin{array}{l}\text { Electric Field } \\
\begin{array}{l}\text { Strength } \\
\text { (kV/cm) }\end{array}\end{array}$ & Control & 33 & 50 & 67 \\
\cline { 2 - 5 } & $8.29^{\mathrm{A}}$ & $8.32^{\mathrm{A}}$ & $8.38^{\mathrm{A}}$ & $8.23^{\mathrm{A}}$ \\
\hline Pulse Number & Control & 20 & 40 & 60 \\
\cline { 2 - 5 } & $8.29^{\mathrm{A}}$ & $8.30^{\mathrm{A}}$ & $8.35^{\mathrm{A}}$ & $8.30^{\mathrm{A}}$ \\
\hline
\end{tabular}

*Means with the same letter in a row are not significantly different at $95 \%$ level

**Control - sample underwent soaking and drying but no PEF treatment

Table 6.1 reveals that indeed, finely ground $<60$ mesh powder yielded a higher mean concentration compared to the coarser $<48$ particles $(\mathrm{p}<0.0001)$. This confirms that increased grinding results in higher concentrations, but does not reflect the desired effect of PEF treatment on increasing podophyllotoxin extraction from $P$. peltatum. There is no significant difference in concentration of podophyllotoxin extracted from PEF treated and control samples, even if electric field strength is increased from $33 \mathrm{kV} / \mathrm{cm}$ to $67 \mathrm{kV} / \mathrm{cm}$ $(p=0.51)$. Pulse number also did not affect the concentration of podophyllotoxin extracted from PEF treated $P$. peltatum $(\mathrm{p}=0.86)$.

This demonstrates that increased mechanical fragmentation facilitates the release and diffusion of podophyllotoxin. As a result of increased grinding, the proportion of broken cells exposed to the solvent were higher and the amount of intact cells in the interior of the particles lower. Hence, the diffusion of podophyllotoxin was enhanced through the direct mechanical breakage of cells. Furthermore, the distance that podophyllotoxin had to diffuse through was reduced (as previously discussed and illustrated in Figure 6.4). However, there are limitations on the extent of mechanical fragmentation that can be performed and therefore the maximum amount of podophyllotoxin extraction cannot be 
attained. Similar findings were reported by El-Belghiti et al. (2008), where thinner gratings of fennel yielded higher solute concentration compared to thicker gratings. Moreover, as grating size increased, the concentration of solute extracted decreased. ElBelghiti et al. (2008) discussed that the effect of PEF treatment on the fennel was more pronounced for the thicker grating sizes, as the solute concentration for the smaller particles was largely governed by the effect of mechanical fragmentation rather than PEF treatment.

The lack of any substantial change in concentration due to PEF treatment led to the investigation of the actual concentration of the $P$. peltatum samples without secondary treatment such as soaking or vacuum oven drying. Perhaps the values in the results are in fact the maximum amount of podophyllotoxin that can be extracted from $P$. peltatum. Hence, why there was no change in the results with variation of PEF treatment since the threshold had already been reached. Table 6.2 presents the concentration of $<60,<48$, and $>48$ mesh $P$. peltatum particles. These samples were not exposed to any form of secondary treatment except for grinding, and only served as a means for comparison.

Table 6.2: Mean concentration of podophyllotoxin from $P$. peltatum of varying particle size without any PEF treatment, soaking, or vacuum drying.

\begin{tabular}{|c|c|c|}
\hline Particle Size & Relative Size & $\begin{array}{c}\text { Mean } \\
\text { Concentration } \\
(\mathrm{mg} / \mathrm{g})\end{array}$ \\
\hline$<60$ & Fine & $6.82 \pm 0.11$ \\
\hline$<48$ & Medium & $6.65 \pm 0.11$ \\
\hline$>48$ & Large & $2.73 \pm 0.099$ \\
\hline
\end{tabular}

In accordance with the results obtained (Figure 6.7) and the discussion that smaller particle sizes release higher amounts of podophyllotoxin during extraction, Table 6.2 
further indicates that mechanical fragmentation enhances podophyllotoxin extraction. The mean concentration of the control and PEF treated samples are presented in Table 6.3 , and compared with the samples without secondary treatment.

Table 6.3: Mean concentration of podophyllotoxin from control and PEF treated $P$. peltatum samples of varying particle sizes compared with $P$. peltatum samples without any secondary treatment.

\begin{tabular}{|c|c|c|c|c|}
\hline $\begin{array}{c}\text { Particle } \\
\text { Size }\end{array}$ & $\begin{array}{c}\text { Average } \\
\text { Concentration of } \\
\text { Control Samples } \\
(\mathrm{mg} / \mathrm{g})\end{array}$ & $\begin{array}{c}\text { Average } \\
\text { Concentration of } \\
\text { PEF Treated } \\
\text { Samples }(\mathrm{mg} / \mathrm{g})\end{array}$ & $\begin{array}{c}\text { Change in Mean } \\
\text { Control } \\
\text { Concentration } \\
\text { from Table 6.2 } \\
(\mathrm{mg} / \mathrm{g})\end{array}$ & $\begin{array}{c}\text { Change in } \\
\text { Mean PEF } \\
\text { Treated } \\
\text { Concentration } \\
\text { from Table 6.2 } \\
(\mathrm{mg} / \mathrm{g})\end{array}$ \\
\hline$<60$ & 9.11 & 9.21 & 2.29 & 2.39 \\
\hline$<48$ & 7.59 & 7.63 & 0.94 & 0.98 \\
\hline
\end{tabular}

It was expected that the mean concentration of podophyllotoxin from the control samples would have the same mean concentration as the untreated samples (Table 6.2). The same applies to the PEF treated samples as it was revealed from statistical analysis that there was no significant difference between PEF treated and control samples. Instead, the control samples and the PEF treated samples both exhibited substantially higher podophyllotoxin concentrations than the untreated samples (Table 6.3). Since the PEF treatment did not cause this increase in concentration (Table 6.1), hence another variable that was not taken into account for was responsible. The difference between the untreated samples (Table 6.2) and the control and PEF treated samples (Table 6.3) is that the latter were soaked in water for $24 \mathrm{~h}$ and subsequently dried. This indicates that the soaking of the $P$. peltatum samples prior to PEF treatment was a major contributor to the increase of podophyllotoxin extraction, which could potentially act as a confounding variable. There could be many reasons for the increase of concentration due to prolonged soaking but they will not be discussed, as it is not within the scope of this research. Soaking time 
must be taken into account as the effect of PEF on P. peltatum could be masked by the effect of prolonged soaking on podophyllotoxin concentration increase.

The results thus far indicate that PEF treatment of $P$. peltatum with instant charge reversal pulses was insufficient in causing damage to the cell wall and membranes of $P$. peltatum, even with high electric field strengths. Even though it was determined that prolonged soaking acted as a confounding variable, there was still potential for additional increase in concentration of the $<48$ mesh $P$. peltatum. In an ideal situation where PEF treatment was successful, the $<48$ mesh $P$. peltatum would have at least reached the same concentration obtained by the $<60$ mesh $P$. peltatum. Hence, these results confirm that there are intact cells within $<48$ mesh $P$. peltatum that prevent the diffusion of $P$. peltatum.

The duration of an instant charge reversal pulse is almost instantaneous such that the cell wall and membranes experience an electric field for a brief period of time. This brief moment was likely inadequate to cause damage to the $P$. peltatum sample. The inadequacy of instant charge reversal pulses for plant cells is likely the reason why the majority of research involving the treatment of plant materials with PEF is performed with rectangular pulses. This is demonstrated in the results of the literature review in Table 3.1. This prompted the consideration of a higher process temperature (Phase II) and rectangular pulses (Phase III). 


\subsubsection{Phase II}

The PEF process parameters employed were similar to the parameters used in Phase I. However, in this case, the PEF treatment was conducted at a higher temperature of $45^{\circ} \mathrm{C}$ rather than room temperature for $<48$ mesh $P$. peltatum. It was determined from previous research that plant cells are more sensitive to electrical treatment at high temperatures (Amami et al. 2005). Previous results from Phase I revealed that PEF treatment was insufficient to affect the cells of $P$. peltatum. Perhaps, the application of PEF treatment will be successful when the cell barriers are more vulnerable due to increased temperatures during PEF treatment. Figure 6.8 presents the results of $<48$ mesh $P$. peltatum treated with instant charge reversal pulses at $45^{\circ} \mathrm{C}$ and $24^{\circ} \mathrm{C}$.

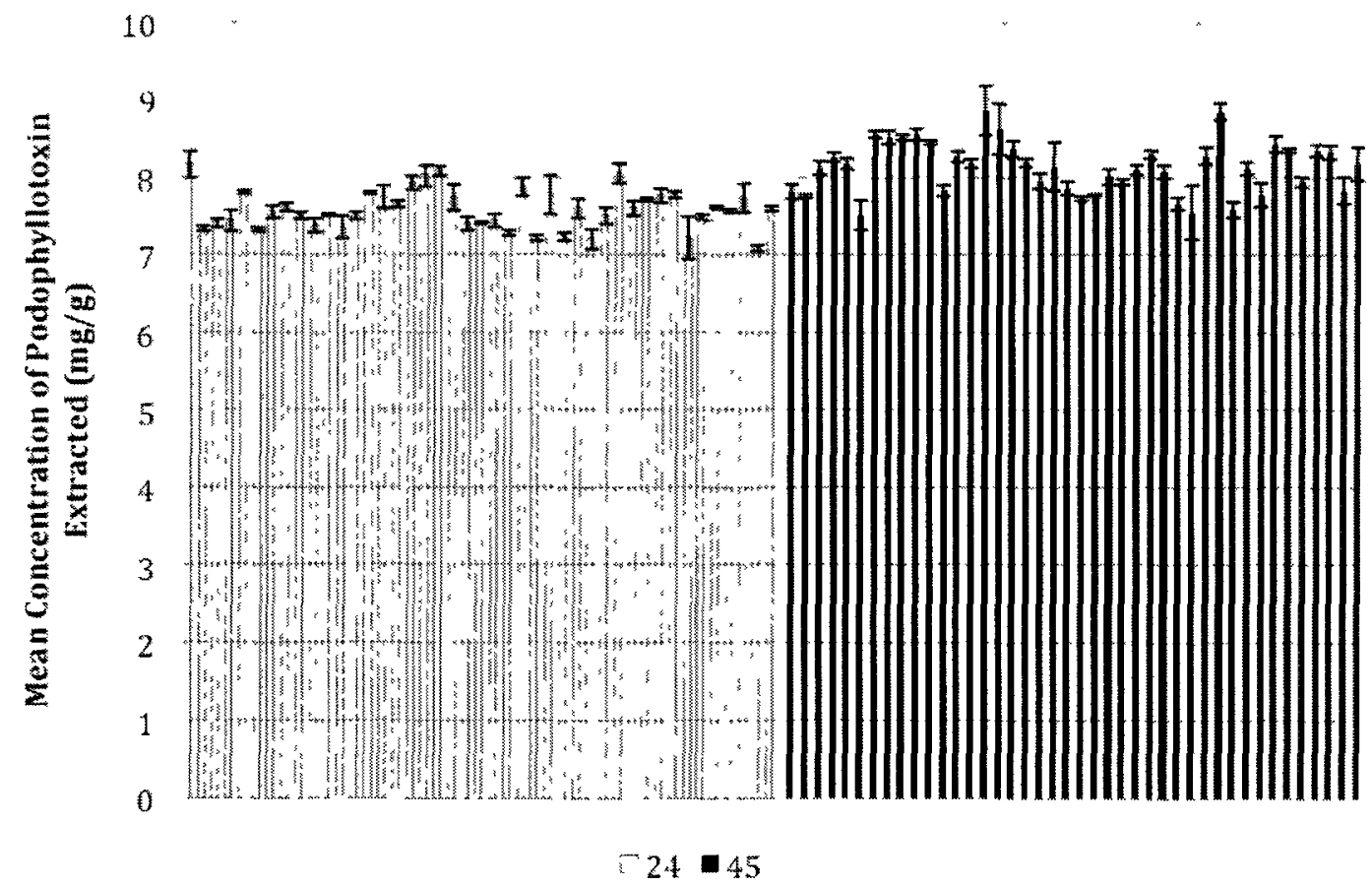

Figure 6.8: Effect of temperature on the extraction of podophyllotoxin from PEF treated $<48$ mesh $P$. peltatum using instant charge reversal pulses 
Figure 6.8 indicates that there is a slight increase in podophyllotoxin concentration for the treatment of $P$. peltatum at a higher temperature of $45^{\circ} \mathrm{C}$. PEF treatment of $<48$ mesh $P$. peltatum performed at room temperature resulted in a mean concentration of $7.63 \pm$ $0.16 \mathrm{mg} / \mathrm{g}$ and at $45^{\circ} \mathrm{C}$ a mean concentration of $8.18 \pm 0.21 \mathrm{mg} / \mathrm{g}$ was obtained. The significance of these results is presented in Table 6.4 .

Table 6.4: Effect of high temperature and PEF process variables on the extraction of podophyllotoxin $(\mathrm{mg} / \mathrm{g}$ ) from $<48$ mesh $P$. peltatum using instant charge reversal pulses.

\begin{tabular}{|l|l|l|l|l|}
\hline $\begin{array}{l}\text { Temperature } \\
\left({ }^{\circ} \mathrm{C}\right)\end{array}$ & 24 & 45 & & \\
\hline & $7.62^{\mathrm{B}}$ & $8.14^{\mathrm{A}}$ & & \\
\hline $\begin{array}{l}\text { Electric Field } \\
\begin{array}{l}\text { Strength } \\
(\mathrm{kV} / \mathrm{cm})\end{array}\end{array}$ & Control & 33 & 50 & 67 \\
\hline & $7.75^{\mathrm{BC}}$ & $8.05^{\mathrm{A}}$ & $7.71^{\mathrm{C}}$ & $7.92^{\mathrm{AB}}$ \\
\hline Pulse Number & Control & 20 & & \\
\cline { 2 - 5 } & $7.75^{\mathrm{B}}$ & $7.95^{\mathrm{A}}$ & 70 & 60 \\
\hline
\end{tabular}

*Means with the same letter in a row are not significantly different at $95 \%$ level

*** Control - sample underwent soaking and drying but no PEF treatment

Table 6.4 confirms that the amount of podophyllotoxin extracted from PEF treated $<48$ mesh $P$. peltatum at $45^{\circ} \mathrm{C}$ is higher than at room temperature $(\mathrm{p}<0.0001)$. The electric field strength had a significant effect on the extraction of podophyllotoxin $(p=0.0003)$. Moreover, $33.33 \mathrm{kV} / \mathrm{cm}$ provided the most significant increase in concentration of podophyllotoxin compared to the control. The pulse number also increased extraction yield ( $\mathrm{p}=0.044)$, where 20 and 40 pulses equally resulted in the highest in concentration of podophyllotoxin compared to the control.

These results suggest that PEF treatment with instant charge reversal pulses at $45^{\circ} \mathrm{C}$ has a significant effect on the extraction of podophyllotoxin from $P$. peltatum. Increasing the temperature of $P$. peltatum during PEF treatment slightly assisted in increasing the mean concentration of podophyllotoxin extracted from $P$. peltatum from $7.63 \pm 0.16 \mathrm{mg} / \mathrm{g}$ to 
$8.18 \pm 0.21 \mathrm{mg} / \mathrm{g}(\mathrm{p}<0.0001)$. However, the critical drying of plants can cause the membranes of cells to become more rigid (Hoekstra et al. 2001). Therefore, increased temperature could have possibly reduced the rigidity of the cell wall and membranes. Gurtovenko \& Vattulainen (2005) discussed that the sequence of events involved in electropermeabilizing biological cells are the same for low or high temperatures. However, at higher temperatures, ionic transport and pore formation occur faster.

The investigation continues to inquire whether rectangular pulses will contribute higher podophyllotoxin yield relative to results obtained from PEF treatment with instant charge reversal pulses.

\subsubsection{Phase III}

From the results obtained in Phase I, it was determined that PEF treatment with instant charge reversal pulses was unsuccessful and in Phase II, was not as effective as expected for fulfilling the objectives of this research. It was hypothesized that rectangular pulses with higher pulse duration would prove to be more effective in damaging the cellular barriers of $P$. peltatum. Although previous studies on various plant tissues have had success with pulse durations that are almost instantaneous (i.e. exponential decay pulses, instant charge reversal pulses), the cellular structure of $P$. peltatum is harder to damage compared to the soft-cellular plants previously investigated such as fruits and vegetables (Table 3.1). In this case, rectangular pulses offer more potential for cellular rupture as the cells are exposed to a high electric field strength for a longer duration of time. 
Larger particles of $>48$ mesh were treated with PEF. Results from Phase I revealed that relatively smaller $P$. peltatum particles were highly affected by mechanical fragmentation. Therefore a larger particle size was more appropriate to observe any pronounced effects of PEF treatment on podophyllotoxin extraction. Furthermore, soaking time was no longer $24 \mathrm{~h}$ and was reduced to $0.25,0.5,1$ or $2 \mathrm{~h}$. It was determined from Phase I that prolonged soaking prior to PEF treatment caused an increase in podophyllotoxin concentration, which could conceal the desired effect of PEF treatment. For $>48$ mesh $P$. peltatum, it was assumed that since the particle was larger than $<60$ and $<48$ mesh, a longer PEF treatment time, and hence, a higher number of pulses would be required to damage the cells of $P$. peltatum. Hence, 2 to 6 min total PEF treatment time were tested for $>48$ mesh $P$. peltatum (Section 5.5.3). Finally, the pulse frequency was varied between 84 and $840 \mathrm{~Hz}$ for both sample sizes. Using total PEF treatment time and frequency, the pulse number was calculated.

SEM was utilized to examine the condition of the cell before and after PEF treatment to directly observe the effect of rectangular pulses on $P$. peltatum. Figure 6.9 is a micrograph of a $P$. peltatum control sample that was soaked in water for $1 \mathrm{~h}$ followed by vacuum drying. 


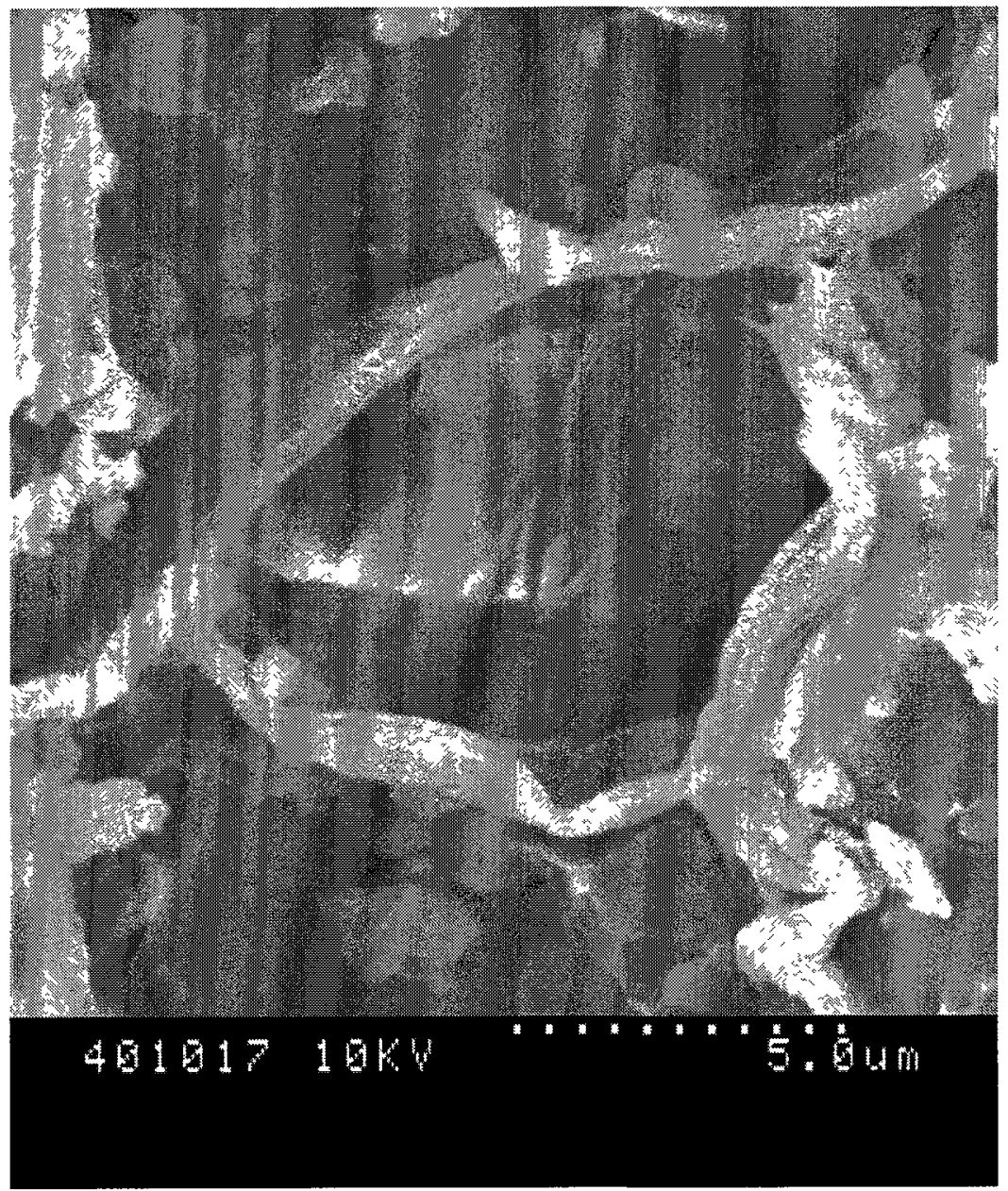

Figure 6.9: Examination of exterior cell of a P. peltatum control sample to determine condition of cell wall prior to PEF treatment $(7500 x)$. Secondary treatment was $1 \mathrm{~h}$ soaking followed by vacuum drying.

The cell wall of the P. peltatum control sample in Figure 6.9 is smooth and does not show any irregularities. There appears to be a part of the cell wall that has been ruptured due to the grinding process. In addition, there is debris of cellular material that was also due to grinding. Regardless, the thick cell wall does not appear to be deformed due to the dehydration process, soaking, or drying, and instead appears to be smooth with no obvious deformation. Aside from the damage to the cells in the exterior of the particle, it 
is assumed that the internal cells are intact and were not affected by mechanical fragmentation.

An unusual occurrence was observed after the completion of an experiment with PEF treatment times of 3 and $4 \mathrm{~min}$. Throughout all the experiments, the colour of ground $P$. peltatum before and after PEF treatment was consistently a pale, sand-like yellow colour. A significant colour change occurred to the sample exposed to 4 min of PEF treatment. An image of this experiment is given in Figure 6.10.

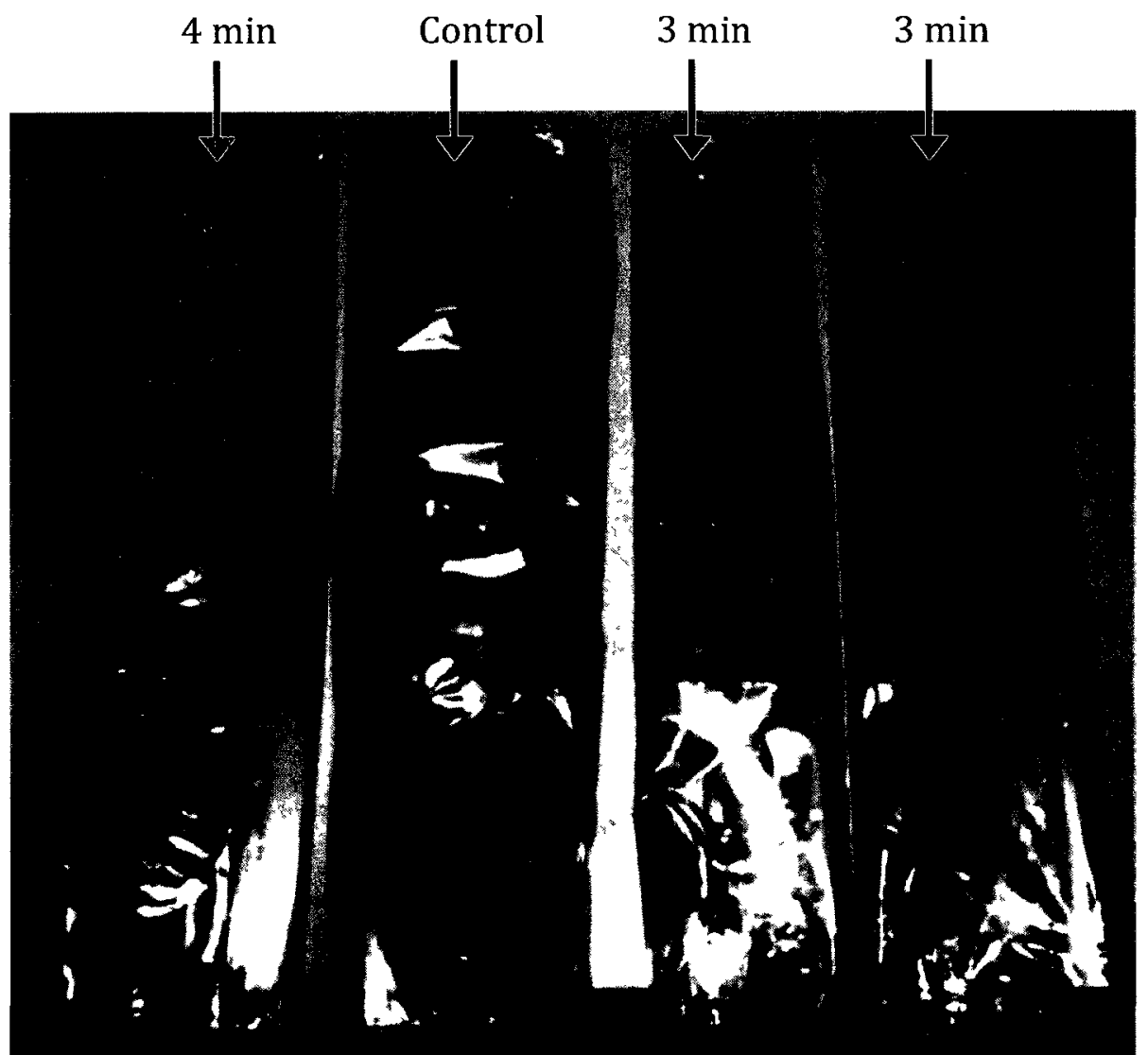

Figure 6.10: Deep red colour change observed in Phase III experiment with $>48$ mesh $P$. peltatum

Experiments were repeated to validate the colour change and for each experiment where PEF treatment time exceeded 4 min $(201,600$ pulses $)$, the $>48$ mesh $P$. peltatum samples 
changed to a deep red colour In addition, after each PEF treatment of 4 min or more, the $P$ peltatum samples were visually observed to increase in apparent viscosity and became sticky This led to the assumption that the PEF treatment was successful in causing damage to the barners of the $P$ peltatum cells such that the efflux of cellular contents resulted in the colour change It is unknown what chemical reactions caused this red colour, however, it is outside the scope of the research objectıves and will not be investigated Scanning electron micrographs of the samples that experienced the colour change were acquired for further insight

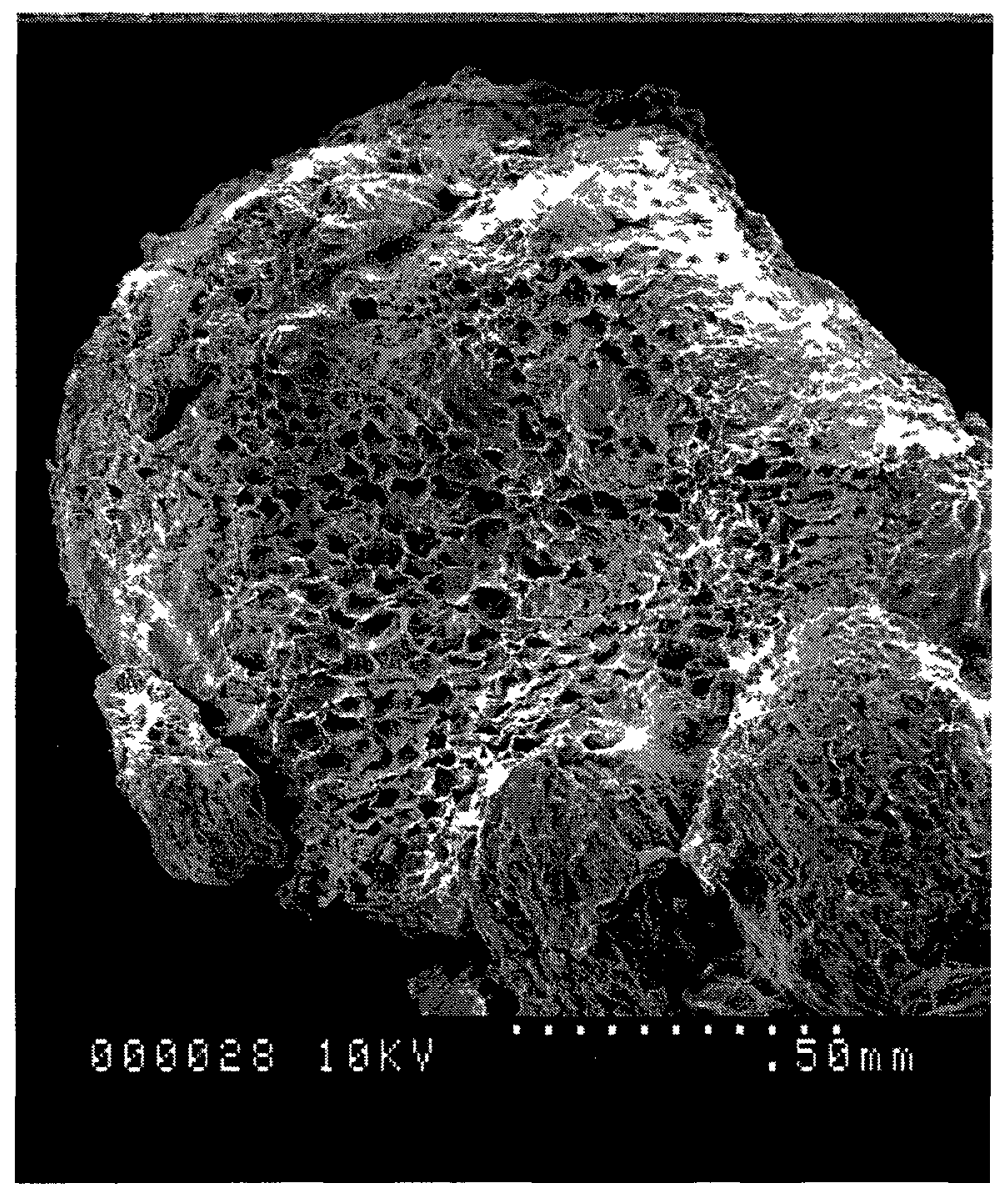

Figure 6.11: Examination of exterior cells of $>48$ mesh $P$. peltatum to determine condition of cells after colour change. Sample was soaked in water for $1 \mathrm{~h}$, PEF treated with 201,600 rectangular pulses and $18.57 \mathrm{kV} / \mathrm{cm}$ at room temperature $(60 \mathrm{x})$ 
Figure 6.11 illustrates a $>48$ mesh $P$. peltatum particle which was $\mathrm{PEF}$ treated for $4 \mathrm{~min}$ and displayed a change of colour and apparent viscosity. The cells of $P$. peltatum are clearly visible, however they appear to be vacant. While handling the samples that were PEF treated for more than $4 \mathrm{~min}$, the increase in apparent viscosity led to clustering of particles. This is observed in the micrograph where it is observed that several particles were adhered to one another.

To examine the condition of the cell wall after PEF treatment, a higher magnification of the sample is illustrated in Figure 6.12.

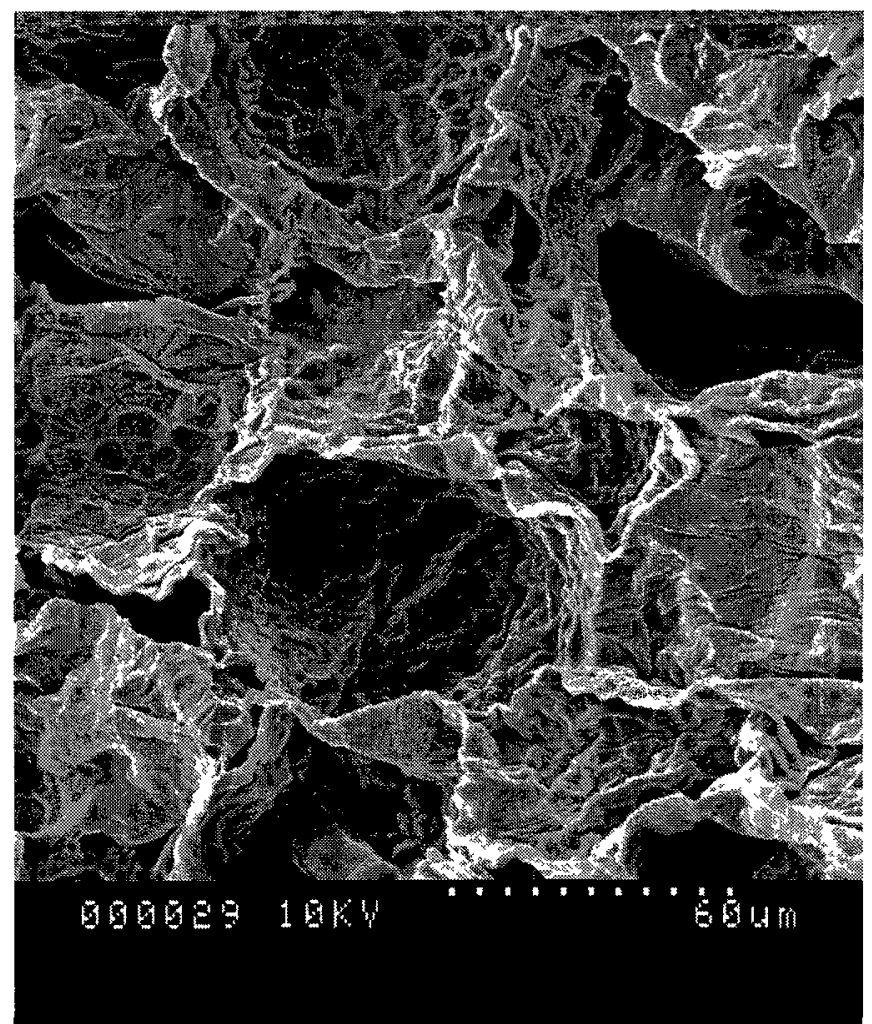

Figure 6.12: Examination of exterior cells of $>48$ mesh $P$. peltatum to determine condition of cells after colour change. Sample was soaked in water for $1 \mathrm{~h}$, PEF treated with 201,600 rectangular pulses and $18.57 \mathrm{kV} / \mathrm{cm}$ at room temperature $(500 \mathrm{x})$ 
The cell constituents are no longer found in the cells and only the cell walls remain. What are usually smooth cell walls are deformed due to the PEF treatment. However, it is not clear what has happened to the cell constituents, however their past presence remains imprinted within the cell wall. The particle was cut in half in order to determine the state of the interior cells.

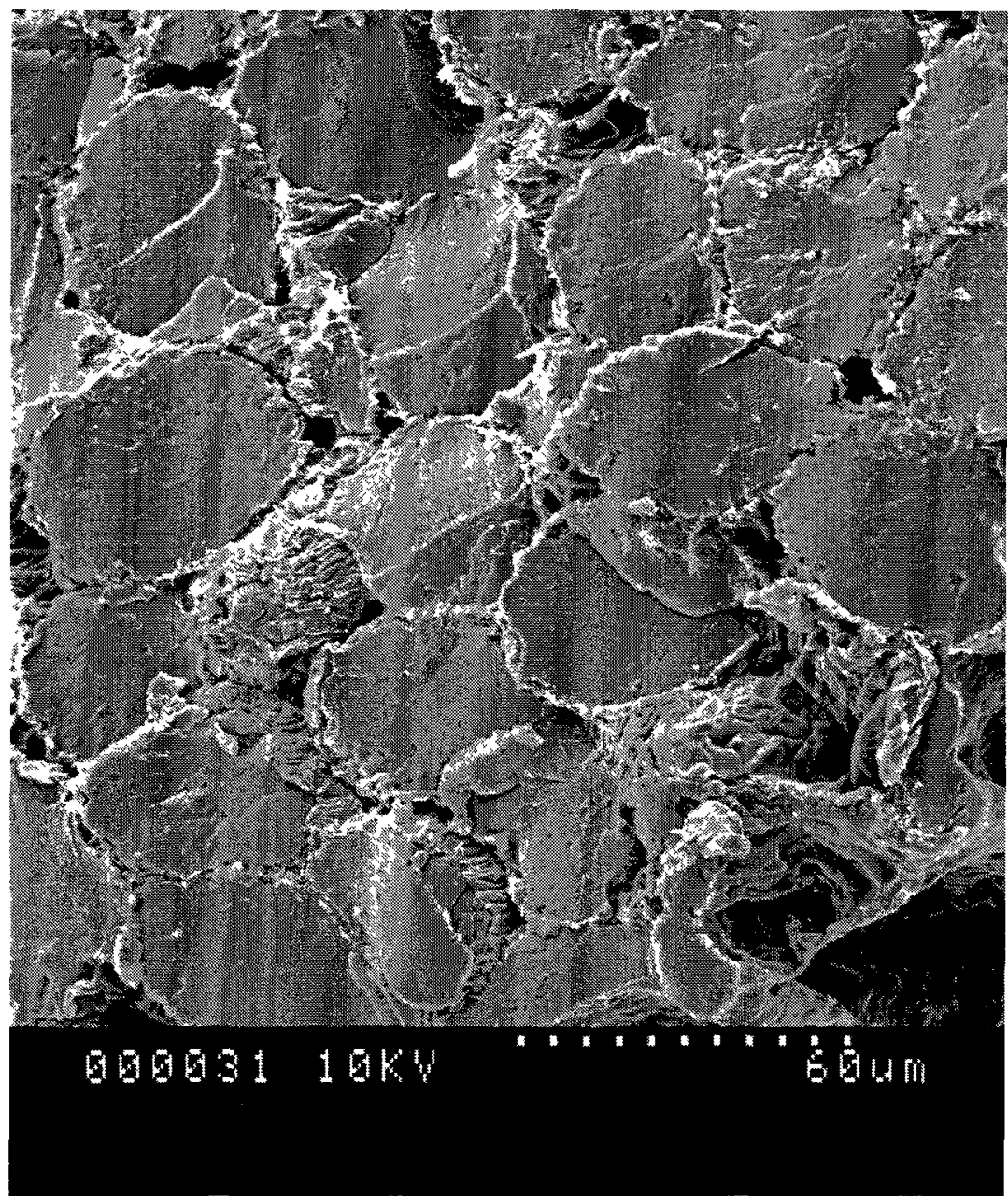

Figure 6.13: Cross-sectional examination of $>48$ mesh $P$. peltatum to determine condition of interior cells after colour change. Sample was soaked in water for $1 \mathrm{~h}$, PEF treated with 201,600 rectangular pulses and $18.57 \mathrm{kV} / \mathrm{cm}$ at room temperature $(500 \mathrm{x})$. Cross-section was obtained by cutting with blade. 
Figure 6.13 is a cross section of the PEF treated $P$. peltatum that resulted in a drastic change in colour and texture. The micrograph reveals complete collapse of cellular structures as all the constituents melted and solidified. However, this serves to demonstrate the solid matrix of the cell wall. Even though the cellular constituents within the cell failed completely, the cell wall still managed to contain the remnants within each cell. Figure 6.14 was captured at a different angle to obtain a better perspective of the cell wall.

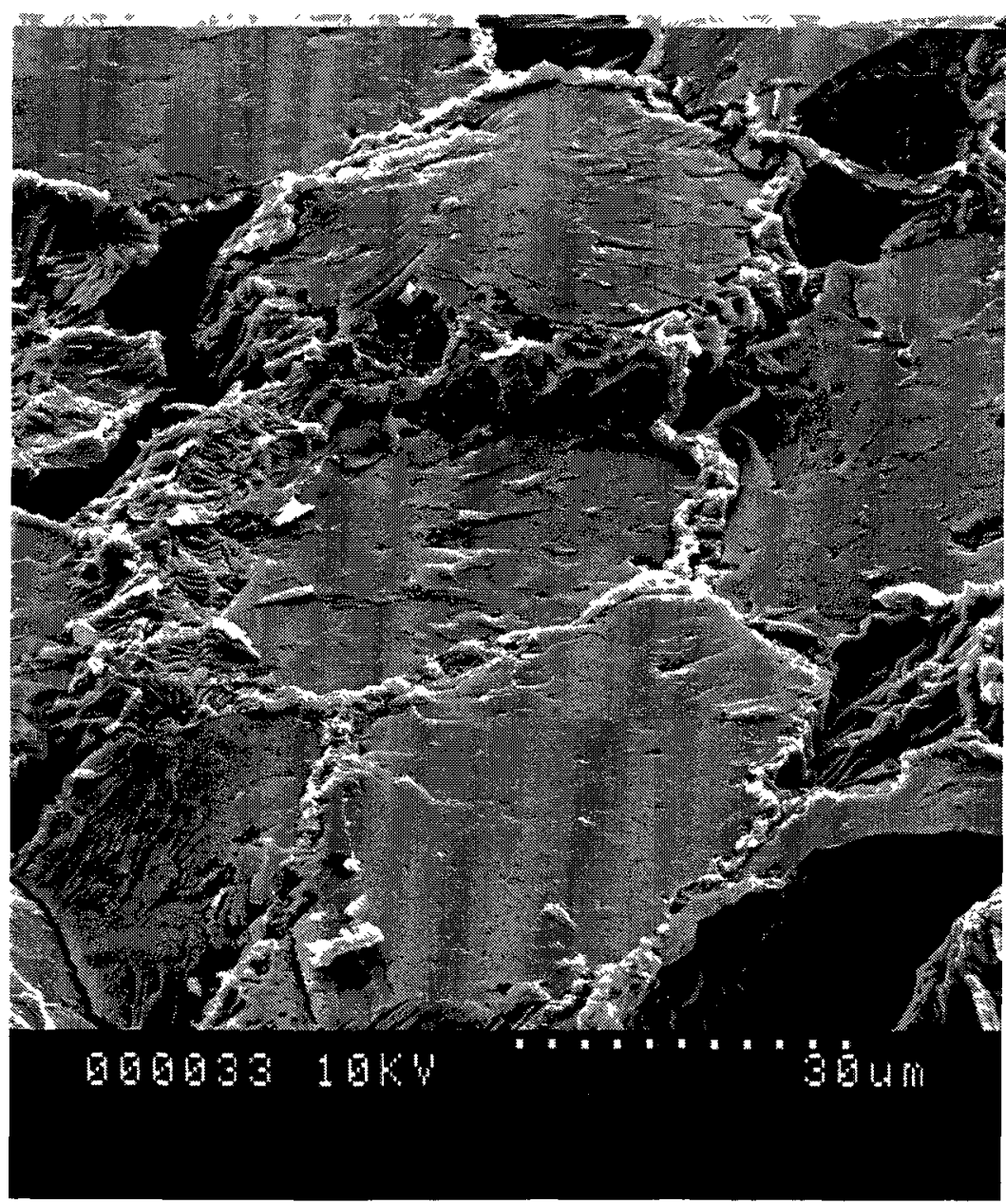

Figure 6.14: Cross-sectional examination of $>48$ mesh $P$. peltatum to determine condition of interior cells after colour change. Sample was soaked in water for $1 \mathrm{~h}$, PEF treated with 201,600 rectangular pulses and $18.57 \mathrm{kV} / \mathrm{cm}$ at room temperature $(1000 \mathrm{x})$. Cross-section was obtained by cutting with blade. 
The cell walls were completely deteriorated from PEF treatment of 4 min with 201,600 rectangular pulses. The cell walls were no longer smooth and instead appear to be rippled and obliterated. The high PEF treatment successfully damaged the cell barriers, however, at the cost of causing complete degradation of the cells' constituents. Viewing these results prompted one more experiment with the colour change parameters to find the cause of the cellular "meltdown". A temperature sensor was used to check the temperature of the $P$. peltatum sample after PEF treatment. For previous experiments, there was no notice of increase in temperature as the chamber was thoroughly insulated. In addition, no direct contact was made with the $P$. peltatum material as tools were utilized to transfer the material from the chamber and into the ceramic bowls for vacuum drying. The temperature sensor revealed that the extensive PEF treatment caused the temperature of the sample to increase dramatically and was recorded to be $67^{\circ} \mathrm{C}$. This temperature was well beyond the degradation temperature of podophyllotoxin, at $54^{\circ} \mathrm{C}$.

The significant change in the physical properties of $P$. peltatum pressed for an additional phase of experiments except in this case, with temperature control. At such a high temperature of $67^{\circ} \mathrm{C}$, the combination of starch, water, and heat from the PEF treatment caused starch gelatinization, however starch gelatinization is known to produce a dull white paste, not red. Hence, chemical reactions most likely occurred to cause the red colour change. Although it is unknown at what temperature starch granules in P. peltatum gelatinize, the starch gelatinization temperature of potato was used as a close approximation since potato, like $P$. peltatum, has a high starch content that gelatinizes between 50 and $60^{\circ} \mathrm{C}$ (Sweetman 1933). Han et al. (2009) also maintained a temperature 
below $50^{\circ} \mathrm{C}$ for the $\mathrm{PEF}$ treatment of potato to ensure that the starch granules do not gelatinize.

\subsubsection{Phase IV}

Phase IV of the research treated $>48$ mesh $P$. peltatum with the PEF process variables in Phase III that significantly altered the physical properties of P. peltatum. However, these experiments were performed with temperature control. Rather than treating $P$. peltatum for several minutes continuously, the PEF treatment was paused for relaxation time to allow for cooling and then PEF treatment was continued to fulfill the desired PEF total treatment time. The degradation temperature of podophyllotoxin is $54^{\circ} \mathrm{C}$, and therefore, the temperature of the samples were maintained at approximately $50^{\circ} \mathrm{C}$ to ensure that podophyllotoxin was not damaged and to reduce starch gelatinization. After PEF treatment, the $P$. peltatum samples were extracted using varying solvent extraction methods.

Like Phase III, the samples in these experiments also changed into the deep red colour after PEF treatment time exceeded $4 \mathrm{~min}$, even with intermission periods in between treatment. Figures 6.15 and 6.16 are micrographs of two different samples treated with PEF for $5 \min (252,000$ pulses $)$. 


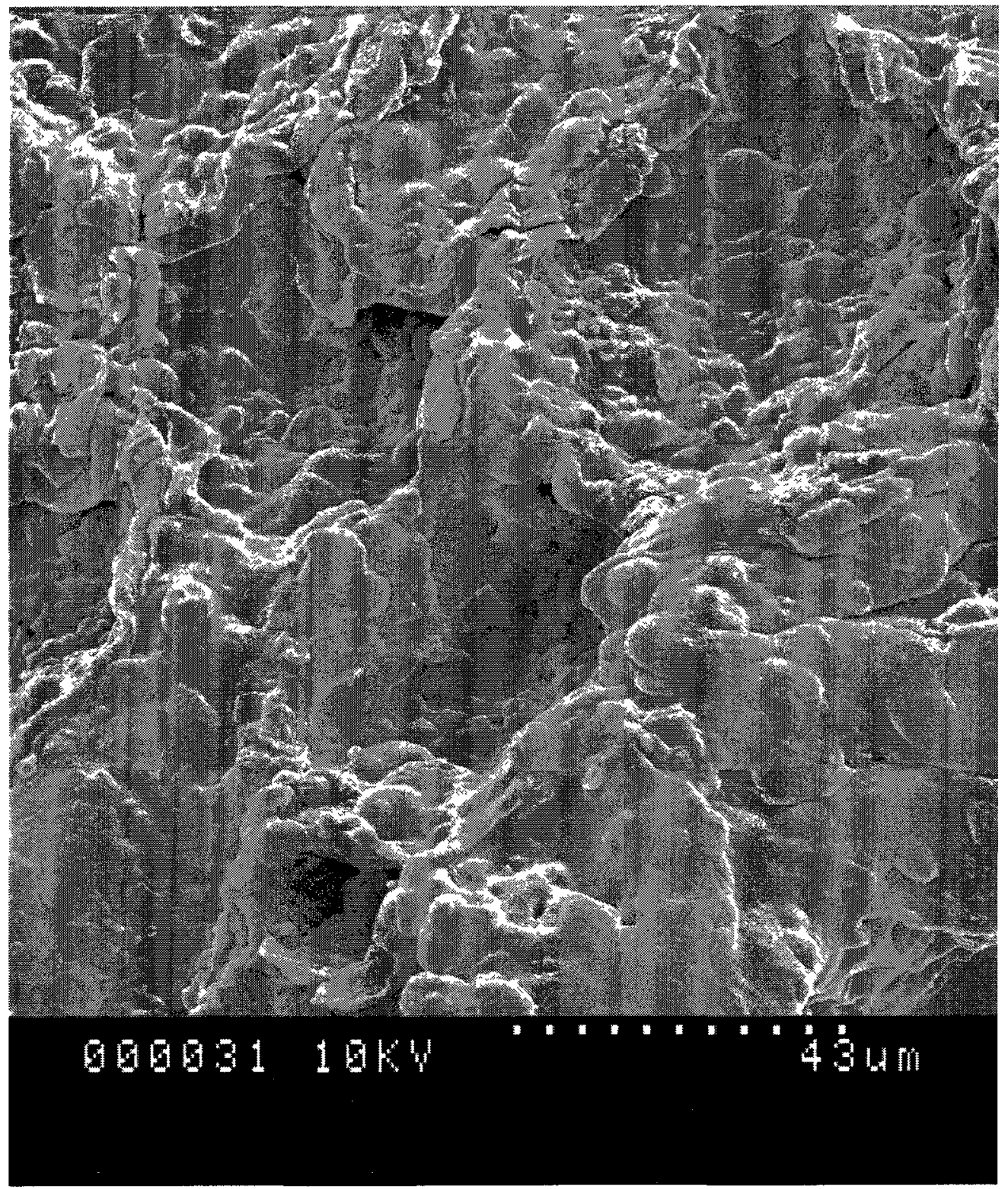

Figure 6.15: Examination of exterior cells of $>48$ mesh $P$. peltatum to determine condition of cells after colour change due to PEF treatment with temperature control. Sample was soaked in water for $1 \mathrm{~h}$, PEF treated with 252,000 rectangular pulses and $17.7 \mathrm{kV} / \mathrm{cm}$, at room temperature $(700 \mathrm{x})$

It is important to note that the cells appear to be less occupied with starch granules and other compounds compared to Figure 6.5 due to the secondary treatment experienced by the samples. As samples are ground, soaked, and dried, some of the cell contents that are exposed on the surface of the particles are removed. 


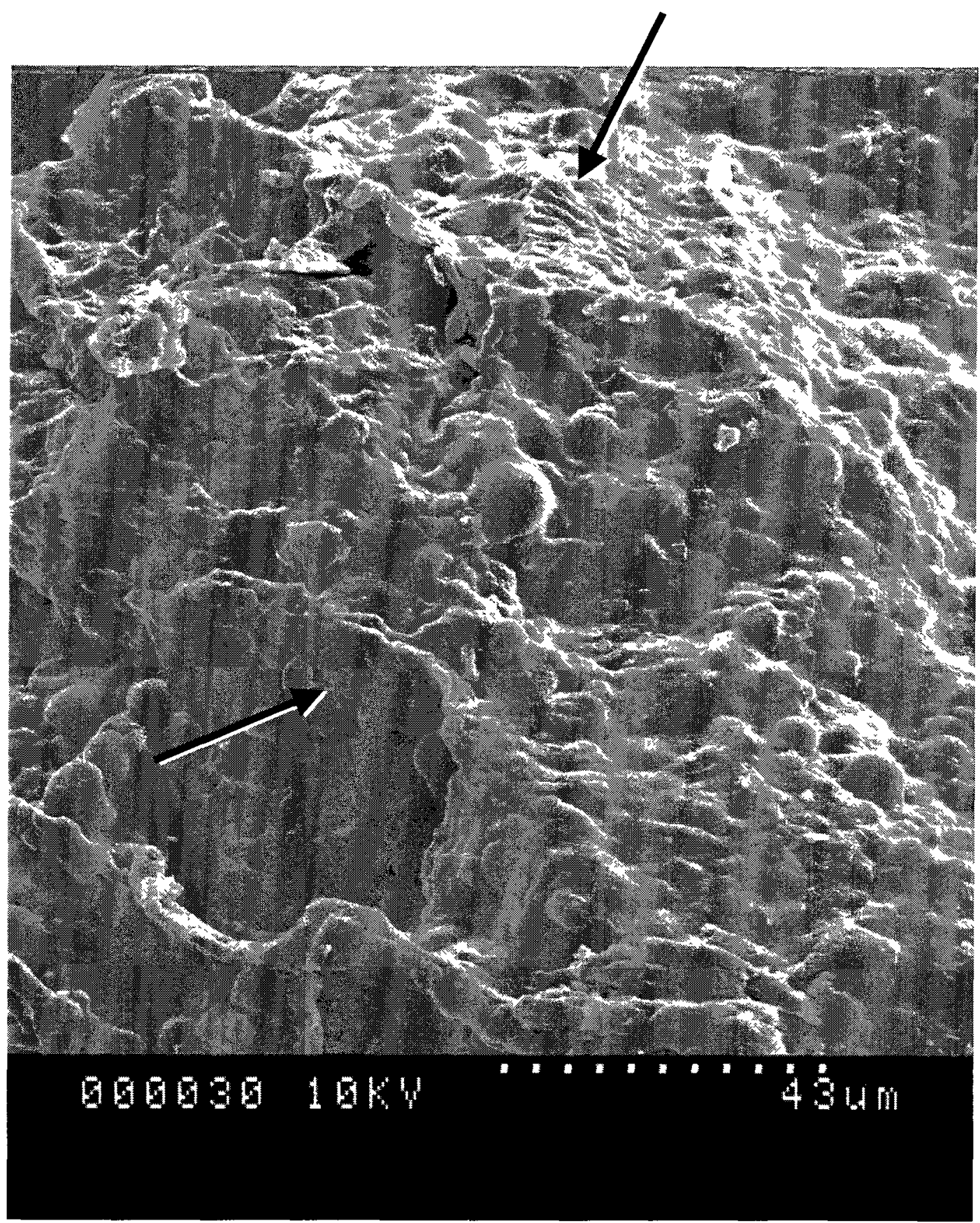

Figure 6.16: Examination of exterior cells of $>48$ mesh $P$. peltatum to determine condition of cells after colour change due to PEF treatment with temperature control. Sample was soaked in water for $1 \mathrm{~h}$, PEF treated with 252,000 rectangular pulses and $17.7 \mathrm{kV} / \mathrm{cm}$, at room temperature $(700 \mathrm{x})$. 
The micrographs reveal that a large number of starch granules at the surface of the $>48$ mesh particles are still present and remain ungelatinized. Hence, the temperature control during PEF treatment was successful in preserving the integrity of the cell constituents. A thin film appears to have covered the $P$. peltatum particles; this film is likely to be the material that is displaying the red colour. It is possible that some material was released from the interior of the $P$. peltatum particles, thereby coating the outer surface of the particles. This is a possible indication of cell barrier damage. Due to the film covering the samples, it is difficult to assess the condition of the cell wall, however, in some areas indicated on Figure 6.16, the smooth structure of the cell wall is no longer observed. The results of the concentration yield of podophyllotoxin will confirm whether or not longer PEF treatment time has imposed enough damage on the $P$. peltatum samples to enhance the diffusion of podophyllotoxin.

Rather than displaying results of the maximum yield, a change in concentration between the control and PEF treated sample is presented. In this research, the main interest is the increase of concentration as a result of PEF treatment. Each P. peltatum plant may vary in concentration of podophyllotoxin and it would not be an accurate form of comparison to analyze PEF treated samples with each other. Hence, Table 6.5 presents the changes in concentration of PEF treated $>48$ mesh $P$. peltatum compared to the control obtained from the same $P$. peltatum sample. Both samples, whether PEF treated or control, were treated with the same extraction method. Hence, the PEF treated sample termed "soaking for $24 \mathrm{~h}$ ", was compared with a control sample that also had podophyllotoxin extracted with the same method of soaking the sample in aqueous ethanol for $24 \mathrm{~h}$. 
Table 6.5: Change in concentration between PEF treated and control $>48$ mesh $P$. peltatum samples, exposed to $1 \mathrm{~h}$ pre-soaking, 252,000 rectangular pulses, and $17.70 \mathrm{kV} / \mathrm{cm}$. Temperature of $P E F$ treated samples was maintained below $54^{\circ} \mathrm{C}$. Podophyllotoxin was extracted with various solvent extraction parameters with $30 \%$ aqueous ethanol solution.

\begin{tabular}{|c|c|c|c|c|}
\hline $\begin{array}{c}\text { Solvent Extraction } \\
\text { Parameters }\end{array}$ & $\begin{array}{c}\text { Mean } \\
\text { Concentration } \\
(\mathrm{mg} / \mathrm{g})\end{array}$ & $\begin{array}{c}\text { Standard } \\
\text { Deviation } \\
(\mathrm{mg} / \mathrm{g})\end{array}$ & $\begin{array}{c}\text { Change in Mean } \\
\text { Concentration } \\
(\mathrm{mg} / \mathrm{g})\end{array}$ & $\begin{array}{c}\text { Change in Mean } \\
\text { Concentration } \\
(\%)\end{array}$ \\
\hline Stir at $50^{\circ} \mathrm{C}$ for $10 \mathrm{~min}$ & 3.83 & 0.36 & -0.44 & -10.34 \\
\hline Stir at $50^{\circ} \mathrm{C}$ for $10 \mathrm{~min}^{*}$ & 4.27 & 0.075 & & 17.23 \\
\hline Stir at $50^{\circ} \mathrm{C}$ for $1 \mathrm{~h}$ & 6.19 & 0.30 & 0.91 & 23.26 \\
\hline Stir at $50^{\circ} \mathrm{C}$ for $1 \mathrm{~h}$ & 6.51 & 0.58 & 1.23 & 24.48 \\
\hline Stir at $50^{\circ} \mathrm{C}$ for $1 \mathrm{~h}^{*}$ & 5.28 & 0.19 & & 27.97 \\
\hline Soak for $24 \mathrm{~h}$ & 5.90 & 0.38 & 1.16 & \\
\hline Soak for $24 \mathrm{~h}$ & 6.07 & 0.13 & 1.33 & \\
\hline Soak for $24 \mathrm{~h}^{*}$ & 4.74 & 0.16 & & \\
\hline
\end{tabular}

*Control samples

With the exception of one sample, all of the PEF treated samples resulted in a significant increase of extracted podophyllotoxin, ranging from a $17 \%$ increase up to a $28 \%$ increase. This demonstrates that PEF treatment of 5 min $(252,000$ pulses $)$ successfully permeated the cell barriers of $P$. peltatum, and enhanced the extraction of podophyllotoxin by up to $28 \%$.

The properties of $P$. peltatum samples treated with more than 201,600 rectangular pulses changed drastically. It was visually observed that the sample displayed a change in colour and an increase in apparent viscosity. Due to the chemical reactions that occurred as a result of PEF treatment, the intra- and extra- cellular fluid properties were altered. This decreased the mass diffusivity of podophyllotoxin through the modified material, thus requiring longer extraction times. Hence, 10 min solvent extraction time was insufficient for the extraction of podophyllotoxin. This reduced the concentration of podophyllotoxin extracted from the PEF treated sample compared to the control, and displayed a negative 
change in concentration. Therefore, podophyllotoxin required greater than $10 \mathrm{~min}$ of Solvent extraction to diffuse out of the particles and into the solvent. For extraction times of 1 and $24 \mathrm{~h}$, the extracted concentration of PEF treated samples increased by up to $28 \%$.

Further intensification of total PEF treatment time was employed with 6 and 8 min treatment time $(302,400$ and 403,200 pulses, respectively). These experiments were performed to investigate whether further damage would occur to the cells of $P$. peltatum causing additional increase in podophyllotoxin concentration.

Table 6.6: Change in concentration between PEF treated and control $>48$ mesh $P$. peltatum samples, exposed to $1 \mathrm{~h}$ pre-soaking, 302,400 and 403,200 rectangular pulses, and $19.4 \mathrm{kV} / \mathrm{cm}$. Temperature of PEF treated samples was maintained below $54^{\circ} \mathrm{C}$. Podophyllotoxin was extracted with various solvent extraction parameters with $30 \%$ aqueous ethanol solution.

\begin{tabular}{|c|c|c|c|c|c|c|}
\hline $\begin{array}{l}\text { Total PEF } \\
\text { Treatment } \\
\text { Time (min) }\end{array}$ & $\begin{array}{l}\text { Pulse } \\
\text { Number }\end{array}$ & $\begin{array}{l}\text { Solvent Extraction } \\
\text { Parameters }\end{array}$ & $\begin{array}{c}\text { Mean } \\
\text { Concentration } \\
(\mathrm{mg} / \mathrm{g})\end{array}$ & $\begin{array}{c}\text { Standard } \\
\text { Deviation } \\
(\mathrm{mg} / \mathrm{g})\end{array}$ & $\begin{array}{c}\text { Change in } \\
\text { Mean } \\
\text { Concentration } \\
(\mathrm{mg} / \mathrm{g})\end{array}$ & $\begin{array}{c}\text { Change in } \\
\text { Mean } \\
\text { Concentration } \\
(\%)\end{array}$ \\
\hline 6 & 302400 & Stir at $50^{\circ} \mathrm{C}$ for $2 \mathrm{~min}$ & 1.16 & 0.037 & -1.17 & -50.28 \\
\hline 8 & 403200 & Stir at $50^{\circ} \mathrm{C}$ for $2 \mathrm{~min}$ & 1.019 & 0.093 & -1.30 & -56.13 \\
\hline \multicolumn{2}{|c|}{ Control } & Stir at $50^{\circ} \mathrm{C}$ for $2 \mathrm{~min}$ & 2.32 & 0.092 & & \\
\hline 6 & 302400 & Stir at $50^{\circ} \mathrm{C}$ for $1 \mathrm{~h}$ & 6.68 & 0.66 & 1.40 & 26.43 \\
\hline 8 & 403200 & Stir at $50^{\circ} \mathrm{C}$ for $1 \mathrm{~h}$ & 5.89 & 0.28 & 0.60 & 11.41 \\
\hline \multicolumn{2}{|c|}{ Control } & Stir at $50^{\circ} \mathrm{C}$ for $1 \mathrm{~h}$ & 5.28 & 0.32 & & \\
\hline 6 & 302400 & Soak for $24 \mathrm{~h}$ & 5.64 & 0.40 & 0.83 & 17.29 \\
\hline 8 & 403200 & Soak for $24 \mathrm{~h}$ & 5.34 & 0.12 & 0.53 & 11.10 \\
\hline \multicolumn{2}{|c|}{ Control } & Soak for $24 \mathrm{~h}$ & 4.81 & 0.097 & & \\
\hline 6 & 302400 & $\begin{array}{l}\text { Stir at } 50^{\circ} \mathrm{C} \text { for } 1 \mathrm{~h} \mathrm{\&} \\
\text { soak for } 24 \mathrm{~h}\end{array}$ & 7.18 & 0.58 & 2.30 & 47.03 \\
\hline 8 & 403200 & $\begin{array}{c}\text { Stir at } 50^{\circ} \mathrm{C} \text { for } 1 \mathrm{~h} \& \\
\text { soak for } 24 \mathrm{~h}\end{array}$ & 5.38 & 0.20 & 0.49 & 10.13 \\
\hline \multicolumn{2}{|c|}{ Control } & $\begin{array}{l}\text { Stir at } 50^{\circ} \mathrm{C} \text { for } 1 \mathrm{~h} \& \\
\text { soak for } 24 \mathrm{~h}\end{array}$ & 4.88 & 0.42 & & \\
\hline
\end{tabular}


Table 6.6 presents the change in concentration of $P$. peltatum treated with PEF for 6 $(302,400$ pulses) or 8 min $(403,200$ pulses). For all extraction methods, except for "stir at $50^{\circ} \mathrm{C}$ for 2 min", PEF treatment with 302,400 and 403,200 rectangular pulses increased podophyllotoxin concentration. The concentration of podophyllotoxin treated with 302,400 rectangular pulses was increased by up to $47 \%$. However, 2 min solvent extraction time resulted in a decrease of podophyllotoxin concentration. For PEF treatment with 302,400 and 403,200 rectangular pulses, the properties of the intra- and extra-cellular fluid were altered causing an increase in apparent viscosity, which was visually observed upon examination of the $P$. peltatum material. Therefore, longer solvent extraction times were required since the diffusivity of podophyllotoxin through the modified material was reduced. Therefore, $2 \mathrm{~min}$ and $10 \mathrm{~min}$ (Table 6.5) extraction times were inadequate for the diffusion of podophyllotoxin into the solvent for HPLC detection. The extraction methods of stirring at $50^{\circ} \mathrm{C}$ for $1 \mathrm{~h}$, soaking for $24 \mathrm{~h}$ or the combination of the two were more appropriate for the extraction of podophyllotoxin.

A clear trend is displayed in Table 6.6 for PEF treatment with 302,400 and 403,200 rectangular pulses. Although both treatments resulted in an increase of extracted podophyllotoxin, 302,400 pulses consistently resulted in a higher podophyllotoxin concentration compared to 403,200 . With treatment of 403,200 pulses, the concentration of podophyllotoxin was reduced. It is unknown what caused the decrease in podophyllotoxin. Zhang et al. (2007) examined the effect of PEF on a pure, isolated glycoside named cyanidin-3-glucoside. It was determined that as electric field intensity and PEF treatment time increased, significant degradation of the glycoside occurred. 
However, the exact mechanism of degradation was unclear and was set as a goal for future work. The effect of PEF on the cyanidin-3-glucoside may have caused the degradation of the podophyllotoxin glucoside stored in the vacuole at 403,200 pulses.

\subsubsection{Possible Mechanism of Enhanced Podophyllum peltatum Permeability With Pulsed Electric Field Treatment}

The cell barriers that govern the solvent extraction yield of podophyllotoxin are the membranes (vacuole and cytoplasm) and cell wall. The treatment of $P$. peltatum with PEF for 5, 6, and 8 min $(252,000,302,400$ and 403,200 rectangular pulses) successfully damaged one or more of the cell barriers of $P$. peltatum that would normally hinder the diffusion of podophyllotoxin during conventional extraction methods performed in the pharmaceutical industry. The direct observation of $P$. peltatum using scanning electron microscopy revealed that the cell wall was indeed damaged. It is highly likely that the cell membrane and tonoplast were also damaged, however, direct examination of this damage was not possible in this research. However, results revealed a significant increase in concentration due to PEF treatment, which was the main aim of this research. The mechanism in which podophyllotoxin concentration was enhanced is unknown as there are many unknown variables and limited information.

Due to the toxic nature of podophyllotoxin, it is stored in the vacuole as an inactive glycoside (Moraes et al. 2004). Podophyllotoxin glucoside is isolated from the rest of the cell and is restricted in the vacuole due to the tonoplast that surrounds it. The membrane of the vacuole and cytoplasm is a lipid bilayer, which is selectively permeable. Hence, for the release of podophyllotoxin from the cell, Farkya et al. (2004) affirms that the 
tonoplast and plasma membrane must be permeabilized. Furthermore, the podophyllotoxin glucoside is more hydrophilic than its aglycone form and therefore does not have optimal lipid solubility (Stein 1981). Therefore, the molecules are not capable of freely diffusing through the lipid membrane, unless the membrane is permeated.

Although the cell wall is not selectively permeable like the membranes of the vacuole and cytoplasm, the cell wall still restricts the transfer of podophyllotoxin out of the cell as it poses high resistance to the mass transfer of solutes (Fincan \& Dejmek 2002). For a small solute such as glucose, the diffusivity of the solute is reduced dramatically by the cell wall compared to the cytoplasm. It is approximated that the diffusion of glucose through the cell wall is $10^{6}$ times lower than the diffusion through the adjacent fluid of the cytoplasm (Sensoy \& Sastry 2004). Podophyllotoxin is relatively larger than glucose and hence the permeation rate of the molecule is further reduced due to the compact cellulose matrix of the cell wall and its filtering capabilities based on molecular size (Stein 1981). Furthermore, the penetration of molecules through the cell wall is compromised when lignin is deposited within the cell walls of $P$. peltatum. All of these factors delay or inhibit the diffusion of the podophyllotoxin through the cell wall. This barrier must be permeabilized by PEF treatment in order to enhance extraction rates.

The mechanism in which PEF treatment enhanced podophyllotoxin permeability and increased podophyllotoxin concentration by up to $48 \%$ is unknown. However, based on the results, several deductions can be made. Once PEF was applied to the $P$. peltatum samples, the ions that were naturally present within the inter- and intra-cellular fluid 
induced a transmembrane potential across the barriers of the cell. The transmembrane potential of a plant cell strives to maintain equilibrium with the external electric field, however, once the external field exceeds the transmembrane potential, the barriers experience structural rearrangements and permeability is enhanced (Ho \& Mittal 2000). The exact mechanism of PEF imposed damage on biological materials is unknown and has been debated within literature. Several theories have been discussed, however, electroporation is the most widely accepted mechanism (Bluhm 2006). The sequence of events that occur after permeabilization such as cellular fluid mixing and mass transfer is also unknown (Fincan \& Dejmek 2002).

Due to the heterogeneity of the $P$. peltatum sample, PEF treatment was non-uniform and the permeabilization of the cells occurred gradually. Furthermore, the cells in P. peltatum are of different sizes, cell wall thickness, and lignin content, amongst other structural properties. Hence, the amount of time to permeabilize the heterogeneous cells differs. For instance, a cell with a large diameter requires less PEF treatment to cause damage compared to a cell with a smaller diameter (Jemai \& Vorobiev 2002). More importantly, it is assumed that the electroporation of $P$. peltatum required longer PEF treatment time compared to soft-cellular plants due to the tough structure of the cell. The exact mechanism through which PEF affects pore size and structure in biological materials is not understood (Tieleman et al. 2003). However, Soliva-Fortuny et al. (2009) suggests that increasing PEF treatment time causes larger pores. Thus, in addition to more cells being electroporated, it is possible that the cells with barriers that have already been porated, will increase in size with continued PEF treatment. It is important to note that 
with increased PEF treatment time, the temperature of the sample also increased. This is a common effect that occurs during electrical treatment of biological materials (Jemai \& Vorobiev 2002). When the samples resist the displacement current imposed by the electric field, friction occurs and energy is dissipated in the form of heat (Kaufmann \& Christen 2002). The PEF treatment with intermission was performed to keep temperature under $50^{\circ} \mathrm{C}$, however, due to the unpredictable nature of the sample the temperature reached a maximum of $53.7^{\circ} \mathrm{C}$, which is just below the degradation temperature of podophyllotoxin at $54^{\circ} \mathrm{C}$. However, the rise in temperature may have been beneficial for the PEF treatment of $P$. peltatum. As discussed in the results of Phase II, temperature enhances the electroporation of biological materials. Therefore, the synergistic effect of high temperature and PEF application enhanced the permeation of $P$. peltatum cells and as a result increased podophyllotoxin concentration.

It is hypothesized that podophyllotoxin glucoside was liberated from the vacuole after PEF electroporation of the cell barriers. Once the tonoplast was damaged, the vacuolar sap along with podophyllotoxin glucoside was rapidly leaked into the cytoplasm where the contents mixed, and reactions between the previously partitioned chemicals occurred. The podophyllotoxin glucoside was then converted to podophyllotoxin by the enzyme $\beta$ glucosidase, which is located in the cytoplasm and has high substrate specificity for podophyllotoxin glucoside (Dayan et al. 2003). While PEF treatment continued, it is possible that the apparent viscosity of the cellular fluid increased as numerous reactions took place as a result of electroporation and cellular fluid interactions. This increase in 
viscosity of the inter- and intra-cellular fluid decreased the mass diffusivity of solutes and slowed down the diffusion of substances out of the cell.

With respect to solvent extraction with ethanol, the solubility of podophyllotoxin in ethanol increases with higher temperatures (Gan et al. 2009). Mass transfer is increased and the viscosity of the solvent is decreased and therefore the ethanol solvent is penetrated into $P$. peltatum at a higher rate improving the interaction between podophyllotoxin and the ethanol solvent (Vinatoru et al. 1997). Hence, extraction at $50^{\circ} \mathrm{C}$ for $1 \mathrm{~h}$ provided results comparable to extraction for $24 \mathrm{~h}$ at room temperature. The combination of the two methods resulted in the highest concentration yield (Table 6.6). In all cases, the PEF treated material experienced a significant change in podophyllotoxin concentration compared to the control samples which were exposed to similar extraction methods. Therefore, the change in concentration of podophyllotoxin is attributed to the effect of PEF treatment, and ultimately the damage created by such treatment to the barriers that normally restrict the diffusion of podophyllotoxin. 


\section{CONCLUSION AND RECOMMENDATIONS}

\subsection{CONCLUSIONS}

1. Reducing particle size yielded higher concentrations of extracted podophyllotoxin from P. peltatum.

2. Prolonged pre-soaking treatment in water $(24 \mathrm{~h})$ led to a higher concentration of extracted podophyllotoxin from P. peltatum.

3. Instant charge reversal pulses at room temperature were inadequate to cause damage to the cell barriers of $P$. peltatum. This was attributed to the low pulse duration of instant charge reversal pulses.

4. PEF treatment using instant charge reversal pulses at $45^{\circ} \mathrm{C}$ was effective in increasing the mean concentration of $P$. peltatum from $7.63 \pm 0.16 \mathrm{mg} / \mathrm{g}$ to $8.18 \pm$ $0.21 \mathrm{mg} / \mathrm{g}(\mathrm{p}<0.0001)$. Higher temperatures during PEF treatment enhanced ionic transport and pore formation of the membranes.

5. The concentration of podophyllotoxin was increased by up to $47 \%$ and was consistently higher than control samples when treated with 252000,302400 , and 403200 rectangular pulses. This indicated that the electropermeabilization of the

barriers of $P$. peltatum was successful due to the higher pulse duration of 
rectangular pulses and the synergistic effect of high temperature and PEF treatment.

\subsection{FUTURE WORK}

The use of PEF treatment for the electropermeabilization of $P$. peltatum has proven to be successful by increasing the concentration of podophyllotoxin by up to $47 \%$. However, further work is needed to optimize the PEF treatment variables and enhance the repeatability of the results.

It is recommended that further experiments are conducted for $>48$ mesh $P$. peltatum. The number of pulses that successfully increased the concentration of podophyllotoxin extracted from $P$. peltatum were 252,000 and 302,400 . These corresponded to a PEF treatment time of 5 and $6 \mathrm{~min}$, meanwhile $8 \mathrm{~min}$ reduced the concentration of podophyllotoxin dramatically. Although these variables were sufficient for achieving the objective of this research, further experiments should entail a higher range of PEF treatment times. This will provide a better perspective of the PEF process variables that result in an approximate range of peak concentration and the point of degradation of podophyllotoxin.

Although the mechanism of PEF induced damage on biological membranes is unknown, several theories suggest that the accumulation of charges around the membrane are responsible for the formation of pores. In this research, deionized water was used to soak the $P$. peltatum particles before and during PEF treatment. Future research should investigate the use of a fluid with a higher content of ionic solutes such as a salt solution. 
It is essential to establish optimal PEF process variables for each proposed application individually. It is difficult and inaccurate to analyze and compare past research since each application was performed without any consistency. Thus, making it impossible to agree on optimal conditions for each type of plant material and assessing the effectiveness of experimental results. Hence, it is encouraged that future research should be standardized in order to provide results that are comparative. 


\section{REFERENCES}

Aguilera, J. M. (2003). Solid-Liquid Extraction. In C. Tzia and G. Liadakis, Extraction Optimization in Food Engineering. Marcel Dekker, Inc., New York, 35-36.

Amami, E., Fersi, A., Vorobiev, E., \& Kechaou, N. (2007). Osmotic dehydration of carrot tissue enhanced by pulsed electric field, salt and centrifugal force. Journal of Food Engineering, 83, 605-613.

Amami, E., Vorobiev, E., \& Kechaou, N. (2005). Effect of pulsed electric field on the osmotic dehydration and mass transfer kinetics of apple tissue. Drying Technology, 23, $581-595$.

Arevalo, P., Ngadi, M. O., Bazhal, M. I., \& Raghavan, G. S. V. (2004). Impact of pulsed electric fields on the dehydration and physical properties of apple and potato slices.

Drying Technology, 22 (5), 1233-1246.

Barbosa-Canovas, G. V., Pierson, M. D., Zhang, Q. H., \& Schaffner, D. W. (2000). Pulse electric fields. Journal of Food Science Supplement, 65-79.

Bazhal, M., Lebovka, N., \& Vorobiev, E. (2003). Optimisation of pulsed electric field strength for electroplasmolysis of vegetable tissues. Biosystems Engineering, 86 (3), 339 345.

Bazhal, M., Lebovka, N., \& Vorobiev, E. (2001). Pulsed electric field treatment of apple tissue during compression for juice extraction. Journal of Food Engineering, 50, 129139.

Bazhal, M., Ngadi, M., \& Raghavan, V. G. S. (2002). Application of pulsed electric field technologies in food extraction processes. North Atlantic Bioengineering Conference 2002, June 2002, Quebec City. Paper no.02-035.

Bazhal, M. I., \& Vorobiev, E. I. (2000). Electric treatment of apple slices for intensifying juice pressing. Journal of the Science of Food and Agriculture, 80 (1), 1-7.

Bedir, E., Tellez, M., Lata, H., Khan, I., Cushman, K. E., \& Moraes, R. M. (2006). Postharvest and scale-up extraction of American mayapple leaves for podophyllotoxin production. Industrial Crops and Products, 24, 3-7.

Bluhm, H., The Essence of Pulsed Power, in Pulsed Power Systems: Principles and Applications, Springer, Berlin, 2006, p. 1-6. 
Brodelius, P., Funk, C., \& Shillito, R. D. (1988). Permeabilization of cultivated plant cells by electroporation for release of intracellularly stored secondary products. Plant Cell Reports, 7, 186-188.

Canel, C., Dayan, F. E., Ganzera, M., Khan, I. A., Rimando, A., Burandt Jr., C. L., \& Moraes, R. M. (2001). High yield of podophyllotoxin from leaves of Podophyllum peltatum by in situ conversion of podophyllotoxin-4-O- $\beta$-D-glucopyranoside. Planta Med, $67,97-99$.

Canel, C., Moraes, R. M., Dayan, F. E., \& Ferreira, D. (2000). Molecules of interest podophyllotoxin. Phytochemistry, 54, 115-120.

Chalermchat, Y., \& Dejmek, P. (2005). Effect of pulsed electric field pretreatment on solid-liquid expression from potato tissue. Journal of Food Engineering, 7I, 164-169.

Cosgrove, D. J. (2000). Loosening of plant cell walls by expansins. Nature, 407, 321 326.

Corrales, M., Toepfl, S., Butz, P., Knorr, D., \& Tauscher, B. (2008). Extraction of anthocyanins from grape by-products assisted by ultrasonic's, high hydrostatic pressure or pulsed electric fields: A comparison. Innovative Food Science and Emerging Technologies, 9, 85-91.

Cushman, K. E., Maqbool, M., Lata, H., Bedir, E., Khan, I. A., \& Moraes, R. M. (2005). Podophyllotoxin content and yield of American mayapple leaves in sun and shade. American Society of Horticultural Science, 40 (1), 60-63.

Dayan, F. E., Kuhajek, J. M., Canel, C., Watson, S. B., \& Moraes, R. M. (2003). Podophylum peltatum possesses a $\beta$-glucosidase with high substrate specificity for the aryltetralin lignan podophyllotoxin. Biochimica et Biophysics Ata, 1646, 157-163.

De Vito, F., Ferrari, G., Lebovka N. I., Shynkaryk, N. V., \& Vorobiev, E. (2008). Pulse duration and efficiency of soft-cellular tissue disintegration by pulsed electric fields. Food Bioprocessing Technology, 1 (4), 307-313.

El-Belghiti, K., Moubarik, A., \& Vorobiev, E. (2008). Aqueous extraction of solutes from fennel (Foeniculum vulgare) assisted by pulsed electric field. Journal of Food Process Engineering, 31, 548-563.

Eshtiaghi, M. N., \& Knorr, D. (2002). High electric field pulse pretreatment: potential for sugar beet processing. Journal of Food Engineering, 52, 265-272.

Eyberger, A. L., Dondapati, R., \& Porter, J. R. (2006). Endophyte fungal isolates from Podophyllum peltatum produce podophyllotoxin. Journal of Natural Products, 69(8), 1121-1124. 
Fahr, A., Hoogevest, P., May, S., Bergstrand, N., \& Leigh, M. L. S. (2005). Transfer of lipophilic drugs between liposomal membranes and biological interfaces: Consequences for drug delivery. European Journal of Pharmaceutical Sciences, 26, 251-265.

Farkya, S., Bisaria, V. S., \& Srivastava, A. K. (2004). Biotechnological aspects of the production of the anticancer drug podophyllotoxin. Applied Microbiology and Biotechnology, 65, 504-519.

Fincan, M., \& Dejmek, P. (2002). In situ visualization of the effect of a pulsed electric field on plant tissue. Journal of Food Engineering, 55, 223-230.

Gachovska, M. O., Ngadi, M. O., \& Raghavan, G. S. V. (2006). Pulsed electric field assisted juice extraction from alfalfa. Canadian Biosystems Engineering, 48, 33-37.

Galindo, F. G., Vernier, P. T., Dejmek, P., Vicente, A., \& Gundersen, M. A. (2008). Pulsed electric field reduces the permeability of potato cell wall. Bioelectromagnetics, 29, 296-301.

Gan, L. S., Wang, Z. Z., \& Zhou, C. X. (2009). Solubility of podophyllotoxin in six organic solvents from (283.2 to 323.2) K. Journal of Chemical Engineering Data, 54, $160-161$.

Grimi, N., Lebovka, N. I., Vorobiev, E., \& Vaxelaire, J. (2009). Effect of a pulsed electric field treatment on expression behaviour and juice quality of Chardonnay grape. Food Biophysics, 4, 191-198.

Guderjan, M., Elez-Martinez, P., \& Knorr, D. (2007). Application of pulsed electric fields at oil yield and content of functional food ingredients at the production of rapeseed oil. Innovative Food Science and Emerging Technologies, 8, 55-62.

Guderjan, M., Töpfl, S., Angersbach, A., \& Knorr, D. (2005). Impact of pulsed electric field treatment on the recovery and quality of plant oils. Journal of Food Engineering, $67,281-287$.

Gurtovenko, A. A, \& Vattulainen, I. (2005). Pore formation coupled to ion transport through lipid membranes as induced by transmembrane ionic charge imbalance: atomistic molecular dynamics study. Journal of American Chemical Society, 127, 17570-17571.

Han, Z., Zeng. X. A., Zhang, B. S., \& Yu, S. J. Effects of pulsed electric fields (PEF) treatment on the properties of corn starch. Journal of Food Engineering, 93, 318-323.

Haijun, L., Yan, X., Guoqing, S., Chunyan, L., Li, W., \& Yujun, L. (2004). Research progress on production of podophyllotoxin from Sinopodophyllum hexandrum. Forestry Studies in China, 6 (1), 48-53. 
Himachal Pharmaceuticals (2009), Accessed November 19, 2009, $<$ http://himpharm.com/admin/upload/Podophyllotoxin.png >

Ho, S., \& Mittal, G. S. (2000). High voltage pulsed electrical field for liquid food pasteurization. Food Reviews International, I6 (4), 395-434.

Ho, S. Y., Mittal, G. S., \& Cross, J. D. (1997). Effects of high electric field pulses on the activity of selected enzymes. Journal of Food Engineering, 31, 69-84.

Hoekstra, F. A., Golovina, E. A., \& Buitink, J. (2001). Mechanisms of plant desiccation tolerance. Trends in Plant Science, 6 (9), 431-438.

Izadifar, M., \& Baik, O. D. (2008). An optimum ethanol-water solvent system for extraction of podophyllotoxin: Experimental study, diffusivity determination and modeling. Separation and Purification Technology, 63, 53-60.

Jalté, M., Lanoisellé, J. L., Lebovka, N. I., \& Vorobiev, E. (2009). Freezing of potato tissue pre-treated by pulsed electric fields. Food Science and Technology, 42, 576-580.

Jemai, A. B. \& Vorobiev, E. (2002). Effect of moderate electric field pulses on the diffusion coefficient of soluble substances from apple slices. International Journal of Food Science and Technology, 37, 73-86.

Jones, C. S \& Watson, M. A. (2001). Heteroblasty and performation in mayapple, Podophyllum peltatum (Berberidaceae): Developmental flexibility and morphological constraint. American Journal of Botany, 88 (8), 1340-1358.

Kaufmann, B., \& Christen, P. (2002). Recent extraction techniques for natural products: microwave-assisted extraction and pressurized solvent extraction. Phytochemical Analysis, 13, 105-113.

Kuri-Brena F. (1992). Studies on plant cell cultures of Podophyllum peltatum and Tripterygium wilfordii for biosynthesis of biologically active compounds. Thesis (Ph.D.). University of British Columbia.

Knorr, D., \& Angersbach, A. (1998). Impact of high-intensity electric field pulses on plant membrane permeabilization. Trends in Food Science \& Technology, 9, 185-191.

Lebovka, N. I., Bazhal, M. I., \& Vorobiev, E. (2001). Pulsed electric field breakage of cellular tissues: visualization of percolative properties. Innovative Food Science and Emerging Technologies, 2, 113-125.

Liu, Y. Q., Yang, L., \& Tian, X. (2007). Podophyllotoxin: current perspectives. Current Bioactive Compounds, 3, 37-66. 
López, N., Puértolas, E., Condón, S., Raso, J., \& Álvarez, I. (2009). Enhancement of the solid-liquid extraction of sucrose from sugar beet (Beta vulgaris) by pulsed electric fields. LWT-Food Science and Technology, 42, 1674-1680.

Meijer, W. (1974). Podophyllum peltatum - mayapple a potential new cash-crop plant of Eastern North America. Economic Botany, 28, 68-72.

Mittal, G. S. (2009). Non-thermal food processing with pulsed electric field technology. Resource: Engineering \& Technology for a Sustainable World (Food Safety Series), 6-8.

Moraes, R. M. (2002). The Lignans of Podophyllum. In A. Atta-ur-Rahman, Bioactive Natural Products. Elsevier Science B. V., Amsterdam, 148-182.

Moraes, R. M., Andrade, Z. D., Bedir, E., Dayan, F. E., Lata, H., Khan, I., \& Pereira, A. M. S. (2004). Arbuscular mycorrhiza improves acclimatization and increases lignan content of micropropagated mayapple (Podophyllum peltatum L.). Plant Science, 166 , 23-29.

Moraes, R. M., Burandt Jr., C., Ganzera, M., Li, X., Khan, I., \& Canel, C. (2000). The American mayapple revisited - Pophyllum peltatum - still a potential cash crop? Economic Botany, 54 (4), 471-476.

Perumalla, C. J., Peterson, C. A., \& Enstone, D. E. (1990). A survey of angiosperm species to detect hypodermal Casparian bands. I. Roots with a uniseriate hypodermis and epidermis. Botanical Journal of Linnean Society, 103, 93-112.

Phoon, P. Y., Galindo, F. G., Vicente, A., \& Dejmek, P. (2008). Pulsed electric field in combination with vacuum impregnation with trehalose improves the freezing tolerance of spinach leaves. Journal of Food Engineering, 88, 144-148.

Sayre, L. E. (1917). Manual of Organic Materia Medica and Pharmacognosy. P. Blakiston's Son \& Co. Philadelphia.

Schilling, S., Alber, T., Toepfl, S., Neidhart, S., Knorr, D., Schieber, A., \& Carle, R. (2007). Effects of pulsed electric field treatment of apple mash on juice yield and quality attributes of apple juices. Innovative Food Science and Emerging Technologies, 8, $127-$ 134.

Schoepke, T. (2003). Podophyllum peltatum, Allevameno di Fossombrone, Accessed November 19, 2009, $<$ http://www.difossombrone.it/piantemedicinali/main200podophyllum_peltatum.htm>

Sensoy, I., \& Sastry, S. K. (2004). Extraction using moderate electric fields. Journal of Food Science, 69 (1), 7-13. 
Sohn, J. J., \& Policansky, D. (1977). The costs of reproduction in the mayapple Podophyllum peltatum (Berberidaceae). Ecology, 58, 1366-1374.

Soliva-Fortuny, R., Balasa, A., Knorr, D., \& Martin-Belloso, O. (2009). Effects of pulsed electric fields on bioactive compounds in foods: a review. Trends in Food Science and Technology, 20, 544-556.

Stein, W. D. (1981). Permeability for lipophilic molecules. In S. L. Bonting and J. J. De Pont. Membrane Transport New Comprehensive Biochemistry, Elsevier, Amsterdam, 123.

Sweetman, M. D. (1933). The physio-chemical changes produced by the cooking of potatoes. American Journal of Potato Research, 10 (9), 169-173.

Taiwo, K. A., Angersbach, A., \& Knorr, D. (2003). Effects of pulsed electric field on quality factors and mass transfer during osmotic dehydration of apples. Journal of Food Process Engineering, 26, 31-48.

Tieleman, D. P., Leontiadou, H., Mark, A. E., \& Marrink, S. J. (2003). Simulation of pore formation in lipid bilayers by mechanical stress and electric fields. Journal of American Chemical Society, 125, 6382-6383.

Viehoever, A \& Mack, H. (1937). Biochemistry of May Apple root (Podophyllum peltatum) I. Journal of American Pharmaceutical Association, 27 (8), 632-643.

Vinatoru, M., Toma, M., Radu, O., Filip, P. I., Lazurca, D., \& Mason, T. J. (1997). The use of ultrasound for the extraction of bioactive principles from plant materials. Ultrasonics Sonochemistry, 4, 135-139.

Zhang, Y., Liao, X., Ni, Y., Wu, J., Hu, X., Wang, Z., \& Chen, F. (2007). Kinetic analysis of the degradation and its color change of cyaniding-3-glucoside exposed to pulsed electric field. European Food Research and Technology, 224, 597-603.

Zhao, W., Yang, R., Lu, R., Wang, M., Qian, P., \& Yang, W. (2008). Effect of PEF on microbial inactivation and physical-chemical properties of green tea extracts. Swiss Society of Food Science and Technology, 41, 425-431.

Zhao, W., Yang, R., Wang, M., \& Lu, R. (2008). Effects of pulsed electric fields on bioactive components, colour and flavour of green tea infusions. International Journal of Food Science and Technology, 44, 312-321.

Zheljazkov, V. D., Jones, A. M., Avula, B., Maddox, V., \& Rowe, D. E. (2009). Lignan and nutrient concentrations in American Mayapple (Podophyllum peltatum L.) in the Eastern United States. HortScience, 44 (2), 349-353. 
Zimmerman, U., Pilwat, G., \& Riemann, F. (1974). Dielectric breakdown of cell membranes. Biophysical Journal, 14, 881-899. 


\section{APPENDIX A - EXPERIMENTAL DATA}

Table A 1: Phase I results for PEF treatment of $24 \mathrm{~h}$ pre-soaked $P$. peltatum performed at room temperature $\left(24^{\circ} \mathrm{C}\right.$ ) with instant charge reversal pulses of $2 \mu$ s duration and $0.5 \mathrm{~Hz}$ frequency. Extraction of podophyllotoxin was performed with $30 \%$ aqueous ethanol at $50^{\circ} \mathrm{C}$ for 2 min.

\begin{tabular}{|c|c|c|c|c|}
\hline $\begin{array}{l}\text { Particle } \\
\text { Size } \\
\text { (Mesh) }\end{array}$ & $\begin{array}{c}\text { Electric Field } \\
\text { Strength } \\
(\mathrm{kV} / \mathrm{cm})\end{array}$ & Pulse Number & $\begin{array}{c}\text { Mean } \\
\text { Concentration } \\
(\mathrm{mg} / \mathrm{g})\end{array}$ & $\begin{array}{c}\text { Standard } \\
\text { Deviation }(\mathrm{mg} / \mathrm{g})\end{array}$ \\
\hline$<60$ & 33.33 & 20 & 8.977429 & 0.244458 \\
\hline$<60$ & 33.33 & 20 & 8.642165 & 0.345475 \\
\hline$<60$ & 33.33 & 40 & 9.188965 & 0.155916 \\
\hline$<60$ & 33.33 & 40 & 9.348011 & 0.208638 \\
\hline$<60$ & 33.33 & 60 & 9.036147 & 0.141147 \\
\hline$<60$ & 33.33 & 60 & 9.305008 & 0.261452 \\
\hline$<60$ & \multicolumn{2}{|c|}{ Control } & 8.864475 & 0.214638 \\
\hline$<60$ & 33.33 & 20 & 8.667413 & 0.116674 \\
\hline$<60$ & 33.33 & 20 & 8.582362 & 0.233839 \\
\hline$<60$ & 33.33 & 40 & 8.890711 & 0.477947 \\
\hline$<60$ & 33.33 & 40 & 9.203998 & 0.442575 \\
\hline$<60$ & 33.33 & 60 & 9.25674 & 0.111161 \\
\hline$<60$ & \multicolumn{2}{|c|}{ Control } & 8.874522 & 0.184006 \\
\hline$<60$ & 50.00 & 20 & 9.354473 & 0.138785 \\
\hline$<60$ & 50.00 & 20 & 8.673367 & 0.242294 \\
\hline$<60$ & 50.00 & 40 & 8.934863 & 0.287551 \\
\hline$<60$ & 50.00 & 40 & 9.040059 & 0.158065 \\
\hline$<60$ & 50.00 & 60 & 8.322258 & 0.582871 \\
\hline$<60$ & 50.00 & 60 & 9.021778 & 0.409335 \\
\hline$<60$ & \multicolumn{2}{|c|}{ Control } & 9.089449 & 0.289102 \\
\hline$<60$ & 50.00 & 20 & 9.708293 & 0.242826 \\
\hline$<60$ & 50.00 & 20 & 9.73821 & 0.192994 \\
\hline$<60$ & 50.00 & 40 & 9.488768 & 0.012697 \\
\hline$<60$ & 50.00 & 40 & 9.608815 & 0.015133 \\
\hline$<60$ & 50.00 & 60 & 9.685701 & 0.138236 \\
\hline$<60$ & 50.00 & 60 & 9.650983 & 0.142736 \\
\hline$<60$ & \multicolumn{2}{|c|}{ Control } & 9.66338 & 0.117195 \\
\hline$<60$ & 66.67 & 20 & 8.87592 & 0.148111 \\
\hline$<60$ & 66.67 & 20 & 9.672635 & 0.082164 \\
\hline$<60$ & 66.67 & 40 & 9.560296 & 0.104217 \\
\hline$<60$ & 66.67 & 40 & 9.393736 & 0.068772 \\
\hline$<60$ & 66.67 & 60 & 9.717303 & 0.079309 \\
\hline$<60$ & 66.67 & 60 & 9.512909 & 0.126566 \\
\hline
\end{tabular}




\begin{tabular}{|c|c|c|c|c|}
\hline$<60$ & \multicolumn{2}{|c|}{ Control } & 9.33482 & 0.167735 \\
\hline$<60$ & \multicolumn{2}{|c|}{ Control } & 8.805282 & 0.160764 \\
\hline$<48$ & \multicolumn{2}{|c|}{ Control } & 8.17793 & 0.339818 \\
\hline$<48$ & 66.67 & 20 & 8.058474 & 0.247779 \\
\hline$<48$ & 66.67 & 20 & 7.608524 & 0.187906 \\
\hline$<48$ & 66.67 & 40 & 7.720428 & 0.038251 \\
\hline$<48$ & 66.67 & 40 & 7.76867 & 0.182976 \\
\hline$<48$ & 66.67 & 60 & 7.780631 & 0.085679 \\
\hline$<48$ & 66.67 & 60 & 7.227543 & 0.545455 \\
\hline$<48$ & \multicolumn{2}{|c|}{ Control } & 7.345753 & 0.070605 \\
\hline$<48$ & 66.67 & 20 & 7.496522 & 0.067933 \\
\hline$<48$ & 66.67 & 20 & 7.626261 & 0.036799 \\
\hline$<48$ & 66.67 & 40 & 7.578522 & 0.046668 \\
\hline$<48$ & 66.67 & 40 & 7.745781 & 0.365567 \\
\hline$<48$ & 66.67 & 60 & 7.098935 & 0.081761 \\
\hline$<48$ & 66.67 & 60 & 7.608003 & 0.062951 \\
\hline$<48$ & \multicolumn{2}{|c|}{ Control } & 7.417581 & 0.111105 \\
\hline$<48$ & 50.00 & 20 & 7.749252 & 0.330292 \\
\hline$<48$ & 50.00 & 20 & 7.410844 & 0.176441 \\
\hline$<48$ & 50.00 & 40 & 7.420245 & 0.034645 \\
\hline$<48$ & 50.00 & 40 & 7.447077 & 0.173848 \\
\hline$<48$ & 50.00 & 60 & 7.289914 & 0.068227 \\
\hline$<48$ & 50.00 & 60 & 7.879048 & 0.22602 \\
\hline$<48$ & \multicolumn{2}{|c|}{ Control } & 7.446995 & 0.275882 \\
\hline$<48$ & 50.00 & 20 & 7.223503 & 0.076107 \\
\hline$<48$ & 50.00 & 20 & 7.781642 & 0.500294 \\
\hline$<48$ & 50.00 & 40 & 7.246171 & 0.100999 \\
\hline$<48$ & 50.00 & 40 & 7.610684 & 0.246006 \\
\hline$<48$ & 50.00 & 60 & 7.21037 & 0.255485 \\
\hline$<48$ & 50.00 & 60 & 7.511788 & 0.213943 \\
\hline$<48$ & \multicolumn{2}{|c|}{ Control } & 7.812369 & 0.045664 \\
\hline$<48$ & 33.33 & 20 & 7.626418 & 0.100475014 \\
\hline$<48$ & 33.33 & 20 & 7.517505 & 0.087833423 \\
\hline$<48$ & 33.33 & 40 & 7.38739 & 0.181535788 \\
\hline$<48$ & 33.33 & 40 & 7.522733 & 0.029005562 \\
\hline$<48$ & 33.33 & 60 & 7.513618 & 0.101990752 \\
\hline$<48$ & 33.33 & 60 & 7.365198 & 0.284213255 \\
\hline$<48$ & \multicolumn{2}{|c|}{ Control } & 7.335987 & 0.04994445 \\
\hline$<48$ & 33.33 & 20 & 7.804448 & 0.026532153 \\
\hline$<48$ & 33.33 & 20 & 7.750829 & 0.293799853 \\
\hline$<48$ & 33.33 & 40 & 7.658859 & 0.086933272 \\
\hline
\end{tabular}




\begin{tabular}{|l|l|l|l|l|}
\hline$<48$ & 33.33 & 40 & 7.939268 & 0.185022814 \\
\hline$<48$ & 33.33 & 60 & 8.023746 & 0.270300667 \\
\hline$<48$ & 33.33 & 60 & 8.092287 & 0.124419731 \\
\hline$<48$ & \multicolumn{2}{|c|}{ Control } & 7.564576 & 0.159912721 \\
\hline
\end{tabular}


Table A2: Phase II results for PEF treatment of 24 h pre-soaked, $<48$ mesh $P$. peltatum performed at high temperature $\left(45^{\circ} \mathrm{C}\right)$ with instant charge reversal pulses of $2 \mu$ s duration and $0.5 \mathrm{~Hz}$ frequency. Extraction of podophyllotoxin was performed with $30 \%$ aqueous ethanol at $50^{\circ} \mathrm{C}$ for 2 min.

\begin{tabular}{|c|c|c|c|}
\hline $\begin{array}{c}\text { Electric Field } \\
\text { Strength }(\mathrm{kV} / \mathrm{cm})\end{array}$ & Pulse Number & $\begin{array}{c}\text { Mean Concentration } \\
(\mathrm{mg} / \mathrm{g})\end{array}$ & $\begin{array}{c}\text { Standard Deviation } \\
(\mathrm{mg} / \mathrm{g})\end{array}$ \\
\hline 50.00 & 20 & 7.964381 & 0.198311 \\
\hline 50.00 & 20 & 8.152879 & 0.625536 \\
\hline 50.00 & 40 & 7.871013 & 0.170588 \\
\hline 50.00 & 40 & 7.736778 & 0.056333 \\
\hline 50.00 & 60 & 7.78313 & 0.024754 \\
\hline 50.00 & 60 & 8.015691 & 0.198721 \\
\hline \multicolumn{2}{|c|}{ Control } & 7.823317 & 0.189628 \\
\hline 50.00 & 20 & 7.950021 & 0.073342 \\
\hline 50.00 & 20 & 8.105427 & 0.119173 \\
\hline 50.00 & 40 & 8.305078 & 0.103898 \\
\hline 50.00 & 40 & 8.087386 & 0.168555 \\
\hline 50.00 & 60 & 7.675438 & 0.157256 \\
\hline 50.00 & 60 & 7.564035 & 0.694242 \\
\hline \multicolumn{2}{|c|}{ Control } & 7.765575 & 0.049979 \\
\hline 66.67 & 20 & 8.289381 & 0.220589 \\
\hline 66.67 & 20 & 8.859436 & 0.207816 \\
\hline 66.67 & 40 & 7.594388 & 0.200694 \\
\hline 66.67 & 40 & 8.126303 & 0.16192 \\
\hline 66.67 & 60 & 7.785372 & 0.309705 \\
\hline 66.67 & 60 & 8.440428 & 0.203981 \\
\hline \multicolumn{2}{|c|}{ Control } & 8.129192 & 0.17657 \\
\hline 66.67 & 20 & 8.356909 & 0.051246 \\
\hline 66.67 & 20 & 7.95221 & 0.130133 \\
\hline 66.67 & 40 & 8.360124 & 0.149634 \\
\hline 66.67 & 40 & 8.339693 & 0.179019 \\
\hline 66.67 & 60 & 7.847158 & 0.342104 \\
\hline 66.67 & 60 & 8.187753 & 0.430393 \\
\hline \multicolumn{2}{|c|}{ Control } & 8.268083 & 0.119705 \\
\hline 33.33 & 20 & 8.567001 & 0.087508 \\
\hline 33.33 & 20 & 8.528951 & 0.174853 \\
\hline 33.33 & 40 & 8.527291 & 0.067928 \\
\hline 33.33 & 40 & 8.561767 & 0.146986 \\
\hline 33.33 & 60 & 8.460137 & 0.051066 \\
\hline 33.33 & 60 & 7.838622 & 0.141585 \\
\hline \multicolumn{2}{|c|}{ Control } & 8.183144 & 0.139445 \\
\hline
\end{tabular}




\begin{tabular}{|l|l|l|l|}
\hline 33.33 & 20 & 8.277965 & 0.140633 \\
\hline 33.33 & 20 & 8.186635 & 0.112052 \\
\hline 33.33 & 40 & 8.86899 & 0.637007 \\
\hline 33.33 & 40 & 8.630386 & 0.651054 \\
\hline 33.33 & 60 & 8.378088 & 0.210263 \\
\hline 33.33 & 60 & 8.20232 & 0.107437 \\
\hline \multicolumn{2}{|c|}{ Control } & 7.52617 & 0.382151 \\
\hline
\end{tabular}


Table A3: Phase III results for PEF treatment of 1 h pre-soaked, $>48$ mesh $P$. peltatum performed at room temperature $\left(24^{\circ} \mathrm{C}\right)$ with rectangular pulses. Extraction of podophyllotoxin was performed with $30 \%$ aqueous ethanol at $50^{\circ} \mathrm{C}$ for $2 \mathrm{~min}$.

\begin{tabular}{|c|c|c|c|c|c|c|}
\hline $\begin{array}{l}\text { Total PEF } \\
\text { Treatment } \\
\text { Time (s) }\end{array}$ & $\begin{array}{l}\text { Frequency } \\
\qquad(\mathrm{Hz})\end{array}$ & $\begin{array}{c}\text { Pulse } \\
\text { Number }\end{array}$ & $\begin{array}{l}\text { Electric } \\
\text { Field } \\
\text { Strength } \\
(\mathrm{kV} / \mathrm{cm})\end{array}$ & $\begin{array}{c}\text { Mean } \\
\text { Concentration } \\
(\mathrm{mg} / \mathrm{g})\end{array}$ & $\begin{array}{c}\text { Standard } \\
\text { Deviation } \\
(\mathrm{mg} / \mathrm{g})\end{array}$ & $\begin{array}{c}\text { Change in } \\
\text { Mean } \\
\text { Concentration } \\
(\mathrm{mg} / \mathrm{g})\end{array}$ \\
\hline 120 & 84 & 10080 & 20.86 & 2.854371 & 0.381853 & -0.935445 \\
\hline 180 & 84 & 15120 & 18.71 & 3.256572 & 0.273835 & -0.533244 \\
\hline 180 & 840 & 151200 & 18.71 & 3.127561 & 0.452653 & -0.662255 \\
\hline \multicolumn{4}{|c|}{ Control } & 3.789816 & 0.31131 & \\
\hline 180 & 84 & 15120 & 18.71 & 3.632448 & 0.395733 & 0.395757 \\
\hline 180 & 840 & 151200 & 18.71 & 3.613312 & 0.649434 & 0.376621 \\
\hline 240 & 840 & 201600 & 18.71 & 1.675213 & 0.342135 & -1.561478 \\
\hline \multicolumn{4}{|c|}{ Control } & 3.236691 & 0.419805 & \\
\hline 180 & 840 & 151200 & 17.57 & 3.290099 & 0.266911 & 0.083391 \\
\hline 240 & 840 & 201600 & 17.57 & 1.244696 & 0.275245 & -1.962012 \\
\hline 300 & 840 & 252000 & 18.14 & 1.223416 & 0.108745 & -1.983292 \\
\hline 360 & 840 & 302400 & 17.57 & 1.070739 & 0.021019 & -2.135969 \\
\hline \multicolumn{4}{|c|}{ Control } & 3.206708 & 0.125218 & \\
\hline 240 & 840 & 201600 & 17.57 & 2.124688 & 0.193827 & -0.368082 \\
\hline 300 & 840 & 252000 & 17.57 & 1.636251 & 0.684504 & -0.856519 \\
\hline 360 & 840 & 302400 & 18.71 & 1.307971 & 0.10247 & -1.184799 \\
\hline 120 & 840 & 100800 & 18.14 & 1.942659 & 0.092896 & -0.550111 \\
\hline \multicolumn{4}{|c|}{ Control } & 2.49277 & 0.214668 & \\
\hline
\end{tabular}


Table A4: Phase IV results for PEF treatment of $1 \mathrm{~h}$ pre-soaked, $>48$ mesh $P$. peltatum performed at room temperature $\left(24^{\circ} \mathrm{C}\right)$ with rectangular pulse frequency of $840 \mathrm{~Hz}$.

\begin{tabular}{|c|c|c|c|c|c|c|c|}
\hline $\begin{array}{c}\text { Total PEF } \\
\text { Treatment } \\
\text { Time }(\mathrm{s})\end{array}$ & $\begin{array}{l}\text { Pulse } \\
\text { Number }\end{array}$ & $\begin{array}{c}\text { Electrıc } \\
\text { Field } \\
\text { Strength } \\
(\mathrm{kV} / \mathrm{cm})\end{array}$ & $\begin{array}{c}\text { Solvent Extraction } \\
\text { Parameters }\end{array}$ & $\begin{array}{c}\text { Mean } \\
\text { Concentration } \\
(\mathrm{mg} / \mathrm{g})\end{array}$ & $\begin{array}{c}\text { Standard } \\
\text { Deviation } \\
(\mathrm{mg} / \mathrm{g})\end{array}$ & $\begin{array}{c}\text { Change in Mean } \\
\text { Concentration } \\
(\mathrm{mg} / \mathrm{g})\end{array}$ & $\begin{array}{l}\text { Change in Mean } \\
\text { Concentration }(\%)\end{array}$ \\
\hline 300 & 252000 & 17.71 & Stir at $50^{\circ} \mathrm{C}$ for $10 \mathrm{~min}$ & 3.826732 & 0.355193 & -0.441475 & -10.34 \\
\hline \multicolumn{3}{|c|}{ Control } & Stir at $50^{\circ} \mathrm{C}$ for $10 \mathrm{~min}$ & 4.268207 & 0.074868 & & \\
\hline 300 & 252000 & 17.71 & Stir at $50^{\circ} \mathrm{C}$ for $1 \mathrm{~h}$ & 6.187553 & 0.301501 & 0.909641 & 17.23 \\
\hline \multicolumn{3}{|c|}{ Control } & Stir at $50^{\circ} \mathrm{C}$ for $1 \mathrm{~h}$ & 5.277912 & 0.19017 & & \\
\hline 300 & 252000 & 17.71 & Soak for $24 \mathrm{~h}$ & 5.901497 & 0.377924 & 1.160536 & 24.48 \\
\hline 300 & 252000 & 17.71 & Soak for $24 \mathrm{~h}$ & 6.067181 & 0.130012 & 1.32622 & 27.97 \\
\hline \multicolumn{3}{|c|}{ Control } & Soak for $24 \mathrm{~h}$ & 4.740961 & 0.163898 & & \\
\hline 360 & 302400 & 19.43 & Stir at $50^{\circ} \mathrm{C}$ for $2 \mathrm{~min}$ & 1.15505 & 0.03731 & -1.168176 & -50.28 \\
\hline 480 & 403200 & 19.43 & Stir at $50^{\circ} \mathrm{C}$ for $2 \mathrm{~min}$ & 1.019228 & 0.092936 & -1.303998 & -56.13 \\
\hline 360 & 302400 & 19.43 & Stir at $50^{\circ} \mathrm{C}$ for $1 \mathrm{~h}$ & 6.679694 & 0.65856 & 1.396455 & 26.43 \\
\hline 480 & 403200 & 19.43 & Stir at $50^{\circ} \mathrm{C}$ for $1 \mathrm{~h}$ & 5.885931 & 0.275256 & 0.602692 & 11.41 \\
\hline \multicolumn{3}{|c|}{ Control } & Stir at $50^{\circ} \mathrm{C}$ for $1 \mathrm{~h}$ & 5.283239 & 0.320391 & & \\
\hline 360 & 302400 & 19.43 & Soak for $24 \mathrm{~h}$ & 5.640618 & 0.395369 & 0.831558 & 17.29 \\
\hline 480 & 403200 & 19.43 & Soak for $24 \mathrm{~h}$ & 5.343096 & 0.115228 & 0.534036 & 11.10 \\
\hline \multicolumn{3}{|c|}{ Control } & Soak for $24 \mathrm{~h}$ & 4.80906 & 0.09719 & & \\
\hline 360 & 302400 & 19.43 & $\begin{array}{c}\text { Stir at } 50^{\circ} \mathrm{C} \text { for } 1 \mathrm{~h} \& \\
\text { soak for } 24 \mathrm{~h}\end{array}$ & 7.177782 & 0.584078 & 2.295942 & 47.03 \\
\hline 480 & 403200 & 19.43 & $\begin{array}{c}\text { Stir at } 50^{\circ} \mathrm{C} \text { for } 1 \mathrm{~h} \& \\
\text { soak for } 24 \mathrm{~h}\end{array}$ & 5.376515 & 0.196517 & 0.494675 & 10.13 \\
\hline \multicolumn{3}{|c|}{ Control } & $\begin{array}{c}\text { Stir at } 50^{\circ} \mathrm{C} \text { for } 1 \mathrm{~h} \& \\
\text { soak for } 24 \mathrm{~h}\end{array}$ & 4.88184 & 0.420736 & & \\
\hline
\end{tabular}




\title{
APPENDIX B - STATISTICAL ANALYSIS
}

\section{SAS STATISTICAL ANALYSIS OF PHASE I RESULTS}

\author{
The SAS System \\ The GLM Procedure \\ Class Level Information \\ Class Levels Values \\ Psize $\quad 2 \quad 4860$ \\ Field $\quad 4 \quad 0335066$ \\ PNumber $\quad 4 \quad 0204060$
}

Number of Observations Read

78

Number of Observations Used

78 
The SAS System

The GLM Procedure

Dependent Variable: Conc Conc

$\begin{array}{lccccc}\text { Source } & \text { DF } & \begin{array}{c}\text { Sum of } \\ \text { Squares }\end{array} & \text { Mean Square } & \text { F Value } & \text { Pr }>\text { F } \\ \text { Model } & 6 & 49.70251979 & 8.28375330 & 77.71 & <.0001 \\ \text { Error } & 71 & 7.56868715 & 0.10660123 & & \\ \text { Corrected Total } & 77 & 57.27120694 & & & \end{array}$

$\begin{array}{llll}\text { R-Square } & \text { Coeff Var } & \text { Root MSE } & \text { Conc Mean } \\ 0.867845 & 3.929506 & 0.326498 & 8.308892\end{array}$

$\begin{array}{llllll}\text { Source } & \text { DF } & \text { Type I SS } & \text { Mean Square } & \text { F Value } & \operatorname{Pr}>\text { F } \\ \text { Psize } & 1 & 49.42122288 & 49.42122288 & 463.61 & <.0001 \\ \text { Field } & 3 & 0.25019172 & 0.08339724 & 0.78 & 0.5077 \\ \text { PNumber } & 2 & 0.03110519 & 0.01555260 & 0.15 & 0.8645 \\ & & & & & \\ \text { Source } & \text { DF } & \text { Type III SS } & \text { Mean Square } & \text { F Value } & \operatorname{Pr}>\text { F } \\ & & & & & \\ \text { Psize } & 1 & 49.41654437 & 49.41654437 & 463.56 & <.0001 \\ \text { Field } & 2 & 0.22193173 & 0.11096586 & 1.04 & 0.3584 \\ \text { PNumber } & 2 & 0.03110519 & 0.01555260 & 0.15 & 0.8645\end{array}$


The SAS System

The GLM Procedure

Duncan's Multiple Range Test for Conc

NOTE: This test controls the Type I comparisonwise error rate, not the experimentwise error rate.

$\begin{array}{ll}\text { Alpha } & 0.05 \\ \text { Error Degrees of Freedom } & 71 \\ \text { Error Mean Square } & 0.106601 \\ \text { Harmonic Mean of Cell Sizes } & 38.58974 \\ & \\ \text { NOTE: Cell sizes are not equal. }\end{array}$

$\begin{array}{ll}\text { Number of Means } & 2 \\ \text { Critical Range } & .1482\end{array}$

Means with the same letter are not significantly different.

$\begin{array}{cccc}\text { Duncan Grouping } & \text { Mean } & \text { N } & \text { Psize } \\ \text { A } & 9.19118 & 35 & 60 \\ \text { B } & 7.59075 & 43 & 48\end{array}$


The SAS System

The GLM Procedure

Duncan's Multiple Range Test for Conc

NOTE: This test controls the Type I comparisonwise error rate, not the experimentwise error rate.
Alpha
0.05
Error Degrees of Freedom
71
Error Mean Square
0.106601
Harmonic Mean of Cell Sizes
18.38036
NOTE: Cell sizes are not equal.

$\begin{array}{llll}\text { Number of Means } & 2 & 3 & 4 \\ \text { Critical Range } & .2147 & .2259 & .2333\end{array}$

Means with the same letter are not significantly different.

$\begin{array}{cccc}\text { Duncan Grouping } & \text { Mean } & \mathrm{N} & \text { Field } \\ \text { A } & 8.3753 & 24 & 50 \\ \text { A } & & & \\ \text { A } & 8.3174 & 23 & 33 \\ \text { A } & & & \\ \text { A } & 8.2872 & 13 & 0 \\ \text { A } & 8.2251 & 18 & 66 \\ \text { A } & & & \end{array}$


The SAS System

The GLM Procedure

Duncan's Multiple Range Test for Conc

NOTE: This test controls the Type I comparisonwise error rate, not the experimentwise error rate.

$\begin{array}{ll}\text { Alpha } & 0.05 \\ \text { Error Degrees of Freedom } & 71 \\ \text { Error Mean Square } & 0.106601 \\ \text { Harmonic Mean of Cell Sizes } & 18.56569 \\ & \\ \text { NOTE: Cell sizes are not equal. }\end{array}$

Number of Means $\quad 2 \quad 3 \quad 4$

$\begin{array}{llll}\text { Critical Range } \quad .2137 & .2248 \quad .2322\end{array}$

Means with the same letter are not significantly different.

$\begin{array}{cccc}\text { Duncan Grouping } & \text { Mean } & \text { N } & \text { PNumber } \\ \text { A } & 8.3502 & 22 & 40 \\ \text { A } & & & \\ \text { A } & 8.2976 & 22 & 20 \\ \text { A } & & & \\ \text { A } & 8.2909 & 21 & 60 \\ \text { A } & & & \\ \text { A } & 8.2872 & 13 & 0\end{array}$


SAS STATISTICAL ANALYSIS OF PHASE II RESULTS

\begin{tabular}{|c|c|c|}
\hline \multicolumn{3}{|c|}{ The SAS System } \\
\hline \multicolumn{3}{|c|}{ The GLM Procedure } \\
\hline \multicolumn{3}{|c|}{ Class Level Information } \\
\hline Class & Levels & Values \\
\hline Temp & 2 & 2445 \\
\hline Field & 4 & 0335067 \\
\hline Number & 4 & 0204060 \\
\hline
\end{tabular}

Number of Observations Read

87

Number of Observations Used

87 
The SAS System

The GLM Procedure

Dependent Variable: Conc

$\begin{array}{lcllll}\text { Source } & \text { DF } & \begin{array}{l}\text { Sum of } \\ \text { Squares }\end{array} & \text { Mean Square } & \text { F Value } & \text { Pr }>\text { F } \\ \text { Model } & 6 & 8.11124496 & 1.35187416 & 17.45 & <.0001 \\ \text { Error } & 80 & 6.19710819 & 0.07746385 & & \\ \text { Corrected Total } & 86 & 14.30835315 & & & \end{array}$

$\begin{array}{llll}\text { R-Square } & \text { Coeff Var } & \text { Root MSE } & \text { Conc Mean } \\ 0.566889 & 3.534639 & 0.278323 & 7.874164\end{array}$

Source DF Type I SS Mean Square F Value $\operatorname{Pr}>$ F

$\begin{array}{llllll}\text { Temp } & 1 & 5.93950037 & 5.93950037 & 76.67 & <.0001\end{array}$

$\begin{array}{llllll}\text { Field } & 3 & 1.66816139 & 0.55605380 & 7.18 & 0.0003\end{array}$

$\begin{array}{llllll}\text { Number } & 2 & 0.50358319 & 0.25179160 & 3.25 & 0.0439\end{array}$

Source DF Type III SS Mean Square F Value Pr $>$ F

$\begin{array}{llllll}\text { Temp } & 1 & 5.99425267 & 5.99425267 & 77.38 & <.0001\end{array}$

$\begin{array}{llllll}\text { Field } & 2 & 1.47449741 & 0.73724871 & 9.52 & 0.0002\end{array}$

$\begin{array}{llllll}\text { Number } & 2 & 0.50358319 & 0.25179160 & 3.25 & 0.0439\end{array}$ 
The SAS System

The GLM Procedure

Duncan's Multiple Range Test for Conc

NOTE: This test controls the Type I comparisonwise error rate, not the experimentwise error rate.

$\begin{array}{ll}\text { Alpha } & 0.05 \\ \text { Error Degrees of Freedom } & 80 \\ \text { Error Mean Square } & 0.077464 \\ \text { Harmonic Mean of Cell Sizes } & 43.44828 \\ \text { NOTE: Cell sizes are not equal. }\end{array}$

$\begin{array}{lc}\text { Number of Means } & 2 \\ \text { Critical Range } & .1188\end{array}$

Means with the same letter are not significantly different.

$\begin{array}{cccc}\text { Duncan Grouping } & \text { Mean } & \text { N } & \text { Temp } \\ \text { A } & 8.14462 & 42 & 45 \\ \text { B } & 7.62174 & 45 & 24\end{array}$




\section{The SAS System}

The GLM Procedure

Duncan's Multiple Range Test for Conc

NOTE: This test controls the Type I comparisonwise error rate, not the experimentwise error rate.

$\begin{array}{ll}\text { Alpha } & 0.05 \\ \text { Error Degrees of Freedom } & 80 \\ \text { Error Mean Square } & 0.077464 \\ \text { Harmonic Mean of Cell Sizes } & 20.12903\end{array}$

NOTE: Cell sizes are not equal.

$\begin{array}{lccc}\text { Number of Means } & 2 & 3 & 4 \\ \text { Critical Range } & .1746 & .1837 & .1897\end{array}$

Means with the same letter are not significantly different.

$\begin{array}{ccccc}\text { Duncan Grouping } & \text { Mean } & \text { N } & \text { Field } \\ & \text { A } & 8.05127 & 24 & 33 \\ \text { A } & & & \\ \text { B } & \text { A } & 7.92436 & 26 & 67 \\ \text { B } & & & & \\ \text { B } & \text { C } & 7.75359 & 13 & 0 \\ \text { C } & & & \\ \text { C } & 7.70799 & 24 & 50\end{array}$


The SAS System

The GLM Procedure

Duncan's Multiple Range Test for Conc

NOTE: This test controls the Type I comparisonwise error rate, not the experimentwise error rate.

\begin{tabular}{ll} 
Alpha & 0.05 \\
Error Degrees of Freedom & 80 \\
Error Mean Square & 0.077464 \\
Harmonic Mean of Cell Sizes & 20.12903 \\
\multicolumn{2}{l}{ NOTE: Cell sizes are not equal. }
\end{tabular}

$\begin{array}{lccc}\text { Number of Means } & 2 & 3 & 4 \\ \text { Critical Range } & .1746 & .1837 & .1897\end{array}$

Means with the same letter are not significantly different.

$\begin{array}{cccc}\text { Duncan Grouping } & \text { Mean } & \text { N } & \text { Number } \\ \text { A } & 7.95189 & 24 & 20 \\ \text { A } & & & \\ \text { A } & 7.94734 & 26 & 40 \\ \text { A } & & & \\ \text { B A } & 7.78247 & 24 & 60 \\ \text { B } & 7.75359 & 13 & 0 \\ \text { B } & & & \end{array}$

